\title{
Phosphorus Determination in Forage and Manure using Portable X-ray Fluorescence Spectroscopy to Support Comprehensive Nutrient Management Planning
}

\author{
Yadav Sapkota
}

Follow this and additional works at: https://researchrepository.wvu.edu/etd

\author{
Recommended Citation \\ Sapkota, Yadav, "Phosphorus Determination in Forage and Manure using Portable X-ray Fluorescence \\ Spectroscopy to Support Comprehensive Nutrient Management Planning" (2017). Graduate Theses, \\ Dissertations, and Problem Reports. 6569. \\ https://researchrepository.wvu.edu/etd/6569
}

This Thesis is protected by copyright and/or related rights. It has been brought to you by the The Research Repository @WVU with permission from the rights-holder(s). You are free to use this Thesis in any way that is permitted by the copyright and related rights legislation that applies to your use. For other uses you must obtain permission from the rights-holder(s) directly, unless additional rights are indicated by a Creative Commons license in the record and/ or on the work itself. This Thesis has been accepted for inclusion in WVU Graduate Theses, Dissertations, and Problem Reports collection by an authorized administrator of The Research Repository @ WVU. For more information, please contact researchrepository@mail.wvu.edu. 
Phosphorus Determination in Forage and Manure using Portable X-ray Fluorescence Spectroscopy to Support Comprehensive Nutrient Management Planning

\author{
Yadav Sapkota
}

Thesis submitted

to the Davis Collage of Agriculture, Natural Resources and Design at West Virginia University

in partial fulfillment of the requirements for the degree of

Master of Science in

Agronomy

Louis M. McDonald, Ph.D., Chair

Thomas Basden

Thomas C. Griggs, Ph.D.

Division of Plant and Soil Sciences

Morgantown, West Virginia

2017

Keywords: Phosphorus, PXRF, forage, manure, analysis 


\section{Abstract \\ Phosphorus Determination in Forage and Manure using Portable X-ray Fluorescence Spectroscopy to Support Comprehensive Nutrient Management Planning}

\section{Yadav Sapkota}

Phosphorus (P) runoff from agricultural fields is a major cause of water quality degradation problems. A P mass balance across the farm could maintain profitability and sustainability of animal-based farms and minimize water quality problems. Comprehensive Nutrient Management Plans (CNMPs) require mineral composition, especially $P$, data on soil, forage, and manure samples for accurate planning. However, traditional wet chemical methods of $P$ determination are costly, time-consuming, and generate hazardous waste. X-ray fluorescence (XRF) could overcome many of these disadvantages and allow rapid determination of $P$ concentrations. Portable XRF (PXRF) units are Energy Dispersive (ED) systems with low power Xray tubes (10-40W) in comparison to benchtop units (50-300W). They are light and convenient to use either in benchtop or field-analysis modes. When a sample is scanned, the resulting spectrum identifies the element (peak position or energy); area under the peak (intensity) is proportional to concentration. A few studies have indicated the possible use of PXRF for the analysis of plant tissue and compost samples. However, there is a lack of information for analysis of heterogeneous forage and manure samples, including optimal sample preparation (particle size and moisture content) and instrumental parameters (scan time). The objective of this study was to evaluate the effect of manure moisture content and forage particle size on elemental concentrations determination using PXRF in benchtop mode. Manure samples $(n=40)$ were oven dried at 50 and ground to $0.5 \mathrm{~mm}$ size and adjusted to four gravimetric moisture ranges: 10-20\%, $20-30 \%, 40-50 \%$, and $60-70 \%$. Dry hay samples $(n=42)$ were oven dried $\left(60^{\circ} \mathrm{C}\right.$ for 3 days) and ground into two particle sizes $(0.25-0.5 \mathrm{~mm}$ and $1-2 \mathrm{~mm})$. Prepared samples were scanned by PXRF using a vacuum ( $<10$ torr) and without a filter. Samples were placed in a sample cup over a thin proline X-ray film and scanned for 180 s. Some forage samples $(n=29)$ were also scanned for 60 s and 120 s for scan time analysis. Spectra for each analysis, photon counts (intensity) and $P$ concentration were collected using the S1PXRF software. Reference standards were prepared by microwave digesting forage and manure samples in triplicate followed by elemental quantification through Inductively Coupled Plasma Optical Emission Spectrometry (ICP). Regression analysis, two sample t-test, matched paired t-test, and repeated measures ANOVA were used for data analysis. ICP measured P, K, Ca, Mg, Fe and Cu were in close agreement with West Virginia Department of Agriculture-measured concentration in manure samples. Dried and ground manure samples produced a stronger relationship with ICP-determined $\mathrm{P}, \mathrm{K}, \mathrm{Ca}, \mathrm{Fe}, \mathrm{Cu}$, $\mathrm{Zn}\left(r^{2}>0.90\right)$ and $\mathrm{Mg}\left(r^{2}=0.59\right)$. Presence of moisture negatively affected elemental determination in manure samples. The strength of the relationship decreased with increasing moisture content beyond $20 \%$. 
Comparison of PXRF concentration with ICP-determined value indicated that forage $\mathrm{P}, \mathrm{K}, \mathrm{Ca}$, and Fe $\left(r^{2}>0.88\right)$ could potentially be determined with portable XRF. The strength of the relationship increased with decreasing particle size in forage samples. The particle size of the sample was significant while the scan time and the interaction between scan time and particle size were not significant. There was no significant difference between ICP and PXRF measured concentration for 0.25-0.5 mm sample but significant difference between ICP and PXRF concentration for 1-2 $\mathrm{mm}$ samples. Likewise, there was a significant difference $(p<0.001)$ between PXRF concentration measured with the two particle size of the sample. Use of different scanning time $(60 \mathrm{~s}, 120 \mathrm{~s}$, and 180s) did not affect the relationship with ICP concentration for the samples of particle size. Thus, $\mathrm{P}, \mathrm{K}, \mathrm{Ca}, \mathrm{Fe}, \mathrm{Cu}$ and $\mathrm{Zn}$ can be accurately be measured in manure samples and $\mathrm{P}, \mathrm{K}, \mathrm{Ca}$, and Fe in forage samples using PXRF in benchtop mode. Additional work is needed to extend this to in-field analysis. This simplification of the elemental analytical method could expedite CNMP planning process and contribute to better whole-farm $P$ management. 


\section{Acknowledgement}

This thesis would not have been possible without the support of several individuals and organizations. I am thankful to all individuals and organization who supported during the entire period of my study.

I would like to thank my advisor Dr. Louis McDonald for his encouragement, support, and guidance throughout my study and research. I would also like to thank my committee members Dr. Thomas C. Griggs and Thomas Basden for cooperation, guidance, and support during the entire period of this research.

I am grateful to the funding agency United States Department of Agriculture-Natural Resource Conservation Service (NRCS). I cannot remain without providing gratitude to West Virginia University, Davis College of Agriculture, Natural Resource and Design, and Division of Plant and Soil Sciences for providing this opportunity. I am thankful to Government of Nepal and Department of Agriculture of Nepal for approving study leave.

I am thankful to Dr. Dorothy Vesper for providing training and lab for digesting my samples. I would like to thank Lanjun Deng for helping me in lab work and doing ICP analysis for my samples.

I would like to thank Justin Brackenrich and Bethani Chambers for their support during this research. Special thanks to my lab members Lili Lei, Kelley Morgano, and Rebecca McGrail for their support. I would also like to thank Mitchell King, Samantha Collins, Samantha Thomas, Collin Wagoner, and Logan Keller for helping me in collecting samples.

I would like to recognize my parents, uncle, brother, and mother in law for their encouragement and support during this work. Last but not the least, thanks to my wife Sapana Bastola for all the support, patience, and encouragement. Finally, I am grateful to my daughter Sayara Sapkota who added joy and happiness in our life.

Yadav Sapkota 


\section{Table of Contents}

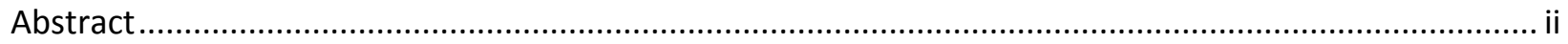

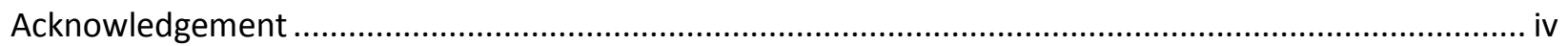

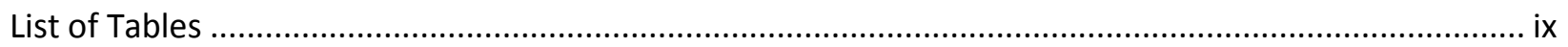

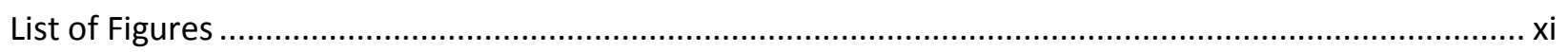

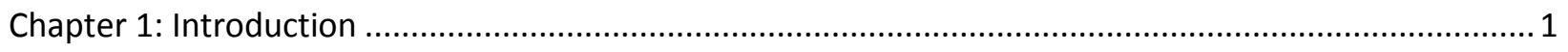

Comprehensive Nutrient Management Plans ….............................................................................. 1

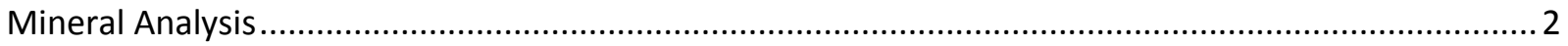

Forages

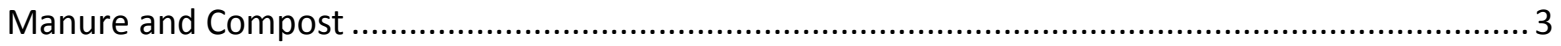

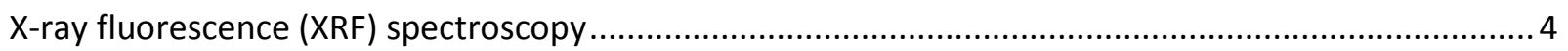

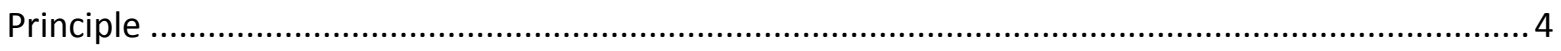

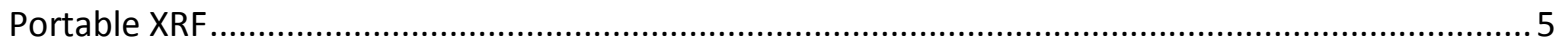

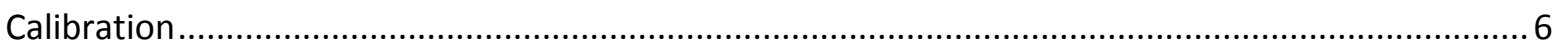

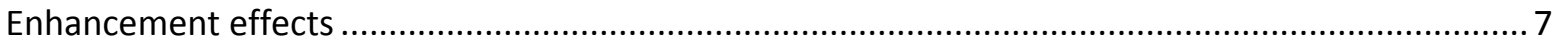

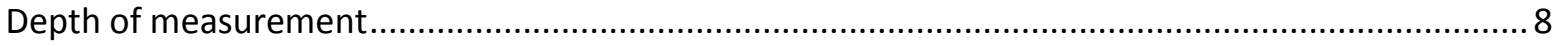

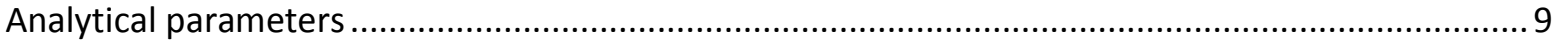

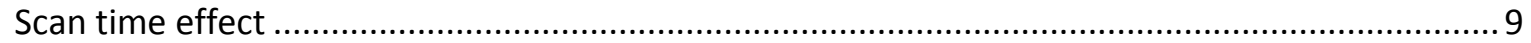

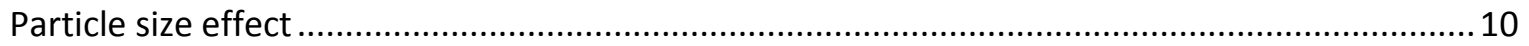

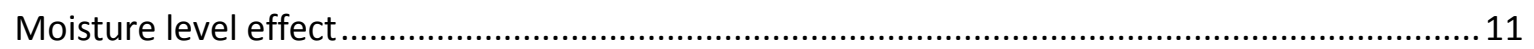

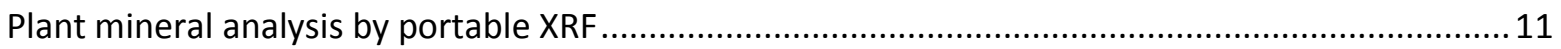

Compost mineral analysis by portable XRF........................................................................... 12

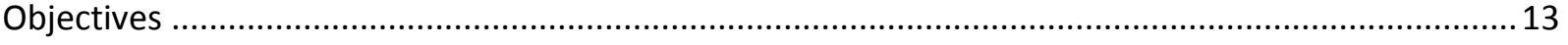

Literature Cited

Chapter 2: Moisture Effect on Elemental Concentration Determination in Manure using Portable X-ray

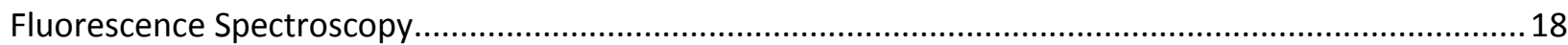

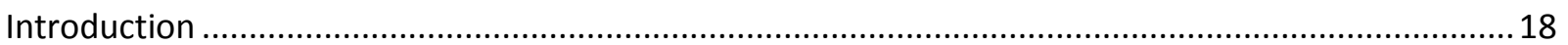

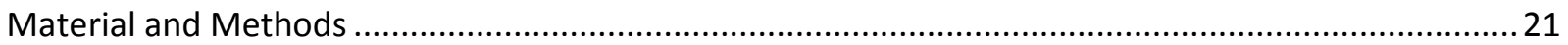

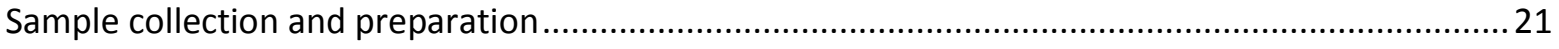

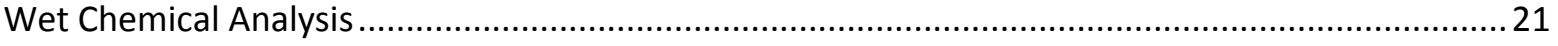

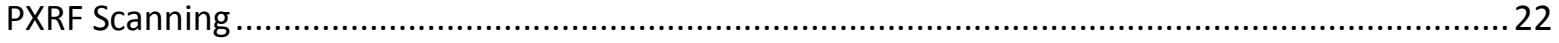

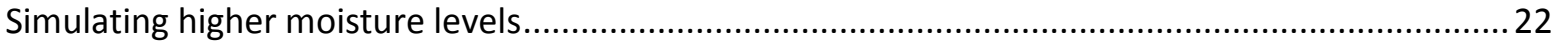

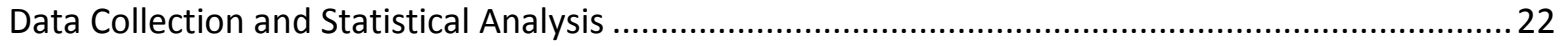




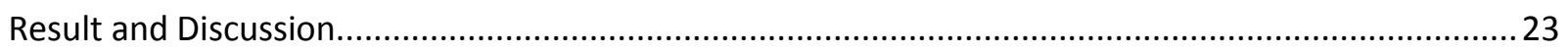

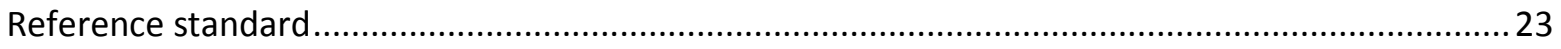

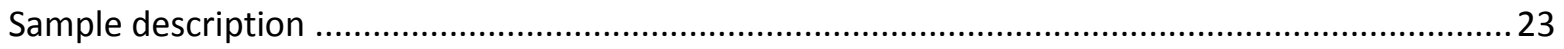

Comparability between ICP-OES and WVDA measured concentrations .........................................23

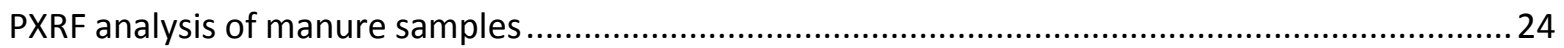

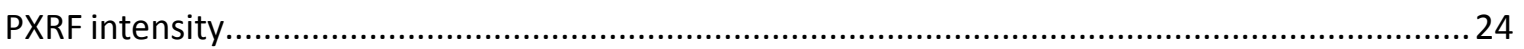

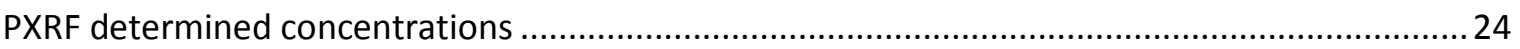

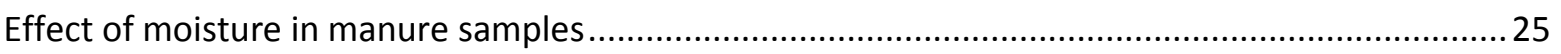

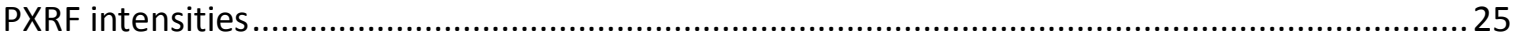

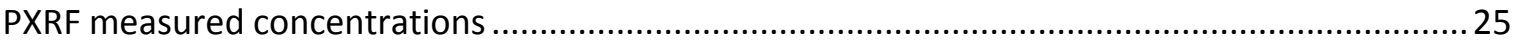

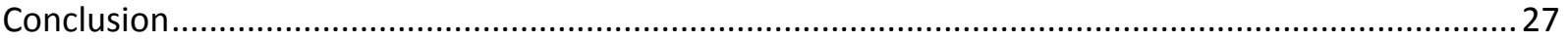

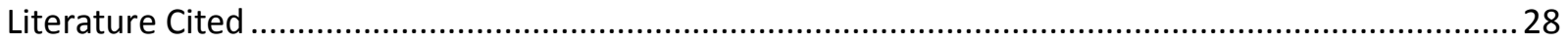

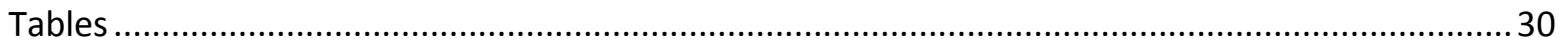

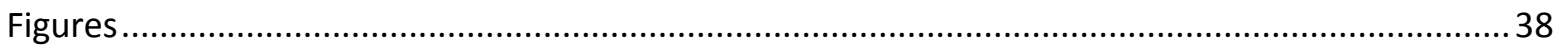

Chapter 3: Particle Size Effect on Elemental Concentration Determination in Forage using Portable X-ray

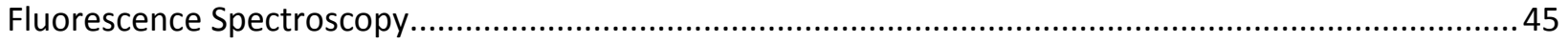

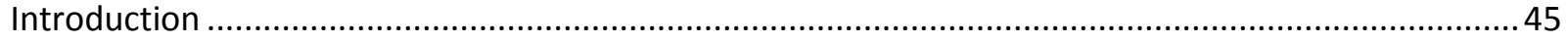

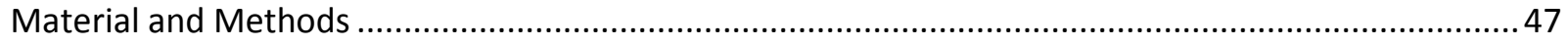

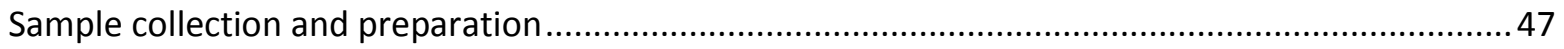

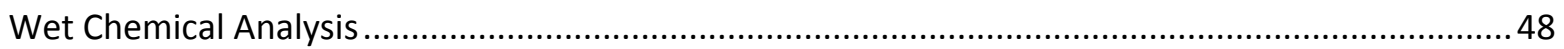

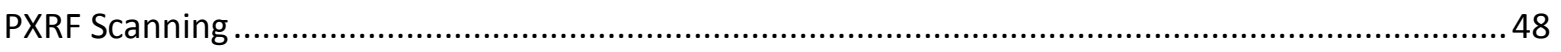

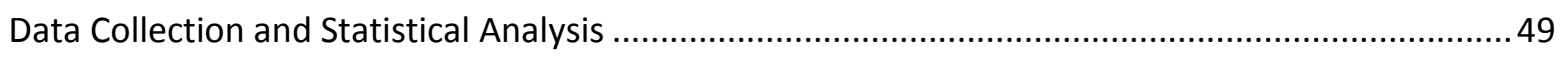

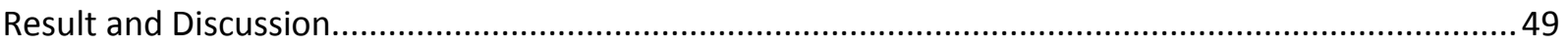

Wet chemical elemental concentrations ..................................................................................... 49

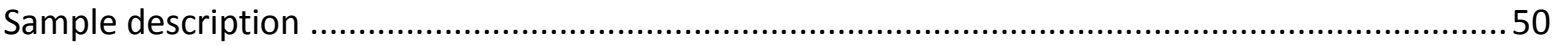

Comparability between ICP-OES and CVAS concentration ......................................................... 50

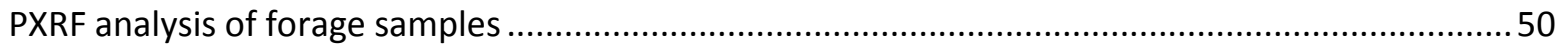

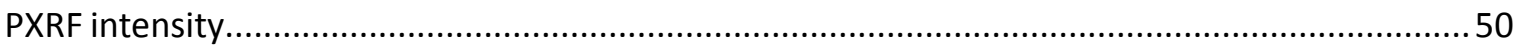

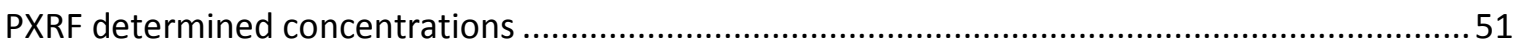

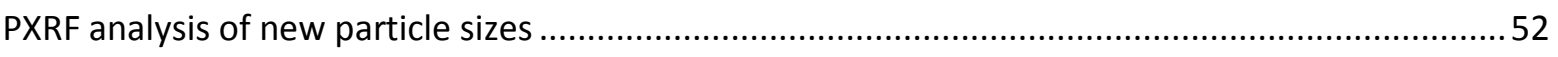

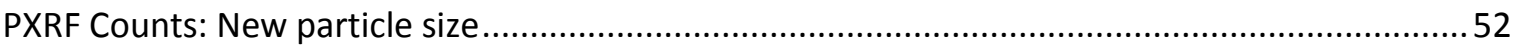

PXRF measured concentration: New particle size .................................................................... 53

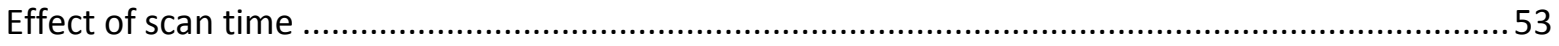




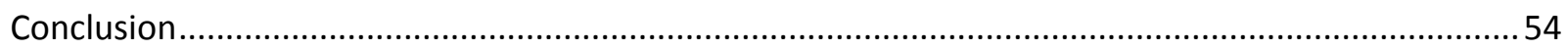

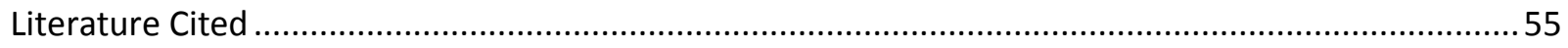

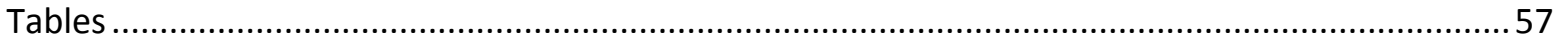

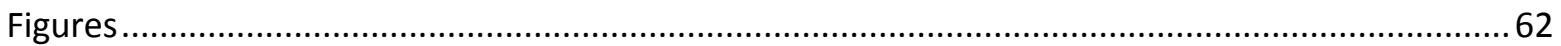

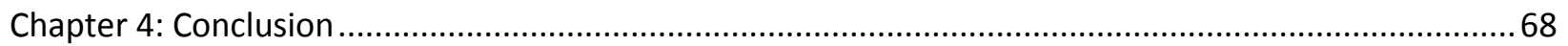

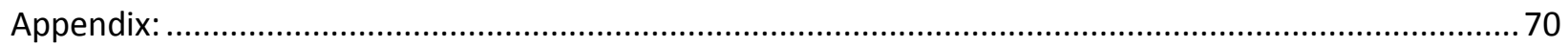

Appendix 1: Regression between ICP and WVDA determined elemental concentrations $(\mathrm{mg} / \mathrm{kg})$ in

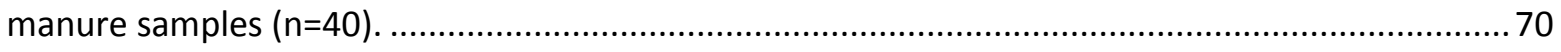

Appendix 2: Regression between ICP determined concentration $(\mathrm{mg} / \mathrm{kg}$ ) and PXRF intensities (cps)

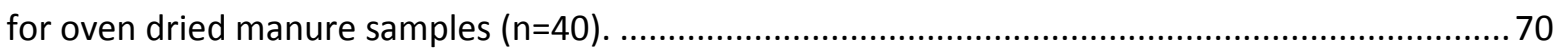

Appendix 3: Regression between ICP and PXRF measured concentration ( $\mathrm{mg} / \mathrm{kg}$ ) for oven dried manure samples $(n=40)$.

Appendix 4: Regression between ICP and CVAS determined elemental concentrations $(\mathrm{mg} / \mathrm{kg})$ in forage samples $(n=42)$.

Appendix 5: Regression between ICP-OES determined concentration $(\mathrm{mg} / \mathrm{kg}$ ) and PXRF intensities (cps) for 3 different particle size of forage samples ( $n=42)$.

Appendix 6: Regression between ICP and PXRF concentration $(\mathrm{mg} / \mathrm{kg})$ for 3 different particle size of forage samples $(n=42)$.

Appendix 7: Regression between ICP determined concentration $(\mathrm{mg} / \mathrm{kg}$ ) and PXRF intensities (cps) for two new particle size of forage samples $(n=42)$.

Appendix 8: Regression between ICP and PXRF concentration $(\mathrm{mg} / \mathrm{kg}$ ) for 2-particle size (new particle size) of forage samples ( $n=42)$.

Appendix 9: WVDA, ICP, and PXRF measured P concentration $(\mathrm{mg} / \mathrm{kg}$ ) and PXRF intensity of P (cps) in manure samples at different moisture level.

Appendix 10: WVDA, ICP, and PXRF measured $\mathrm{K}$ concentration $(\mathrm{mg} / \mathrm{kg}$ ) and PXRF intensity of $\mathrm{K}$ (cps) in manure samples at different moisture level.

Appendix 11: WVDA, ICP, and PXRF measured Ca concentration $(\mathrm{mg} / \mathrm{kg})$ and PXRF intensity of Ca (cps) in manure samples at different moisture level.

Appendix 12: WVDA, ICP, and PXRF measured $\mathrm{Mg}$ concentration $(\mathrm{mg} / \mathrm{kg})$ and PXRF intensity of $\mathrm{Mg}$ (cps) in manure samples at different moisture level.

Appendix 13: WVDA, ICP, and PXRF measured Fe concentration $(\mathrm{mg} / \mathrm{kg})$ and PXRF intensity of Fe (cps) in manure samples at different moisture level.

Appendix 14: WVDA and ICP measured Cu concentration $(\mathrm{mg} / \mathrm{kg})$ and PXRF intensity of $\mathrm{Cu}(\mathrm{cps})$ in manure samples at different moisture level.

Appendix 15: ICP measured concentration $(\mathrm{mg} / \mathrm{kg}$ ) and PXRF intensity of $\mathrm{Zn}(\mathrm{cps})$ in manure samples at different moisture level. 
Appendix 16: CVAS, ICP and PXRF measured concentration $(\mathrm{mg} / \mathrm{kg}$ ) and PXRF intensity of P (cps) in forage samples at two different particle size.

Appendix 17: CVAS, ICP, and PXRF measured concentration $(\mathrm{mg} / \mathrm{kg})$ and PXRF intensity of $\mathrm{K}(\mathrm{cps})$ in forage samples at two different particle size.

Appendix 18: CVAS, ICP, and PXRF measured concentration $(\mathrm{mg} / \mathrm{kg}$ ) and PXRF intensity of Ca (cps)

in forage samples at two different particle size.

Appendix 19: CVAS, ICP, and PXRF measured concentration $(\mathrm{mg} / \mathrm{kg}$ ) and PXRF intensity of $\mathrm{Mg}$ (cps) in forage samples at two different particle size.

Appendix 20: CVAS and ICP measured concentration $(\mathrm{mg} / \mathrm{kg}$ ) and PXRF intensity of Fe (cps) in forage samples at two different particle size.

Appendix 21: CVAS and ICP measured concentration (mg/kg) and PXRF intensity of $\mathrm{Cu}(\mathrm{cps})$ in forage samples at two different particle size.

Appendix 22: CVAS and ICP measured concentration $(\mathrm{mg} / \mathrm{kg}$ ) and PXRF intensity of $\mathrm{Zn}(\mathrm{cps})$ in forage samples at two different particle size.

Appendix 23: $R$ codes for Moisture analysis in manure samples for Phosphorus. 88

Appendix 24: $\mathrm{R}$ codes for particle size analysis in forage samples for Phosphorus .90 


\section{List of Tables}

Table 2.1 Average Relative Standard Deviation (RSD) for three replications of manure sample digestion and RSD for SRM digested with manure samples $(n=40)$. 30

Table 2.2 Summary Statistics for ICP determined elemental concentrations $(\mathrm{mg} / \mathrm{kg})$ in manure samples $(n=40)$.

Table 2.3 Summary Statistics for WVDA determined elemental concentrations $(\mathrm{mg} / \mathrm{kg})$ in manure samples $(n=40)$.

Table 2.4 Mean comparison between ICP and WVDA measured concentrations $(\mathrm{mg} / \mathrm{kg})$ in manure samples $(n=40)$

Table 2.5 Summary statistics for PXRF intensities (cps) of oven dried manure samples scanned at 180 seconds $(n=40)$.

Table 2.6 Summary statistics of PXRF determined concentrations $(\mathrm{mg} / \mathrm{kg})$ in oven-dried manure samples $(n=40)$

Table 2.7 Welch two-sample t-test results between ICP and PXRF measured concentration $(\mathrm{mg} / \mathrm{kg})(\mathrm{n}=40)$.

Table 2.8 Summary statistics for PXRF intensities (cps) of manure samples adjusted to four moisture ranges $(10-20 \%, 20-30 \%, 40-50 \%$, and $60-70 \%)(n=40)$.

Table 2.9 Regression between PXRF intensities (cps) of manure samples adjusted to four moisture ranges and ICP determined concentrations $(\mathrm{mg} / \mathrm{kg})(\mathrm{n}=40)$......

Table 2.10 Summary statistics for PXRF determined concentrations $(\mathrm{mg} / \mathrm{kg})$ of manure samples adjusted to four moisture ranges (10-20\%, 20-30\%, 40-50\%, and $60-70 \%)$ $(n=40)$

Table 2.11 Repeated measures ANOVA results for the effect of moisture on elemental concentration $(\mathrm{mg} / \mathrm{kg})$ measured by PXRF $(\mathrm{n}=40)$.

Table 2.12 Welch two-sample t-test results for the effect of moisture on elemental concentration $(\mathrm{mg} / \mathrm{kg})$ measured by PXRF $(\mathrm{n}=40)$.

Table 2.13 Regression between PXRF concentration of manure samples adjusted to four moisture ranges and ICP determined concentrations $(\mathrm{mg} / \mathrm{kg})$

Table 3.1 Average Relative Standard Deviation (RSD) for 3 replications of forage sample digestion and RSD for SRM digested with forage samples $(n=42)$

Table 3.2 Summary Statistics for ICP determined elemental concentrations $(\mathrm{mg} / \mathrm{kg})$ forage samples $(n=42)$ 
Table 3.3 Summary Statistics for CVAS determined elemental concentrations $(\mathrm{mg} / \mathrm{kg})$ in 30 subsets of forage samples.......

Table 3.4 Summary statistics for PXRF intensities (cps) for 3 different particle size forage samples $(n=42)$...

Table 3.5 Summary statistics for PXRF determined concentrations $(\mathrm{mg} / \mathrm{kg})$ for 3 different particle size forage samples $(n=42)$. 59

Table 3.6 Summary statistics for PXRF intensities (cps) for 2 different particle size (new particle size) forage samples $(n=42)$.. 60

Table 3.7 Summary statistics for PXRF determined concentrations $(\mathrm{mg} / \mathrm{kg})$ for two new particle size of forage samples $(n=42)$. 60

Table 3.8 Matched paired t-test between ICP and PXRF measured concentration $(\mathrm{mg} / \mathrm{kg})$ for 2-particle size (new particle size) of forage samples $(n=42)$...............................................

Table 3.9 Repeated measures ANOVA results for the effect of scan time and particle size on PXRF measured elemental concentration $(n=29)$. 61 


\section{List of Figures}

Figure 1.1 Effect of particle size of sample on X-ray Fluorescence.

Figure 2.1 Regression plots between ICP and WVDA measured P, K, Ca, Mg, and Cu concentration.

Figure 2.2 Regression plots between ICP measured concentration and PXRF intensities for

$\mathrm{P}, \mathrm{K}, \mathrm{Ca}, \mathrm{Mg}, \mathrm{Fe}, \mathrm{Cu}$ and $\mathrm{Zn}$ in oven dried manure samples.

Figure 2.3 Regression plots between ICP and PXRF measured concentration for $\mathrm{P}, \mathrm{K}, \mathrm{Ca}$,

$\mathrm{Mg}$, and Fe in oven dried manure samples.

Figure 2.4 Mean comparison of $\mathrm{P}, \mathrm{K}, \mathrm{Ca}, \mathrm{Mg}, \mathrm{Fe}, \mathrm{Cu}$, and $\mathrm{Zn}$ intensities measured at five moisture ranges

Figure 2.5 Relative Standard Deviation of PXRF intensities measured at five moisture ranges.

Figure 2.6 $\quad r^{2}$ values (regression between ICP measured concentration PXRF intensities) produced over different moisture range intensities measured at five moisture ranges.

Figure 2.7 Mean comparison of $\mathrm{P}, \mathrm{K}, \mathrm{Ca}, \mathrm{Mg}$ and Fe concentrations measured at five moisture ranges

Figure 2.8 Relative Standard Deviation of PXRF concentration measured at five moisture ranges..

Figure 2.9 $\quad r^{2}$ values (regression between ICP and PXRF measured concentration) produced over different moisture range.

Figure 2.10 Regression between moisture content and P Intensity by sample for 3 samples varying in $\mathrm{P}$ concentration...

Figure 2.11 Regression between moisture content and P, K, and Ca Intensity... 44

Figure 3.1 Regression plots between ICP and CVAS measured P, K, Ca and Mg....... 62

Figure 3.2 Regression plots between ICP measured concentration and PXRF intensity for $P$, $\mathrm{K}, \mathrm{Ca}, \mathrm{Mg}$, and $\mathrm{Fe}$.

Figure 3.3 Regression plots between ICP measured concentration and PXRF measured concentration for $\mathrm{P}, \mathrm{K}, \mathrm{Ca}$ and $\mathrm{Mg}$......

Figure 3.4(a) Regression plots between ICP measured concentration and PXRF intensity for $\mathrm{P}$, $\mathrm{K}$, and $\mathrm{Ca}$ for two new particle size of forage samples.. 
Figure 3.4(b) Regression plots between ICP measured concentration and PXRF intensity for $\mathrm{Mg}$, Fe and $\mathrm{Zn}$ for two new particle size of forage samples...................................... 66

Figure 3.5 Regression plots between ICP and PXRF measured P, K, Ca, Mg and Fe concentrations. 


\section{Chapter 1: Introduction}

\section{Comprehensive Nutrient Management Plans}

A Comprehensive Nutrient Management Plan (CNMP) is a conservation plan for animal feeding operations (AFO). It is used to help AFO owners manage on-farm nutrients and meet local, state, and federal water quality goals and regulations (USDA-NRCS, 2003). It includes conservation practices and management activities related to livestock and cropping operations. It emphasizes optimal animal feeding practices to minimize mineral nutrients in manure, appropriate use of manure in the field, and the use of conservation practices that address natural resource concerns related to manure and organic by-product effects on water quality. Manure and wastewater handling and storage, land treatment practices, nutrient management, record keeping and feed management are the major components of a CNMP (USDA-NRCS, 2010).

The Conservation Planning Standard for Nutrient Management (Ac. 590) has defined nutrient management as the management of the amount, source, placement, form, and timing of nutrient applications and soil amendments (NRCS-WV, 2010). The major objectives of the 590 standard are to budget and supply plant nutrients, properly utilize manure and organic by-products in plant nutrition, maintain or improve soil health and minimize surface and groundwater pollution due to agricultural nonpoint sources (NRCS-WV, 2010; Evanylo and Beegle, 2006). Soil, manure, forage, and feed analysis are an important part of the planning process that helps to determine application rates of manure and commercial fertilizers in crop fields and optimize animal rations.

Phosphorus (P) is one of the important macronutrients essential for growth and development of a plant. It is a building block of deoxyribonucleic acid (DNA) and ribonucleic acid (RNA) in plant cells and responsible for energy storage and transfer. Plants acquire all of their P from the soil. Weathering process, external applications of manure, fertilizers, and crop residues add P to soil. In animal farms, manure is a major source of soil P.

Since the nitrogen (N)-to-P ratio in manure is less than what is required by crop plants, N-based manure applications will lead to excess soil P and thus potential losses to water bodies (Maguire, 2014). High soil test $P$, soil erosion, and runoff are major contributors to P loss from farms. Since 
there is no gaseous form of $\mathrm{P}$; amounts applied in excess of plant removal could be a potential source to nearby water bodies. Therefore, $P$ mass balance analysis is essential for the sustainability of animal farms. Best management practices could reduce $\mathrm{P}$ loss through soil erosion but optimal use of manures and fertilizers based on soil and manure tests are needed to solve problems associated with positive P mass balances (Maguire, 2014).

Mineral composition data, especially $\mathrm{P}$, of soil, forages, feed, and manures are important components of $\mathrm{P}$ mass balance evaluations and the CNMP development process. However, getting mineral composition data is time-consuming and costly. Simplification of the mineral analysis process could expedite the planning process at a reduced cost. Conventionally, minerals are quantified with expensive and time-consuming wet-chemical methods. This involves acid digestion of samples followed by spectroscopic techniques (Karla, 1998). Although they provide accurate quantification of minerals, they are not free from serious shortcomings. The handling and disposal of acids may result in serious health and environmental consequences. The sample preparation and preservation is tedious. Likewise, these methods are destructive in nature preventing sample reanalysis and there can be a significant lag-time between when the samples are collected and when the data are available.

\section{Mineral Analysis}

\section{Forages}

Minerals occupy almost $10 \%$ of herbage dry matter (Fleming, 1973). Of the important minerals indispensable for animal growth and development, major elements include $\mathrm{P}, \mathrm{K}, \mathrm{Ca}, \mathrm{Mg}, \mathrm{S}$, and $\mathrm{Cl}$ and trace elements include $\mathrm{Fe}, \mathrm{Mn}, \mathrm{Co}, \mathrm{Cu}, \mathrm{Zn}, \mathrm{I}$, and Se (Jones and Thomas, 1987). Mineral composition of forage is influenced by soil mineralogy, moisture content, $\mathrm{pH}$, and external inputs. External inputs of fertilizers into the soil mainly influence $N, P$, and $K$ level in forage while the trace element level is mainly influenced by soil mineralogy (Fleming, 1973). Nitrogen fertilization increases the concentrations of $\mathrm{K}, \mathrm{Ca}$, and $\mathrm{Mg}$ while decreasing the concentration of $\mathrm{P}$ in plants (Reid et al., 1970). In addition, species, plant maturity stage, growing season, and temperature influence mineral composition (Whitehead, 1966; Reid et al., 1970; Fleming, 1973). For example, concentrations of Ca and Mg are higher in legumes compared to grasses (Reid et al., 1970; Baker and Reid, 1977). With advancing maturity, N, P, and K concentrations decrease while 
micronutrient concentrations are unaffected (Baker and Reid, 1977). In addition, maximum concentrations of $\mathrm{P}$ and $\mathrm{K}$ are found in early spring growth but $\mathrm{Ca}$ and $\mathrm{Mg}$ levels are low during spring growth and increase through summer and fall (Reid et al., 1970).

Forage is the major feed and source of minerals for ruminant farm animals. The performance and health of the animal are directly influenced by the mineral content of the forages (Minson, 1990; Van Soest, 1994). The deficiency or excess of specific mineral elements in forage results in poor animal performance and economic return (Reid et al., 1970). The quantity of forage essential to each animal type is determined by the expected level of animal performance, quality of the forage, and its mineral content. Thus, knowing elemental composition ( $\mathrm{Mg}, \mathrm{Ca}, \mathrm{P}, \mathrm{K}, \mathrm{Fe}, \mathrm{Cu}$, and $\mathrm{Zn}$ ) in forage sources is crucial for farmers and/or nutritionists in formulating feeding plans for animals. In addition, large herds require enormous amounts of feed and forage for daily consumption indicating the need to know the nutritional status of the feed and forages frequently for appropriate feeding planning. Since the nutritional status of the forage changes over time, regular sampling and analysis are crucial for ration balancing. However, this increases the monetary burden to farmers (Berzaghi et al., 2005).

\section{Manure and Compost}

Animal manure is rich in minerals essential for plant growth. When available, manure can enhance the production and quality of forage crops. Inadequate use may cause a nutrient deficiency, however, excessive use results in nitrate leaching and $\mathrm{P}$ runoff to water bodies causing eutrophication and associated environmental hazards (Rosen and Bierman, 2005). Having knowledge of the mineral composition of manure either produced within a farm or imported from elsewhere is of tremendous importance for farm nutrient management. Several factors like dietary inputs, the addition of bedding material, water, and storage conditions affect mineral composition of farm manure (Shepherd et. al., 2002).

The availability of minerals to plants depends on the decomposition of manure and soil organic matter and release of minerals into the soil solution. Generally, 70 to $80 \%$ of the P and 80 to $90 \%$ of the $\mathrm{K}$ from manure will be available to plants in the first year after application (Rosen et al., 2005). Residual amounts will be available in subsequent years. However, higher residual amounts may result in runoff to water bodies. Mineral concentrations in manure can be predicted from 
'book values' (Isleib, 2016), however, the actual concentration varies from farm to farm depending on the feed, type and amount of bedding, amount of water used, manure handling and storage. Thus, they are used for prediction of manure composition in the absence of manure tests and do not give exact concentrations (Isleib, 2016). Research from our group has indicated that 'book values' are not always accurate for P (Brackenrich et al., 2016). Thus, only appropriate sampling and testing can provide accurate mineral concentrations and in turn, realistic manure management plans (Martin, 2009; Peters and Combs, 2003).

Forage samples are dried, ground, digested either in a muffle furnace or microwave and elemental concentrations are determined by Inductively Coupled Plasma Optical Emission Spectrometry (ICP-OES). Near-infrared spectroscopy can be used for forage quality analysis along with some elemental concentrations like $\mathrm{N}, \mathrm{P}, \mathrm{K}, \mathrm{Ca}, \mathrm{Mg}$, S, and $\mathrm{Cl}$. The liquid manure samples are well mixed, subsampled, and digested either in a muffle furnace or microwave and determined by ICP. Solid manure samples can be processed as received, however, the homogenization is quite difficult. They can be chopped and rotated to establish homogeneity. Solid manure samples can also be dried and ground before acid digestion for the determination of non-volatile elements like P (Peters and Combs, 2003).

Most laboratories still rely on conventional acid digestion methods for elemental quantification. However, modern spectroscopic techniques have the potential to minimize or eliminate wetchemical methods.

\section{X-ray fluorescence (XRF) spectroscopy}

\section{Principle}

X-rays are electromagnetic radiation with a wavelength from $0.01-10 \mathrm{~nm}$. X-ray photons are emitted from an X-ray tube by the interaction of electrons with a metal anode. When the energy of the incident X-ray is greater than the binding energy of electrons in the shell, inner shell electrons are ejected, leaving a vacant space. In order to fill this vacant space the electron from a higher shell moves to the inner shell emitting secondary $\mathrm{X}$-ray radiation of energy/wavelength characteristic to each element. The emitted radiation is then detected. X-ray energy is inversely proportional to wavelength and is expressed as keV (kilo-electron volt) (Kalnicky and Singhvi, 
2001). XRF possesses a unique ability to measure several elements simultaneously in an extensive concentration range with an accuracy of $1 \%$ (Piorek, 1997).

Based on the way in which the X-ray spectrum is dispersed before it reaches the detector, XRF spectroscopy can be either wavelength dispersive (WD) or energy dispersive (ED).

In WDXRF, an analyzing crystal disperses or splits secondary X-rays such that a detector can measure each wavelength separately (Willis and Duncan, 2008). It has superior resolution and minimal spectral overlaps allowing easy, accurate identification of peaks. Working with higher Xray intensities it produces better detection limits than EDXRF. However, they are large, complex systems, with higher power X-ray tubes and are thus more expensive.

In EDXRF, secondary X-ray photons are detected directly without being dispersed. The dispersion of the entire spectrum occurs directly in the detector in the energy domain (Piorek, 1997). The energy and intensity of X-ray fluorescence are detected in the form of a spectrum. The peak position in the spectrum is proportional to the energy of X-rays (Willis and Duncan, 2008). Thus, the position of peaks identifies elements present in a sample while the magnitude of a peak is proportional to elemental concentration (Weindorf et. al., 2014). They are less expensive and available in portable form.

\section{Portable XRF}

Portable XRF is based on ED principle and has low power X-ray tube (10-40W) in comparison to benchtop units (50-300W). It is light and convenient to use either in benchtop or field analysis modes. Thus, the potential for in-situ measurement and immediate availability of the elemental concentrations are the most appealing parts of PXRF (Potts and West, 2008). Although PXRF can measure most elements, air attenuation of low energy $\mathrm{X}$-rays restricts the measurement of light elements in the periodic table, especially below silicon (Potts and West, 2008) except when equipped with a unique chamber capable of working under vacuum, or a helium atmosphere (Bueno Guerra et al., 2014; Brouwer, 2013). Since air absorbs the radiation from light elements, use of a vacuum is crucial for the detection of light elements like $\mathrm{Na}, \mathrm{Mg}, \mathrm{Si}, \mathrm{P}, \mathrm{S}, \mathrm{K}$, and $\mathrm{Ca}$. If a vacuum results in evaporation problems for liquid and wet samples, a helium atmosphere can be used (Brouwer, 2013). 
PXRF may be qualitative, semi-quantitative, or quantitative as an analytical technique. The quantitative data are obtained by calibrating the XRF with reference wet chemical methods (Maarschalkerweerd and Husted, 2015) or standard addition methods (Reidinger et al., 2012).

XRF analysis has been widely used to quantify elements in several disciplines. Recent advances in XRF technology have led to the development of portable instruments that can be carried to desired places and used to establish mobile laboratories for immediate sample analysis. They can even be used in-situ without sample preparation (AMC, 2008). Some portable units are comparable to benchtop XRF in elemental quantification and limits of detection (Bueno Guerra et al., 2014) but superior in terms of portability, cost-effectiveness, simplicity of operation, potential for in-situ measurement, and analysis of large samples (Bueno Guerra et al., 2014; AMC, 2008). In addition, it can be a superior alternative to wet chemistry in terms the cost- and timeeffectiveness, and non-destructive analysis of samples (Reidinger et al., 2012). Measurement precision varies from 0.01 to $0.5 \%$, depending on the element of interest, its concentration, and the sample matrix (Piorek, 1997). It quantifies total element concentration in the sample volume. In the case of soil, not all portions of the elements present in soil are plant-available. Hence, it is not typically used to determine available elements in the soil.

While PXRF has been found to be effective in quantifying elements in archeology, geology, mining, metallurgy, soil science, and agronomy (Weindorf et al., 2014), very few works have been conducted on its use in plant, compost and manure analysis. To our knowledge, there are no published studies using PXRF in the elemental quantification of forage crops.

\section{Calibration}

Calculation of elemental concentration from the intensity of X-ray photons is done using an appropriate calibration equation. Calibration can be with either fundamental parameters or empirical. Fundamental parameter calibration is a standard-less calibration based on the geometry of XRF instruments and assumption of about sample matrix to produce semiquantitative estimates of elemental concentration (Towett et al., 2016). Only one samplecontaining element of interest is used as a reference standard (Smagunova et al., 2012). It assumes all samples are flat, smooth, homogenous, and infinitely thick for all analyte 
wavelengths (Willis and Duncan, 2008). This calibration is mostly used in commercial and industrial instruments but not reliable for research purposes (Towett et al., 2016).

Reference standards of known concentration are used to develop empirical calibration models for elemental quantification from XRF intensity. Specific empirical calibrations could be developed for each sample matrix using standard reference materials of the same matrix. Matrix effects arise due to elemental interactions (absorption and enhancement) and physical characteristics of particle size, surface, and chemical state of each matrix (Willis and Duncan, 2008). The measured intensity of the target element is influenced by variation in concentration of interfering elements in the matrix (Kalnicky and Singhvi, 2001), indicating the need for matrixspecific calibration. This can be done using the Lucas-Tooth and Price empirical calibration equation (Towet et al., 2016).

$$
\mathrm{C}_{\mathrm{i}}=\mathrm{r}_{0}+\mathrm{I}_{\mathrm{i}}\left(\mathrm{r}_{\mathrm{i}}+\sum \mathrm{r}_{\mathrm{in}}+\mathrm{I}_{\mathrm{n}}\right)
$$

Where,

$\mathrm{C}_{\mathrm{i}}=$ concentration of element,

$r_{0}=$ intercept/empirical constant for element $i$,

$r_{i}=$ slope/empirical coefficient for intensity of element $i$,

$r_{\text {in }}=$ slope/empirical constant for effect of element $n$ on element $i$,

$l_{i}=$ net intensity of element $i$,

$I_{n}=$ net intensity of element $n$.

Empirical calibration considers the variable depth of measurement, uneven voltage distribution, and peak overlap. The reliability of calibration depends on the variability of the reference standards and resemblance to the sample matrix (Towett et al., 2016).

\section{Enhancement effects}

$\mathrm{X}$-ray fluorescence can either be primary or secondary. Primary X-ray fluorescence is produced by the action of incoming X-rays with the atom of an element. Secondary X-ray fluorescence is produced by the action of the emitted primary fluorescence on the atom of another element. The primary fluorescence produced by higher energy elements in a composite sample causes 
enhancement of the lower energy elements through the emission of secondary fluorescence (Salesh, 1988). The fluorescence that reaches to the detector is the combination of primary and secondary fluorescence. It is possible to have tertiary or even higher fluorescence, however, it is almost negligible in practice (Brouwer, 2013). In some cases, $10-30 \%$ of the measured intensity can be attributed to enhancement effect (Salesh, 1988).

Dyck et al. (1986), using EDXRF, in an experiment with environmental samples of medium thickness found that enhancement effect can only be neglected for very thin samples (geological samples: $<0.5 \mathrm{mg} / \mathrm{cm}^{2}$, biological samples: $<20 \mathrm{mg} / \mathrm{cm}^{2}$ ). Thus, the enhancement effect increases with sample thickness until it satisfies infinitely thick criterion.

Some PXRF bears the special facility to control energy, current, and use of a filter for the determination of a specific range of elements. There is a general rule that to get fluorescence from elements, at least $2 \mathrm{KeV}$ more of energy should be released to the sample. For the detection of light element ( $\mathrm{Mg}$ to Fe) a voltage level of $15 \mathrm{KeV}$ and anode current of $26 \mu \mathrm{A}$ is used. The greatest benefit associated with this setting is the reduction of enhancement effects due to the fluorescence associated with higher energy elements.

\section{Depth of measurement}

The volume of the sample interrogated depends on the energy of emitted X-ray and the critical penetration and escape depths. The critical penetration and escape depths are the depth of the sample beyond which almost all of emitted x-rays are absorbed, which is very low (in $\mu$ m range) for light elements (Potts and West, 2008). In addition, it depends on the mass attenuation coefficient and density of the matrix (Towett et al., 2016).

The concentration of the analyte, the thickness of the samples, and their matrix characteristics are the major factors influencing radiation intensity. The intensity of radiation increases with sample thickness up to a point called critical thickness (a point where infinite thickness starts). Below the critical thickness (intermediate thickness) point, both sample thickness and matrix affect the intensity, but beyond critical thickness (infinitely thick samples) intensity is affected by sample matrix only. Thus, a thickness correction is essential for samples of intermediate thickness. The matrix effect is negligible for very thin samples (Sitko, 2009). 
Heavy elements have a short wavelength, high energy, and thus deeper penetration depth. However, light elements, like $\mathrm{P}$, have a longer wavelength, low energy, and thus low penetration depth. In addition, the composition of plant matrix also affects measurement depth. The estimated analytical measurement depth of $\mathrm{P}$ is $80 \mu \mathrm{m}$ in water, $70 \mu \mathrm{m}$ in cellulose and $60 \mu \mathrm{m}$ in fructose (Towett et al., 2016). Thus, $P$ is measured almost at the sample surface that is in contact with the nose of the PXRF reducing the influence of sample thickness.

\section{Analytical parameters}

Accurate determination of the composition depends on proper sample preparation, sample introduction and instrumental setup of the XRF (Towett et al., 2016). In addition, the elemental quantification is affected by the energy level of the element, scanning time, the particle size of the sample, and moisture content (McLaren et al., 2012). Likewise, samples should meet the conditions of homogeneity and infinite thickness along with proper calibration.

\section{Scan time effect}

Raw peak count and spectral resolution increase with increasing scan time (McLaren et al., 2012, Kalnicky and Singhvi, 2001). Along with element of interest and sample matrix, detection limit depends on scan time. Scanning samples for longer time decreases detection limits to smaller levels, however, the number of samples analyzed will be reduced (Kalnicky and Singhvi, 2001), and radiation damage is possible.

Bueno Geurrea et al. (2014) optimized measurement time as 150 seconds by scanning a pellet of NIST SRM 1515 apple leaves from 10 to 300 seconds. The coefficient of variation ranged from 0.1\% for Ca to 3.3\% for P at 150s. Reidinger et al. (2012) used 30s for scanning pelletized ground plant samples. Towett et al. (2016) used 180s for fine powdered ( $<53 \mu \mathrm{m}$ ) plant samples. McLaren et al. (2012) evaluated scan time (120s and 300s) for cotton leaf powder. The spectral peaks were higher for 300s than 120s scanning time in cotton powder. Even though the two scan times produced similar data quality, regression slopes will be greater for longer scanning time thus increasing the accuracy of measurement (McLaren et al., 2012, Kalnicky and Singhvi, 2001). Paltridge et al. (2012a) used 60s for the determination of $\mathrm{Zn}$ and Fe in rice and pearl millet and for the determination of Zn, Fe, and Se in whole grain wheat (Paltridge et al. 2012b). 


\section{Particle size effect}

The texture of sample surface is extremely important in XRF measurement. The surface of the sample should have mirror-finish, which can only be realized with fine powders or metals (Willis and Duncan, 2008). PXRF intensity increases with a decrease in particle size of the sample and is more sensitive for light elements (Maruyama et al., 2008).

Particle size effect is more pronounced in light elements than heavy elements because of lower penetration depth and measurement surface located on or in the proximity of the surface. In addition, there is shadowing effect if the sample is of heterogeneous particle size. Incoming Xrays will irradiate not all particles (Fig 1.1a) and thus no fluorescence will be received from shadowed particles (Yamada, 2014). The best approach to deal with particle size of the sample is to grind to a particle size less than the measurement depth of the element to be determined (Willis and Duncan, 2008). However, grinding sample to fine power is not always beneficial; there is the possibility of contamination by blades in grinding mill.

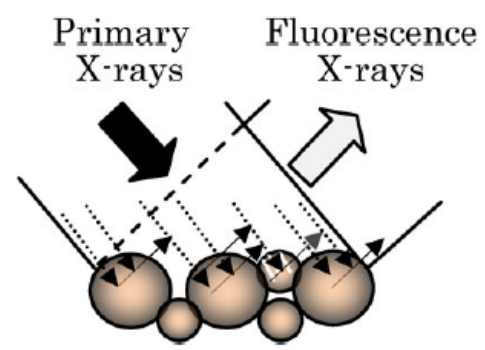

Model (a)

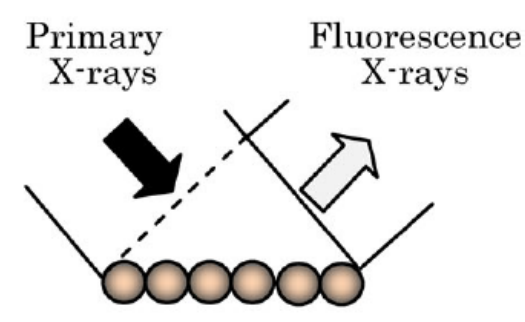

Model (b)

Figure 1.1: Effect of particle size of sample on X-ray Fluorescence (Yamada, 2014)

Imanishi et al. (2010) in a study with soil samples found that particle size of soil samples affected XRF intensity in the determination of light elements. Samples with small particles produced better results for light elements than large particle sizes.

McLaren et al. (2012) found that differences in particle size of cotton (powdered and $2 \mathrm{~mm}$ ) did not affect slope and intercept of the regression line between PXRF and ICP values and indicated the need for further study of particle size effects. 


\section{Moisture level effect}

Water molecules scatter primary X-rays and absorb characteristic X-rays of the analyte, thus reducing the photon counts (Ge et al., 2005; Stockmann et al., 2006). Increased moisture content reduces the apparent concentration and fosters a lower precision, poorer detection limit and reduced accuracy (Stockmann et al., 2006).

Kalnicky and Singhvi (2001) mention that presence of moisture, typically above 20\%, will attenuate $x$-rays and dilute the concentration of elements affecting quantification of elements. This effect is larger for light elements (below $5 \mathrm{Kev}$ ) and may be negligible for the heavy elements, like $\mathrm{Pb}$.

Imanishi et al. (2010) in a study using energy dispersive XRF with soil samples found that dried soil samples with small particles produced better results for light elements than wet samples. Likewise, Sahraoui and Hachichu (2017) in a study to determine the effect of moisture content of soil in elemental concentration of $\mathrm{Ca}, \mathrm{Mg}, \mathrm{P}, \mathrm{Zn}, \mathrm{Fe}, \mathrm{Mn}, \mathrm{Cd}, \mathrm{Cr}, \mathrm{Cu}, \mathrm{Ni}$, and $\mathrm{Pb}$ found that soil moisture content caused significant underestimation of elemental concentration.

McWhirt et al. (2012) in an experiment with the effect of moisture content on the elemental concentration of compost samples using PXRF (Delta Premium DP-4000, Olympus Innov-X, USA) indicated a moderate reduction in predictive ability ( $r^{2}$ decreased by $\left.5-20 \%\right)$ compared to dry scans.

\section{Plant mineral analysis by portable XRF}

Previous studies on different aspects of plant elemental compositional analysis have indicated some avenues to analyze forage samples by portable XRF. Bueno Guerra et al. (2014) in an experiment (using Tracer III-SD; Bruker Elemental, Kennewick, WA) with top visible dewlap leaves of 23 sugarcane varieties found a good correlation ( $r$ ranges from 0.91 to 0.99 ) between acid digestion values and XRF counts for P, K, Ca, P, K, Ca, S, Fe, Mn, and Si. Reidinger et al. (2012), using PXRF (Niton XL3t900 GOLDD Analyzer, Thermo Scientific, Winchester, UK), obtained a linear calibration curve for silicon in Si-spiked methylcellulose between acid digestion and portable XRF counts. Likewise, they found a good correlation $(r=0.98)$ for $P$ determination in certified reference material. 
Towett et al. (2016) in an experiment with analytical parameters of PXRF (Tracer III-SD; Bruker Elemental, Kennewick, WA) taking diverse plant samples found that direct contact on the surface of a portable XRF with the aid of vacuum provided highest sensitivity and accuracy $\left(r^{2}>0.90\right)$ for light elements ( $\mathrm{Mg}$ to $\mathrm{P}$ ) instead of using prolene sample cups. However, compromising some lower detection limits, elements like S, K, and Ca be analyzed without vacuum. The use of sample cups negatively affected the measurement of nutrients indicating the potential for the in-situ analysis of plant samples.

Kalcsits (2016) studied the suitability of PXRF (Tracer III-V; Bruker Elemental, Kennewick, WA) in measuring $\mathrm{Ca}$ and $\mathrm{K}$ concentration in apple and pear fruits. There was a significant correlation $(r=$ 0.73 to 0.97 ) between PXRF measurement and wet chemical analysis results.

McLaren et al. (2012) using PXRF (Tracer III-V; Bruker Elemental, Kennewick, WA) studied the effect of scanning time and particle size on data quality using four plant species: corn tops ( 2 $\mathrm{mm}$ ), wheat tops (2 $\mathrm{mm}$ and powder), cotton leaves (powder), and soybean grains (powder). They found similar $r^{2}$ values for the same sample at different scan times. Likewise, they obtained similar $r^{2}$ for corn and cotton at 120 seconds indicating potentiality of using a single calibration curve for different plant species. They found a significant linear relationship between the acid digest and portable XRF readings for $\mathrm{Ca}, \mathrm{Co}, \mathrm{Cr}$, Fe, K, Mn, Ni, P, S, Si, and $\mathrm{Zn}$ in three plant species (corn, cotton, and soybean).

Paltridge et al. (2012a) in an experiment using PXRF (X-Supreme 8000, Oxford Instruments, Abingdon, UK) to determine $\mathrm{Zn}$ and Fe concentration in rice and pearl millet grain, found that EDXRF results were highly correlated with ICP values $\left(r^{2}=0.79-0.98\right)$. EDXRF predicted $\mathrm{Zn}$ and Fe in rice within 1.9 and $1.6 \mathrm{mg} \mathrm{kg}^{-1}$ of ICP values, and in pearl millet within 7.6 and $12.5 \mathrm{mg} \mathrm{kg}^{-1}$ of ICP values at a 95\% confidence level. In a similar experiment with whole wheat grain, Paltridge et al. (2012b) found EDXRF values for $\mathrm{Zn}$, Fe, and Se were highly correlated with ICP-OES values. Standard errors of prediction were $\pm 2.2 \mathrm{mg} \mathrm{Zn} \mathrm{kg}^{-1}, \pm 2.6 \mathrm{mg} \mathrm{Fe} \mathrm{kg}^{-1}$, and $\pm 1.5 \mathrm{mg} \mathrm{Se} \mathrm{kg}{ }^{-1}$.

\section{Compost mineral analysis by portable XRF}

Elemental quantification of compost has implications in both plant nutrition and environmental quality (Weindorf et al., 2014). McWhirt et al. (2012) in an experiment with compost samples 
using PXRF (Delta Premium DP-4000, Olympus Innov-X, USA) indicated that the results for Ca, $\mathrm{Cr}$, $\mathrm{Cu}, \mathrm{Fe}, \mathrm{K}, \mathrm{Mn}, \mathrm{P}$, and $\mathrm{Zn}$ were in close agreement with ICP values. Weindorf et al. (2008) used PXRF (Alpha series, Innov-X, USA) with the single beam for elemental quantification of a single compost feedstock of composted dairy manure. They concluded that PXRF could be a potential tool for quantification of $\mathrm{Ni}, \mathrm{Cu}, \mathrm{Zn}, \mathrm{Se}, \mathrm{Mo}$, and $\mathrm{Pb}$. Recent advances in PXRF technology, especially the addition of vacuum, have extended the applicability of XRF for detection of light elements indicating the need for further study in using XRF for manure samples.

PXRF has been tested for homogenous plant materials but their applicability to heterogeneous plant materials like forage is yet to be determined. As a first step to using PXRF in-field for elemental determinations in manure and forage to support CNMP planning, this study starts with samples at the best analytical conditions (dried and ground samples) and then systematically evaluates the effects of moisture content (manure) and particle size (forage). In addition, appropriate scan times were determined. Standardization of analytical parameters in forage and manure samples would open new avenues in forage and manure mineral analysis.

\section{Objectives}

The overall goal of this thesis is to evaluate the suitability of PXRF to facilitate the development of CNMPs, specifically, the determination of $\mathrm{P}$ in manure and forage to construct whole-farm Pbalances. Because other elements are obtained simultaneously, results for $\mathrm{K}, \mathrm{Ca}, \mathrm{Mg}, \mathrm{Fe}, \mathrm{Cu}$ and Zn are also reported.

To initiate this process we assumed that water content would be the limiting factor for manure analyses and particle size would be the limiting factor for forage analyses. Thus the specific objectives were

1. Quantify the effect of manure moisture content on elemental concentrations (Chapter 2), and

2. Quantify the effect of forage particle size and scan time on elemental concentrations (Chapter 3) 


\section{Literature Cited}

Analytical Methods Committee (AMC), Royal Society of Chemistry. 2008. Evaluation of analytical instrumentation. Part xxiii. Instrumentation for portable x-ray fluorescence spectrometry. Accred. Qual. Assur. 13:453-464

Baker, B.S and R.L. Reid. 1977. Mineral composition of forages species grown in central West Virginia on various soil series. West Virginia University, Agricultural and Forestry Experiment Station, Morgantown. Bulletin 657.

Berzaghi, P., L. Serva, M. Piombino, M. Mirisola, and F. Benozzo. 2005. Prediction performances of portable near infrared instruments for at farm forage analysis. Ital. J. Anim. Sci. 4(SUPPL. 3): 145-147.

Brackenrich, J., L.M. McDonald, T. Basden and K. Shaffer. 2016. Optimizing feeding strategies to minimize phosphorus losses from roofed winter feeding areas. American Society of Agronomy/Crop Science Society of America/Soil Science Society of America Annual Meeting, Phoenix, AZ. Nov. 6-9, 2016.

Brouwer, P. 2013. Theory of XRF. PANanalytial B.V., Almelo, The Netherlands.

Bueno Guerra, M.B., E. de Almeida, G.G.A. Carvalho, P.F. Souza, L.C. Nunes, D.S. Júnior, and F.J. Krug. 2014. Comparison of analytical performance of benchtop and handheld energy dispersive $X$-ray fluorescence systems for the direct analysis of plant materials. J. Anal. At. Spectrom. 29(9): 1667.

Dyck, P.M., S. B. Torok, and R.E. Grieken. 1986. Enhancement effect. Anal. Chem. 58(8): 17611766.

Evanylo, G.K. and D. Beegle. Introduction to nutrient management. 2006. In K. C. Haering and G. K. Evanylo. Mid-Atlantic nutrient management handbook. Mid-Atlantic Regional Water Program, USA.

Fleming, G. A. 1973. Mineral composition of herbage. In G.W. Butler and R.W. Bailey (ed.). Chemistry and biochemistry of herbage. Volume I. Academic Press Inc, New York.

Ge, L., W. Lai, and Y. Lin. 2005. Influence of and correction for moisture in rocks, soils and sediments on in situ XRF analysis. X-Ray Spectrom 34(28): 28-34.

Imanishi, Y., A. Bando, S. Komatani, S. I.Wada, K. Tsuji. 2010. Experimental parameters for XRF analysis of soils. Denver X-ray Conference on Applications of X-ray Analysis. International Centre for Diffraction Data. 1-7.

Isleib, J. 2016. Manure provides plant nutrients, but not always at book value. Michigan State University Extension. http://msue.anr.msu.edu/news/manure provides plant nutrients but not always at book v alue

Jones, D.I.H., and T. A Thomas. 1987. Minerals in pastures and supplements. In R.W. Snaydon (ed.). Ecosystems of the world 17B, Managed grasslands analytical studies. Elsevier, Oxford. 
Kalcsits, L.A. 2016. Non-destructive measurement of calcium and potassium in apple and pear using handheld X-ray fluorescence. Front. Plant Sci. 7:442.

Kalnicky, D.J., and R. Singhvi. 2001. Field portable XRF analysis of environmental samples. J. Hazard. Mater. 83(1-2): 93-122.

Karla, Y. P. 1998. Handbook of reference methods for plant analysis. CRC Press Taylor \& Francis Group.

Maarschalkerweerd, M., and S. Husted. 2015. Recent developments in fast spectroscopy for plant mineral analysis. Front. Plant Sci. 6(March): 1-14.

Maguire, R.O. 2014. Importance of farm phosphorus mass balance and management options. Virginia Cooperative Extension. Publication No. CSES-98P.

Martin, J. 2009. Manure sampling for nutrient management planning. Agronomy Facts 69. Penn State Extension.

Maruyama, Y., K. Ogawa, T. Okada, and M. Kato. 2008. Laboratory experiments of particle size effect in X-ray fluorescence and implications to remote X-ray spectrometry of lunar regolith surface. Earth Planets Sp. 60: 293-297.

McLaren, T.I., C.N. Guppy, and M.K. Tighe. 2012. A rapid and nondestructive plant nutrient analysis using portable X-ray fluorescence. Soil Sci. Soc. Am. J. 76(4): 1446-1453.

McWhirt, A., D.C. Weindorf, and Y. Zhu. 2012. Rapid analysis of elemental concentrations in compost via portable X-ray fluorescence spectrometry. Compost Sci. Util. 20(3): 185193.

Minson, D.J. 1990. Forage in ruminant nutrition. Academic Press, San Diego, USA.

NRCS-WV. 2010. Conservation practice standard, Nutrient Management (Ac.) 590. Natural Resources Conservation Service. West Virginia.

Paltridge, N.G., L.J. Palmer, P.J. Milham, G.E. Guild, and J.C.R. Stangoulis. 2012a. Energydispersive $X$-ray fluorescence analysis of zinc and iron concentration in rice and pearl millet grain. Plant Soil 361(1-2): 251-260.

Paltridge, N.G., P.J. Milham, J.I. Ortiz-Monasterio, G. Velu, Z. Yasmin, L.J. Palmer, G.E. Guild, and J.C.R. Stangoulis. 2012b. Energy-dispersive X-ray fluorescence spectrometry as a tool for zinc, iron and selenium analysis in whole grain wheat. Plant Soil 361(1-2): 261-269.

Peters, J. and S. Combss. 2003. Sampling livestock waste for analysis. In: J. Peters, S.M. Combss, B. Hoskins, J. Jarman, J.L. Kovar, M. E. Watson, A.M. Wolf and N. Wolf. Recommended methods of Manure Analysis, Cooperative Extension Publishing, University of WisconsinExtension.

Piorek, S. 1997. Field-portable X-ray fluorescence spectrometry : past, present, and future. F. Anal. Chem. Technol. 1(6): 317-329.

Potts, P. J., and M. West. 2008. Portable X-ray fluorescence spectrometry: capabilities for in situ analysis. The Royal Society of Chemistry, UK. 
Reid, R. L., A. J. Post, and G. A. Jung. 1970. Mineral composition of forages. West Virginia University, Agricultural Experiment Station, Morgantown. Bulletin 589T.

Reidinger, S., M.H. Ramsey, and S.E. Hartley. 2012. Rapid and accurate analyses of silicon and phosphorus in plants using a portable X-ray fluorescence spectrometer. New Phytol. 195(3): 699-706.

Rosen, C.J., and P.M. Bierman. 2005. Using manure and compost as nutrient sources for vegetable crops. University of Minnesota, Extension Service. http://www.extension.umn.edu/distribution/horticulture/M1192.htmL.

Sahraoui, H., and M. Hachicha. 2017. Effect of soil moisture on trace elements concentrations. J. Fundam. Appl. Sci. 9(1): 468-484.

Salesh, N. 1988. Enhancement effect in XRF analysis. J. Radioanal. Nucl. Chem. 120(1): 161-165

Shepherd, M., J. Webb, and L. Philipps. 2002. Tools for managing manure nutrients. In UK organic research: Proceedings of COR conference. Aberystwyth. 165-168.

Sitko, R. 2009. Quantitative X-ray fluorescence analysis of samples of less than "infinite thickness": Difficulties and possibilities. Spectrochim. Acta - Part B At. Spectrosc. 64(1112): 1161-1172.

Smagunova, A. N., B. Oyuntsetseg, S.D Pan'kov. 2012. Determination of optimum conditions for X-ray fluorescence analysis using coupling equations. J. Anal. Sci. Methods Instrum. 2(2): 81-86.

Stockmann, U., H.J. Jang, B. Minasny, and A. B. McBratney. 2006. The effect of soil moisture and texture on Fe concentration using portable X-ray fluorescence spectrometers. In: A.E. Hartemink and B. Minasny (eds.), Digital Soil Morphometric, Progress in soil science, Springer International Publishing Switzerland.

Towett, E.K., K.D. Shepherd, and B. L. Drake. 2016. Plant elemental composition and portable Xray fluorescence ( $\mathrm{DXRF}$ ) spectroscopy: Quantification under different analytical parameters. X-Ray Spectrom. 45(2): 117-124.

USDA-NRCS. 2003. National planning procedures handbook. United States Department of Agriculture, Natural Resource Conservation Service.

USDA-NRCS. 2010. Statement of work: comprehensive nutrient management plan (code 102), Pensylvania

Van Soest, P. J. 1994. Nutritional ecology of the ruminant. 2nd ed. Comstock Publishing Associates, Ithaca, NY.

Weindorf, D.C., and S. Chakraborty. 2016. Portable X-ray fluorescence spectrometry analysis of soils. Methods Soil Anal. 1(1): 1-8. 
Weindorf, D.C., R. Sarkar, M. Dia, H. Wang, Q. Chang, B. Haggard, A. McWhirt, and A. Wooten. 2008. Correlation of X-ray fluorescence (XRF) spectrometry and inductively coupled plasma atomic emission spectroscopy (ICP-AES) for elemental determination in composted products. Compost Sci. Util. 16 (2): 79-82.

Whitehead, D. C. 1966. Data on mineral composition of grassland herbage from the Grassland Research Institute, Hurley, and the Welsh Plant Breeding Station, Aberystwyth. Grassland Research Institute, Hurley, Maidenhead Berks England. Technical report no. 4.

Willis, J. P., and A. R. Duncan. 2008. Understanding XRF spectrometry, Vol I. PANanalytial B.V., Almelo, The Netherlands.

Yamada, Y. 2014. Sample preparation for X-ray fluorescence analysis I . Outline of sample preparation. Rigaku J. 30(1): 26-29. 


\section{Chapter 2: Moisture Effect on Elemental Concentration Determination in Manure using Portable X-ray Fluorescence Spectroscopy}

\section{Introduction}

A Comprehensive Nutrient Management Plan (CNMP) is a conservation plan for animal feeding operations (AFO). It is used to help AFO owners manage on-farm nutrients and meet local, state, and federal water quality goals and regulations (USDA-NRCS, 2003). Manure and wastewater handling and storage, land treatment practices, nutrient management, record keeping and feed management are the major components of a CNMP (USDA-NRCS, 2010). The major objective of conservation planning standard (Ac. 590) is to budget and supply plant nutrients, properly utilize manure and organic by-products in plant nutrition, maintain or improve soil health and minimize surface and groundwater pollution due to agricultural nonpoint sources (NRCS-WV, 2010; Evanylo and Beegle, 2006).

Phosphorus $(\mathrm{P})$ is one of the important macronutrients essential for growth and development of a plant. It is a building block of deoxyribonucleic acid (DNA) and ribonucleic acid (RNA) in plant cells and responsible for energy storage and transfer. Plants acquire all of their $\mathrm{P}$ from the soil. Weathering process, external applications of manure, fertilizers, and crop residues add P to soil. In animal farms, manure is a major source of soil $\mathrm{P}$. Since the nitrogen (N)-to-P ratio in manure is less than what is required by crop plants, $\mathrm{N}$-based manure applications will lead to excess soil $\mathrm{P}$ and thus potential losses to water bodies (Maguire, 2014). High soil test $P$, soil erosion, and runoff are major contributors to $P$ loss from farms. Since there is no gaseous form of $P$, amounts applied in excess of plant removal could be a potential source to nearby water bodies. Therefore, $\mathrm{P}$ mass balance analysis is essential for the sustainability of animal farms (Maguire, 2014).

Mineral composition data, especially $\mathrm{P}$, of soil and manure are important components of $\mathrm{P}$ mass balance evaluations and the CNMP development process. However, getting mineral composition data is time-consuming and costly. Conventionally, minerals are quantified with expensive and time-consuming wet-chemical methods. This involves acid digestion of samples followed by spectroscopic techniques (Karla, 1998). Although they provide accurate quantification of 
minerals, they are not free from serious shortcomings. They are costly, time-consuming, and generate hazardous waste.

Mineral concentrations in manure can also be predicted from 'book values' (Isleib, 2016), however, the actual concentration varies from farm to farm depending on the feed, type, and amount of bedding, amount of water used, manure handling and storage. Thus, they are used for prediction of manure composition in the absence of manure tests and do not give exact concentrations (Isleib, 2016) and are not accurate for P (Brackenrich et al., 2016). Thus, only appropriate sampling and testing can provide accurate mineral concentrations and in turn, realistic manure management plans (Martin, 2009; Peters and Combs, 2003). Simplification of the mineral analysis process could expedite the planning process at a reduced cost. X-ray fluorescence (XRF) could overcome many of these disadvantages of wet chemical analysis and allow quick determination of $\mathrm{P}$ concentrations.

X-ray photons are emitted from an X-ray tube by the interaction of electrons with a metal anode. When the energy of the incident X-ray is greater than the binding energy of electrons in the shell, inner electrons are ejected leaving a vacant space. In order to fill this vacant space the electron from a higher shell moves to the inner shell emitting secondary X-ray radiation of energy/wavelength characteristic to each element. The emitted radiation is then detected. X-ray energy is inversely proportional to wavelength and is expressed as keV (kilo-electron volt) (Kalnicky and Singhvi, 2001). Portable XRF (PXRF) units are Energy Dispersive (ED) systems with low power X-ray tubes (10-40W) in comparison to benchtop units (50-300W). They are light and convenient to use either in benchtop or field-analysis modes.

When a sample is scanned, the resulting spectrum identifies the element (peak position or energy); area under the peak (intensity) is proportional to concentration (Willis and Duncan, 2008; Weindorf et. al., 2014). Although PXRF can measure most elements, air attenuation of low energy X-rays restricts the measurement of light elements in the periodic table, especially below silicon (Potts and West, 2008) except when equipped with a unique chamber capable of working under vacuum, or a helium atmosphere (Bueno Guerra et al., 2014; Brouwer, 2013). The critical penetration and escape depths are the depth of the sample beyond which almost all of emitted 
$\mathrm{x}$-rays are absorbed, which is very low (in $\mu \mathrm{m}$ range) for light elements (Potts and West, 2008). PXRF may be qualitative, semi-quantitative, or quantitative as an analytical technique. The quantitative data are obtained by calibrating the XRF with reference wet chemical methods (Maarschalkerweerd and Husted, 2015) or standard addition methods (Reidinger et al., 2012).

Some portable units are comparable to benchtop XRF in elemental quantification and limits of detection (Bueno Guerra et al., 2014) but superior in terms of portability, cost-effectiveness, simplicity of operation, potential for in-situ measurement, and analysis of large samples (Bueno Guerra et al., 2014; AMC, 2008). In addition, it can be a superior alternative to wet chemistry in terms the cost- and time-effectiveness, and non-destructive analysis of samples (Reidinger et al., 2012).

Water molecules scatter primary X-rays and absorb characteristic X-rays of the analyte, thus reducing the photon counts (Ge et al., 2005; Stockmann et al., 2006). Increased moisture content reduces the apparent concentration and fosters a lower precision, poorer detection limit and reduced accuracy (Stockmann et al., 2006). Kalnicky and Singhvi, (2001) mention that presence of moisture, typically above $20 \%$, will attenuate $x$-rays and dilute the concentration of elements affecting quantification of elements. This effect is larger for light elements (below $5 \mathrm{Kev}$ ) and may be negligible for the heavy elements like $\mathrm{Pb}$.

Weindorf et al. (2008) concluded that PXRF (Alpha series, Innov-X, USA) could be a potential tool for quantification of $\mathrm{Ni}, \mathrm{Cu}, \mathrm{Zn}, \mathrm{Se}, \mathrm{Mo}$, and $\mathrm{Pb}$ determination in single compost feedstock of composted dairy manure. McWhirt et al. (2012) in an experiment with compost samples using PXRF (Delta Premium DP-4000, Olympus Innov-X, USA) indicated that the results for $\mathrm{Ca}, \mathrm{Cr}, \mathrm{Cu}$, $\mathrm{Fe}, \mathrm{K}, \mathrm{Mn}, \mathrm{P}$, and $\mathrm{Zn}$ were in close agreement with ICP values. However, there is a lack of information for analysis of heterogeneous manure samples, including optimal sample preparation (moisture content) using the PXRF equipped with vacuum, which improves light element measurement.

We hypothesize that PXRF will be useful in the determination of forage elemental composition because our unit has vacuum capability, and PXRF has been used successfully to detect and 
quantify light elemental composition in different plant, soil, geological and archeological samples.

The overall goal of this study is to evaluate the suitability of PXRF to facilitate the development of CNMPs, specifically, the determination of $P$ in manure. Because other elements are obtained simultaneously, results for $\mathrm{K}, \mathrm{Ca}, \mathrm{Mg}, \mathrm{Fe}, \mathrm{Cu}$, and $\mathrm{Zn}$ are also reported. To initiate this process we assumed that water content would be the limiting factor for manure analyses. Thus, the specific objective was to quantify the effect of manure moisture content on elemental concentrations.

\section{Material and Methods}

\section{Sample collection and preparation}

Thirty five manure samples were collected from cattle farms of West Virginia representing various beef and dairy cattle manure. These include decomposed feces, decomposed mixtures of bedding, feces, and urine, and decomposed feces from pasture. In addition, five poultry manure samples were also taken representing broiler, layer, and turkey. Thus, total number of samples collected were 40 .

Samples were refrigerated as received and spread on a filter paper over aluminum foil and oven dried at $50^{\circ} \mathrm{C}$ for 72 hours. Samples were made stone free using mortar and pestle followed by milling in cyclone mill (FOSS Tecator 1093, FOSS North America, Eden Prairie, MN). The whole sample was allowed to pass through a $0.5 \mathrm{~mm}$ screen. Ground samples were subsampled using alternate scooping method into three parts: for PXRF scanning, the wet chemical analysis in WVU lab and wet chemical analysis in West Virginia Department of Agriculture (WVDA), Moorefield, WV.

\section{Wet Chemical Analysis}

Wet chemical elemental concentration were determined by microwave (MARS Xpress, CEM Inc., Matthews, NC)-digesting samples in triplicate followed by Elemental quantification through Inductively Coupled Plasma Optical Emission Spectrometry (ICP-OES) (Optima DV 2100, Perkin Elmer, Norwalk, CT). A Certified Reference Material (CRM), 1573a-tomato leaf, was digested with samples to check the accuracy of digestion. Exactly $10 \mathrm{~mL} 70 \%$ nitric acid was added to $0.5 \mathrm{~g}$ sample in digestion vessels and placed in a fume hood for 1 hour to eliminate the gases produced. 
Then the tubes were placed in a microwave, heated for 15 minutes at $200{ }^{\circ} \mathrm{C}$ followed by holding at $200{ }^{\circ} \mathrm{C}$ for 15 minutes and allowed to cool overnight. The digested liquid was transferred into test tubes, diluted and final volume was made $50 \mathrm{~mL}$ using volumetric flasks. The diluted liquid was filtered before analysis by ICP-OES. Additionally, a part of samples was sent to WVDA for elemental analysis.

\section{PXRF Scanning}

Samples were scanned using portable XRF (Tracer III-SD; Bruker Elemental, Kennewick, WA) equipped with a rhodium tube from which X-rays are emitted, and a Peltier-cooled, silicon PIN diode detector, with a voltage of $15 \mathrm{KeV}$ and anode current of $26 \mathrm{uA}$ without a filter. It was operated on PC trigger mode and vacuum (<10 torr) was used for all scans. Samples were placed in double open-ended sample cups (series: 1500, Chemplex Industries Inc., USA) over a thin Xray film (4 um prolene). The cups containing ground samples were placed in the nose of the PXRF and covered with the X-ray shielding lid.

\section{Simulating higher moisture levels}

Manure samples were adjusted to 4 different moisture level using a gravimetric technique. Ground samples were weighted in sample cups and known mass of water was added. They were allowed to equilibrate for 15 hours and moisture content was determined to be $60-70 \%$. Each sample was scanned twice with PXRF for 180s. They were air-dried and to reduce the moisture content to $40-50 \%, 20-30 \%$, and $10-20 \%$ with subsequent PXRF readings taken at each moisture level. Moisture content was determined gravimetrically.

\section{Data Collection and Statistical Analysis}

Spectrum for each analysis was collected using S1PXRF software (Bruker Elemental, WA, USA). The intensity of $\mathrm{P}, \mathrm{K}, \mathrm{Ca}, \mathrm{Mg}, \mathrm{Fe}, \mathrm{Cu}$ and $\mathrm{Zn}$ in count per second (cps) and elemental concentration of $\mathrm{P}, \mathrm{K}, \mathrm{Ca}$ and $\mathrm{Mg}$ in weight percent were obtained from the same software. A standard-based calibration (obtained from personal communication with Dr. Lee Drake, Senior Application Scientist, Bruker AXS, Albuquerque, NM) for plant samples was used to obtain elemental concentration.

Data were organized in Microsoft Excel and analyzed by JMP (JMP ${ }^{\circledR}$, Version Pro 12.2, SAS Institute Inc., Cary, NC, Copyright (C2015), SAS (SAS ${ }^{\circledR}$, Version 9.4, SAS Institute Inc., Cary, NC, 
Copyright (C2002-2012), and R (R Foundation for Statistical Computing, Vienna, Austria). Regression analysis, two sample t-test, and repeated measures ANOVA was used for data analysis. Samples at different moisture level were considered as repeated. The intensity and elemental concentrations obtained from PXRF scanning were compared with the ICP-OES measured values to determine the effect of moisture content on elemental quantification. Likewise, wet chemical analysis results from WVDA and WVU lab were also compared. Significance criterion (alpha) for all tests was 0.05 .

\section{Result and Discussion}

\section{Reference standard}

All of the elements measured by ICP-OES had average Relative Standard Deviation (RSD) below $10 \%$. The RSD for CRM was below $10 \%$ for all elements determined, except for Cu and Zn (Table 2.1). The RSD below $10 \%$ is acceptable for plant elemental analysis (Bueno Guerra et al., 2014).

\section{Sample description}

The summary statistics of the elemental concentration of $\mathrm{P}, \mathrm{K}, \mathrm{Ca}, \mathrm{Mg}, \mathrm{Fe}, \mathrm{Cu}$, and $\mathrm{Zn}$ determined by ICP-OES are presented in Table 2.2 and summary statistics of West Virginia Department of Agriculture (WVDA)-determined concentration of $\mathrm{P}, \mathrm{K}, \mathrm{Ca}, \mathrm{Mg}$ and $\mathrm{Cu}$ are presented in Table 2.3. ICP-determined concentration had RSD ranging from 25\% for $\mathrm{Mg}$ to $120 \%$ for $\mathrm{Cu}$. All the elements under consideration were in RSD of nearly 50\% except $\mathrm{Mg}$ and $\mathrm{Cu}$. WVDA determined elemental concentration had RSD from $26 \%$ for $\mathrm{Mg}$ to $130 \%$ for $\mathrm{Cu}$. Both ICP and DOA determined concentration had comparable RSDs. Moreover, a dataset of $\mathrm{K}, \mathrm{Mg}$, and Fe was symmetrical while moderately to highly right-skewed for $\mathrm{P}, \mathrm{Ca}, \mathrm{Cu}$, and $\mathrm{Zn}$ (Tables 2.2, 2.3).

\section{Comparability between ICP-OES and WVDA measured concentrations}

There was no difference (Welch two-sample t-test) between ICP and WVDA measured elemental concentration (Table 2.4).

Regression between ICP and WVDA measured concentration were significant for all of the elements compared ( $P, K, C a, M g$ and $\mathrm{Cu}$ ) with $r^{2}$ values from 0.92 to 0.99 and $p<0.001$. The slopes of the regression lines were between 0.91 and 1.01 (Fig: 2.1). 
The CNMP uses manure test results from WVDA laboratory. There was close agreement between ICP and WVDA measured elemental concentration of $\mathrm{P}, \mathrm{K}, \mathrm{Ca}, \mathrm{Mg}$, $\mathrm{Fe}$, and $\mathrm{Cu}$. Thus, ICP values can be used as reference standard for evaluating PXRF to support CNMP.

\section{PXRF analysis of manure samples PXRF intensity}

Manure samples had average intensity ranging from $4800 \mathrm{cps}$ for $\mathrm{Mg}$ to 432,900 cps for Ca. The intensities had RSD ranging from $9 \%$ for $\mathrm{Cu}$ to $62 \%$ for $\mathrm{Cu}$. All of the datasets were right-skewed. $\mathrm{K}$ and $\mathrm{Mg}$ were symmetrical while $\mathrm{P}, \mathrm{Ca}, \mathrm{Mg}, \mathrm{Fe}, \mathrm{Cu}$, and $\mathrm{Zn}$ were moderate to highly skewed (Table 2.5).

Regression models between ICP-determined concentration and PXRF counts were significant $(\mathrm{p}<0.001)$ for elements under consideration- $\mathrm{P}, \mathrm{K} \mathrm{Ca}, \mathrm{Mg}, \mathrm{Fe}, \mathrm{Cu}$ and $\mathrm{Zn}$ (Fig 2.2). The relationships were stronger $\left(r^{2}>0.90\right)$ for all elements except $\mathrm{Mg}\left(r^{2}=0.59\right)$ and $\mathrm{Zn}\left(r^{2}=0.56\right)$.

\section{PXRF determined concentrations}

Manure samples (measured with PXRF) had average elemental concentrations ranging from $1,900 \mathrm{mg} / \mathrm{kg}$ for $\mathrm{P}$ to $20,900 \mathrm{mg} / \mathrm{kg}$ for $\mathrm{Ca}$ (Table 2.6). The RSDs were from $38 \%$ for $\mathrm{K}$ to $71 \%$ for Mg. Compared to the ICP determined concentration RSDs were lower for P and K, higher for $\mathrm{Ca}$, $\mathrm{Mg}$ and comparable for Fe (Table 2.2 and 2.5). All of the datasets were moderate to highly rightskewed except K (almost symmetrical).

Regression models between ICP and PXRF measured concentrations were significant $(p<0.001)$ for elements - P, K, Ca, Mg, and Fe (Fig 2.3). The relationships were stronger $\left(r^{2}>0.66\right)$ for all elements except $\mathrm{Mg}\left(\mathrm{r}^{2}=0.25\right)$. Compared to the regression with intensities, PXRF determined concentration produced lower $r^{2}$ values for $P\left(r^{2}\right.$ decreased from 0.93 to 0.66$)$ and $M g\left(r^{2}\right.$ decreased from 0.59 to 0.25$)$. Moreover, $r^{2}$ values for $K$ and Fe were slightly lower while comparable for Ca (Fig 2.2 and 2.3).

The concentration of $\mathrm{P}, \mathrm{K}, \mathrm{Ca}, \mathrm{Fe}$, and $\mathrm{Cu}$ can reliably be measured in dry and ground manure samples with PXRF. Likewise, compromising some accuracy, Mg and $\mathrm{Zn}$ can also be measured with PXRF. McWhirt et al. (2012) also found that P, K, Ca, Fe, $\mathrm{Cu}$, and $\mathrm{Zn}$ could be measured in 
compost samples using portable XRF. The reduced accuracy in Mg measurement might be due to the absorbance of the characteristics X-ray before reaching the detector. Likewise, reduced accuracy in Zn measurement may be due to the use of same factory setting (current, voltage, and filter) used for light elements. Bruker Elemental has recommended using different factory settings for elements above Fe in periodic table. Reduced strength of the relationship with PXRF concentration suggests that a calibration for plant samples is not appropriate for manure samples or the need for a calibration update.

\section{Effect of moisture in manure samples PXRF intensities}

Average intensity (cps) of $\mathrm{P}, \mathrm{K}, \mathrm{Ca}, \mathrm{Mg}$, and Fe decreased with increasing moisture content of sample but a slight increasing trend was observed for $\mathrm{Cu}$ and $\mathrm{Zn}$ beyond moisture range of 1020\% (Table 2.8 and Fig 2.4). Relative standard deviations were comparable for the intensities measured with oven dried (<10\%) and 10-20\% moisture ranges except $\mathrm{Ca}$ and $\mathrm{Cu}$ (slightly increased with moisture). Beyond 10-20\% moisture range RSDs for $\mathrm{P}, \mathrm{Cu}$, and $\mathrm{Zn}$ were decreasing, $\mathrm{Ca}$ and Fe was almost constant, Mg was almost constant except elevated at $30-40 \%$ moisture range, and $\mathrm{K}$ was almost constant except being elevated at $60-70 \%$ moisture range (Table 2.8 and Fig 2.5).

Regression models between ICP determined concentration and PXRF counts were significant $(\mathrm{p}<0.001)$ for elements under consideration- $\mathrm{P}, \mathrm{K} \mathrm{Ca}, \mathrm{Mg}, \mathrm{Fe}, \mathrm{Cu}$ and $\mathrm{Zn}$ (Table 2.9). Moisture content did not affect the strength of relationship for $\mathrm{Cu}\left(r^{2}=0.91\right)$ however strength slightly decreased at $60-70 \%$ moisture range for $\mathrm{Ca}$ and Fe. The strength of relationship decreased with increasing moisture content for $\mathrm{P}, \mathrm{K}$, and $\mathrm{Mg}$ except being increased at 40-50\% moisture range. Likewise, the strength decreased for $\mathrm{Zn}$ up to $20-30 \%$ moisture range and increased thereafter (Table 2.9 and Fig 2.6).

\section{PXRF measured concentrations}

The average concentration of $\mathrm{P}, \mathrm{K}, \mathrm{Ca}, \mathrm{Mg}$, and Fe decreased with increasing moisture content of the sample (Table 2.10, Fig 2.7). Relative standard deviations were comparable for $\mathrm{P}, \mathrm{Ca}$ and $\mathrm{Fe}$ over the moisture range (Fig: 2.8 ) however increasing after $10-20 \%$ moisture range for $\mathrm{K} . \mathrm{Mg}$ RSD 
increased at the beginning and decreased beyond 20-30\% moisture range (Table 2.10 and Fig 2.8). Datasets were right skewed except potassium.

Repeated measures ANOVA results demonstrated that there was evidence of significant relationship and moisture effects on the $\mathrm{P}, \mathrm{K}, \mathrm{Ca}$ and Fe concentration in manure (Table 2.11).

Mean $\mathrm{P}$ and $\mathrm{K}$ concentration measured at $0-10 \%$ and $10-20 \%$ was not significant. Likewise, mean $P$ concentration at $20-30 \%$ and $40-50 \%$ moisture level and $K$ concentration at $40-50 \%$ and $60-70 \%$ moisture levels were not significant (Table 2.12). However, mean Ca and Fe concentrations at each preceding moisture level was not significant (Table 2.12).

Regression models between ICP and PXRF measured concentration in manure sample with 10$20 \%$ moisture were significant $(p<0.001)$ for all elements. Beyond $20 \%$ models were significant for all elements except $\mathrm{Mg}$ (Table 2.12). In the case of $\mathrm{P}$, the strength of the relationship continued decreasing $\left(r^{2}=0.94\right.$ to 0.53$)$ except at the moisture range of $40-50 \%\left(r^{2}=0.80\right)$ with increasing moisture content. Similar trends were observed for $\mathrm{K}, \mathrm{Ca}$ and $\mathrm{Fe}$, however, the strength of relationship remained almost constant for $\mathrm{Mg}$ beyond 20-30\% moisture range. (Table 2.13, Fig 2.9)

Moisture significantly affected the elemental determination in manure samples (Fig 2.10 and 2.11). The effect was more pronounced for $\mathrm{P}, \mathrm{K}, \mathrm{Mg}$ and less for $\mathrm{Ca}, \mathrm{Fe}, \mathrm{Cu}$, and $\mathrm{Zn}$ because light elements have lower energy level. The characteristics X-rays produced will be be absorbed by the moisture, thus reducing the PXRF intensity (Ge et al., 2005; Stockmann et al., 2006). However, elemental concentration in manure samples can be measured, without losing accuracy, up to $20 \%$ moisture. Beyond which moisture correction is advisable especially for elements like $\mathrm{P}$ and K.

Though this method has potential to determine elemental concentration directly in field, moisture is a major challenge. If drying and grinding is not possible, samples can be mixed thoroughly in field to meet the condition of homogeneity and air dried to reduce moisture content. Alternatively, a moisture correction model could be developed. 


\section{Conclusion}

Since the PXRF results were in close agreement with ICP-OES and WVDA results, it can be used to determine $\mathrm{P}, \mathrm{K}, \mathrm{Ca}, \mathrm{Mg}, \mathrm{Fe}, \mathrm{Cu}$ and $\mathrm{Zn}$ concentrations in manure samples. It removes several disadvantages of traditional wet chemical analysis techniques. The result can be obtained quickly at a reduced cost. Though moisture content of the sample affected the result, it can be used for the samples up to $20 \%$ moisture level without losing accuracy. Above $20 \%$, moisture correction is advisable especially for the elements like $\mathrm{P}$ and $\mathrm{K}$.

This method could be a very useful technique for the purpose of CNMP development. The results obtained in benchtop mode were comparable to ICP-OES values. If this method is used directly in the field for the unprocessed sample the results may be better than 'Book Values'. However, at this stage drying and grinding of the sample is recommended. Additional work is recommended to extend this to infield analysis. 


\section{Literature Cited}

Analytical Methods Committee (AMC), Royal Society of Chemistry. 2008. Evaluation of analytical instrumentation. Part xxiii. Instrumentation for portable x-ray fluorescence spectrometry. Accred. Qual. Assur. 13:453-464

Brackenrich, J., L.M. McDonald, T. Basden and K. Shaffer. 2016. Optimizing feeding strategies to minimize phosphorus losses from roofed winter feeding areas. American Society of Agronomy/Crop Science Society of America/Soil Science Society of America Annual Meeting, Phoenix, AZ. Nov. 6-9, 2016.

Brouwer, P. 2013. Theory of XRF. PANanalytial B.V., Almelo, The Netherlands.

Bueno Guerra, M.B., E. de Almeida, G.G.A. Carvalho, P.F. Souza, L.C. Nunes, D.S. Júnior, and F.J. Krug. 2014. Comparison of analytical performance of benchtop and handheld energy dispersive $X$-ray fluorescence systems for the direct analysis of plant materials. J. Anal. At. Spectrom. 29(9): 1667.

Evanylo, G.K. and D. Beegle.2006. Introduction to nutrient management. In K. C. Haering and G. K. Evanylo. Mid-Atlantic nutrient management handbook. Mid-Atlantic Regional Water Program, USA.

Ge, L., W. Lai, and Y. Lin. 2005. Influence of and correction for moisture in rocks, soils and sediments on in situ XRF analysis. X-Ray Spectrom 34(28): 28-34.

Isleib, J. 2016. Manure provides plant nutrients, but not always at book value. Michigan State University Extension.

Kalnicky, D.J., and R. Singhvi. 2001. Field portable XRF analysis of environmental samples. J. Hazard. Mater. 83(1-2): 93-122.

Karla, Y. P. 1998. Handbook of reference methods for plant analysis. CRC Press Taylor \& Francis Group.

Maarschalkerweerd, M., and S. Husted. 2015. Recent developments in fast spectroscopy for plant mineral analysis. Front. Plant Sci. 6(March): 1-14.

Maguire, R.O. 2014. Importance of farm phosphorus mass balance and management options. Virginia Cooperative Extension. Publication No. CSES-98P.

Martin, J. 2009. Manure sampling for nutrient management planning. Agronomy Facts 69. Penn State Extension.

McWhirt, A., D.C. Weindorf, and Y. Zhu. 2012. Rapid analysis of elemental concentrations in compost via portable X-ray fluorescence spectrometry. Compost Sci. Util. 20(3): 185193.

NRCS-WV. 2010. Conservation practice standard, Nutrient Management (Ac.) 590. Natural Resources Conservation Service. West Virginia. 
Peters, J. and S. Combss. 2003. Sampling livestock waste for analysis. In: J. Peters, S.M. Combss, B. Hoskins, J. Jarman, J.L. Kovar, M. E. Watson, A.M. Wolf and N. Wolf. Recommended methods of Manure Analysis, Cooperative Extension Publishing, University of WisconsinExtension.

Potts, P. J., and M. West. 2008. Portable X-ray fluorescence spectrometry: capabilities for in situ analysis. The Royal Society of Chemistry, UK.

Reidinger, S., M.H. Ramsey, and S.E. Hartley. 2012. Rapid and accurate analyses of silicon and phosphorus in plants using a portable X-ray fluorescence spectrometer. New Phytol. 195(3): 699-706.

Stockmann, U., H.J. Jang, B. Minasny, and A. B. McBratney. 2006. The effect of soil moisture and texture on Fe concentration using portable X-ray fluorescence spectrometers. In: A.E. Hartemink and B. Minasny (eds.), Digital Soil Morphometric, Progress in soil science, Springer International Publishing Switzerland.

USDA-NRCS. 2003. National planning procedures handbook. United States Department of Agriculture, Natural Resource Conservation Service.

USDA-NRCS. 2010. Statement of work: comprehensive nutrient management plan (code 102), Pensylvania

Weindorf, D.C., N. Bakr, and Y. Zhu. 2014. Advances in portable X-ray fluorescence (PXRF) for environmental, pedological, and agronomic applications. Adv. Agron. 128:1-45.

Weindorf, D.C., R. Sarkar, M. Dia, H. Wang, Q. Chang, B. Haggard, A. McWhirt, and A. Wooten. 2008. Correlation of X-ray fluorescence (XRF) spectrometry and inductively coupled plasma atomic emission spectroscopy (ICP-AES) for elemental determination in composted products. Compost Sci. Util. 16 (2): 79-82.

Willis, J. P., and A. R. Duncan. 2008. Understanding XRF spectrometry, Vol I. PANanalytial B.V., Almelo, The Netherlands. 
Tables

Table 2.1: Average Relative Standard Deviation (RSD) for three replications of manure sample digestion and RSD for SRM digested with manure samples $(n=40)$.

\begin{tabular}{lccc}
\hline Elements & $\begin{array}{c}\text { Average RSD for } \\
\text { manure samples (\%) }\end{array}$ & $\begin{array}{c}\text { RSD for } \\
\text { SRM (\%) }\end{array}$ & $\begin{array}{c}\text { Difference between standard and } \\
\text { ICP concentration for SRM (\%) }\end{array}$ \\
\hline $\mathrm{P}$ & 8.7 & 5.53 & 4.09 \\
$\mathrm{~K}$ & 8.35 & 3.93 & 4.80 \\
$\mathrm{Ca}$ & 7.78 & 4.25 & 2.42 \\
$\mathrm{Mg}$ & 8.13 & 5.10 & 14.13 \\
$\mathrm{Fe}$ & 7.77 & 8.25 & 13.64 \\
$\mathrm{Cu}$ & 9.54 & 23.21 & 42.34 \\
$\mathrm{Zn}$ & 8.45 & 14.82 & 97.89 \\
\hline
\end{tabular}

Table 2.2: Summary Statistics for ICP determined elemental concentrations $(\mathrm{mg} / \mathrm{kg})$ in manure samples $(n=40)$.

\begin{tabular}{lccccccc}
\hline \multirow{2}{*}{ Statistic } & \multicolumn{7}{c}{ Elemental Concentrations (mg/kg) } \\
& $\mathrm{P}$ & $\mathrm{K}$ & $\mathrm{Ca}$ & $\mathrm{Mg}$ & $\mathrm{Fe}$ & $\mathrm{Cu}$ & $\mathrm{Zn}$ \\
& & & & & & & \\
\hline Mean & 6800 & 20200 & 26700 & 5500 & 4300 & 500 & 200 \\
Minimum & 2200 & 2700 & 10500 & 2100 & 600 & 0 & 100 \\
Maximum & 21900 & 38000 & 84100 & 8100 & 10000 & 2600 & 600 \\
SD & 3600 & 9500 & 14200 & 1400 & 2800 & 600 & 100 \\
RSD (\%) & 52.94 & 47.03 & 53.18 & 25.45 & 65.12 & 120 & 50 \\
Skewness & 2.11 & 0.22 & 1.92 & 0.17 & 0.60 & 1.69 & 1.03 \\
Kurtosis & 6.72 & -0.85 & 5.66 & -0.16 & -0.63 & 2.37 & 1.26 \\
\hline
\end{tabular}


Table 2.3: Summary Statistics for WVDA determined elemental concentrations $(\mathrm{mg} / \mathrm{kg})$ in manure samples $(n=40)$.

\begin{tabular}{lccccc}
\hline \multirow{2}{*}{ Statistic } & \multicolumn{5}{c}{ Elemental Concentrations (mg/kg) } \\
& $\mathrm{P}$ & $\mathrm{K}$ & $\mathrm{Ca}$ & $\mathrm{Mg}$ & $\mathrm{Cu}$ \\
& & & & & \\
\hline Mean & 6600 & 19700 & 24600 & 5300 & 600 \\
Minimum & 2100 & 2500 & 10300 & 2000 & 10 \\
Maximum & 21600 & 35300 & 84800 & 8700 & 2400 \\
Standard Dev & 3500 & 9000 & 14200 & 1400 & 650 \\
RSD (\%) & 53.03 & 45.69 & 57.72 & 26.42 & 130 \\
Skewness & 2.19 & 0.11 & 2.26 & 0.31 & 1.60 \\
Kurtosis & 7.40 & -0.94 & 7.31 & 0.45 & 1.67 \\
\hline
\end{tabular}

Table 2.4: Mean comparison between ICP and WVDA measured concentrations $(\mathrm{mg} / \mathrm{kg})$ in manure samples $(n=40)$.

\begin{tabular}{cccc}
\hline Element & t-value & $\begin{array}{c}\text { Degree of } \\
\text { freedom }\end{array}$ & p-value \\
\hline $\mathrm{P}$ & 0.275 & 78 & 0.784 \\
$\mathrm{~K}$ & 0.238 & 78 & 0.813 \\
$\mathrm{Ca}$ & 0.676 & 78 & 0.501 \\
$\mathrm{Mg}$ & 0.568 & 78 & 0.572 \\
$\mathrm{Cu}$ & 0.067 & 78 & 0.946 \\
\hline
\end{tabular}

Table 2.5: Summary statistics for PXRF intensities (cps) of oven dried manure samples scanned at 180 seconds $(n=40)$.

\begin{tabular}{lccccccc}
\hline \multirow{2}{*}{ Statistic } & \multicolumn{7}{c}{ PXRF intensities (cps) } \\
& $\mathrm{P}$ & $\mathrm{K}$ & $\mathrm{Ca}$ & $\mathrm{Mg}$ & $\mathrm{Fe}$ & $\mathrm{Cu}$ & $\mathrm{Zn}$ \\
\hline Mean & 33000 & 256900 & 432900 & 4800 & 408600 & 85600 & 59800 \\
Minimum & 16300 & 61600 & 183900 & 3800 & 110700 & 43300 & 44200 \\
Maximum & 78700 & 453500 & 1236200 & 5800 & 906600 & 288100 & 84000 \\
Standard Dev & 12600 & 93800 & 195800 & 440 & 213300 & 53400 & 11300 \\
RSD (\%) & 38.18 & 36.51 & 45.23 & 9.17 & 52.20 & 62.38 & 18.90 \\
Skewness & 1.63 & 0.17 & 1.66 & 0.28 & 0.55 & 1.99 & 0.56 \\
Kurtosis & 3.35 & -0.52 & 5.88 & -0.27 & -0.37 & 4.75 & -0.43 \\
\hline
\end{tabular}


Table 2.6: Summary statistics of PXRF determined concentrations $(\mathrm{mg} / \mathrm{kg})$ in oven-dried manure samples $(n=40)$.

\begin{tabular}{lccccc}
\hline \multirow{2}{*}{ Statistic } & \multicolumn{5}{c}{ PXRF determined elemental concentration $(\mathrm{mg} / \mathrm{kg})$} \\
& $\mathrm{P}$ & $\mathrm{K}$ & $\mathrm{Ca}$ & $\mathrm{Mg}$ & $\mathrm{Fe}$ \\
\hline Mean & 5600 & 14500 & 20900 & 3400 & 1900 \\
Minimum & 2700 & 2000 & 5400 & 1000 & 100 \\
Maximum & 10600 & 26200 & 74400 & 12100 & 4800 \\
Standard Dev & 2100 & 5000 & 12800 & 2400 & 1300 \\
RSD (\%) & 37.50 & 34.48 & 61.24 & 70.59 & 68.42 \\
Skewness & 0.69 & -0.12 & 1.91 & 2.32 & 0.63 \\
Kurtosis & -0.47 & 0.40 & 6.64 & 6.25 & -0.27 \\
\hline
\end{tabular}

Table 2.7: Welch two-sample t-test results between ICP and PXRF measured concentration (mg/kg) ( $\mathrm{n}=40)$.

\begin{tabular}{cccc}
\hline Element & $\begin{array}{c}\text { Degrees of } \\
\text { freedom }(\mathrm{df})\end{array}$ & t value & $\mathrm{p}$-value \\
\hline $\mathrm{P}$ & 78 & -1.83 & 0.072 \\
$\mathrm{~K}$ & 78 & 3.34 & 0.002 \\
$\mathrm{Ca}$ & 78 & 1.94 & 0.055 \\
$\mathrm{Mg}$ & 78 & 4.59 & $<0.001$ \\
$\mathrm{Fe}$ & 78 & 4.95 & $<0.001$ \\
\hline
\end{tabular}


Table 2.8: Summary statistics for PXRF intensities (cps) of manure samples adjusted to four moisture ranges $(10-20 \%, 20-30 \%, 40-50 \%$, and $60-70 \%)(n=40)$.

\begin{tabular}{|c|c|c|c|c|c|c|c|c|}
\hline \multirow{2}{*}{$\begin{array}{c}\text { Moisture } \\
\text { range }\end{array}$} & \multirow{2}{*}{ Statistic } & \multicolumn{7}{|c|}{ PXRF intensities (cps) } \\
\hline & & $\mathrm{P}$ & K & $\mathrm{Ca}$ & $\mathrm{Mg}$ & $\mathrm{Fe}$ & $\mathrm{Cu}$ & $\mathrm{Zn}$ \\
\hline \multirow[t]{7}{*}{$10-20 \%$} & Mean & 28700 & 225300 & 388700 & 4400 & 389500 & 83000 & 57800 \\
\hline & Minimum & 16500 & 56300 & 152800 & 3700 & 114500 & 38300 & 39700 \\
\hline & Maximum & 67800 & 382400 & 1229800 & 5400 & 841600 & 283500 & 80600 \\
\hline & Standard Dev & 11000 & 78500 & 196800 & 400 & 195900 & 54800 & 11400 \\
\hline & $\mathrm{RSD}$ & 38.29 & 34.83 & 50.63 & 9.50 & 50.28 & 66.09 & 19.76 \\
\hline & Skewness & 1.74 & -0.07 & 2.01 & 0.70 & 0.69 & 2.03 & 0.30 \\
\hline & Kurtosis & 3.36 & -0.61 & 7.35 & -0.24 & -0.07 & 4.43 & -0.62 \\
\hline \multirow[t]{7}{*}{$20-30 \%$} & Mean & 22300 & 171800 & 315000 & 3900 & 347800 & 83600 & 62000 \\
\hline & Minimum & 7900 & 50600 & 131400 & 1000 & 88800 & 45400 & 46600 \\
\hline & Maximum & 38800 & 337100 & 967100 & 5400 & 762600 & 254000 & 83900 \\
\hline & Standard Dev & 8000 & 62400 & 162000 & 700 & 180000 & 47100 & 9600 \\
\hline & RSD & 35.99 & 36.31 & 51.43 & 18.55 & 51.77 & 56.29 & 15.42 \\
\hline & Skewness & 0.40 & 0.33 & 1.93 & -1.68 & 0.67 & 2.04 & 0.26 \\
\hline & Kurtosis & -0.41 & 0.22 & 5.86 & 5.77 & -0.09 & 4.34 & -0.68 \\
\hline \multirow[t]{7}{*}{$40-50 \%$} & Mean & 20200 & 138300 & 275400 & 3800 & 317700 & 85200 & 65200 \\
\hline & Minimum & 7000 & 41700 & 123400 & 2600 & 97900 & 45100 & 46600 \\
\hline & Maximum & 42100 & 221200 & 901400 & 5000 & 705000 & 241200 & 85400 \\
\hline & Standard Dev & 6700 & 47500 & 147200 & 400 & 164200 & 43100 & 9900 \\
\hline & RSD & 32.99 & 34.35 & 53.43 & 10.26 & 51.70 & 50.63 & 15.13 \\
\hline & Skewness & 1.12 & -0.19 & 2.24 & 0.02 & 0.73 & 1.98 & 0.06 \\
\hline & Kurtosis & 1.78 & -0.75 & 7.63 & 3.15 & -0.04 & 4.23 & -0.67 \\
\hline \multirow[t]{7}{*}{$60-70 \%$} & Mean & 17000 & 126500 & 218500 & 3700 & 271600 & 85400 & 68600 \\
\hline & Minimum & 10200 & 33200 & 91200 & 3200 & 94300 & 49000 & 53200 \\
\hline & Maximum & 31700 & 301300 & 661000 & 5200 & 693500 & 209600 & 86500 \\
\hline & Standard Dev & 4800 & 55800 & 113300 & 300 & 137200 & 35700 & 9200 \\
\hline & RSD & 28.03 & 44.07 & 51.86 & 9.35 & 50.51 & 41.88 & 13.34 \\
\hline & Skewness & 1.23 & 0.80 & 2.50 & 2.39 & 1.10 & 1.77 & 0.16 \\
\hline & Kurtosis & 1.36 & 1.13 & 7.74 & 8.71 & 1.34 & 3.23 & -0.70 \\
\hline
\end{tabular}


Table 2.9: Regression between PXRF intensities (cps) of manure samples adjusted to four moisture ranges and ICP determined concentrations $(\mathrm{mg} / \mathrm{kg})(\mathrm{n}=40)$.

\begin{tabular}{|c|c|c|c|c|c|c|}
\hline Experiment & Element & $r^{2}$ & RMSE & Intercept & Slope & $p$-value \\
\hline \multirow{7}{*}{$\begin{array}{l}\text { ICP Vs } 10-20 \% \\
\text { moisture range }\end{array}$} & $P$ & 0.84 & 1472 & -1801 & 0.30 & $<0.001$ \\
\hline & $\mathrm{K}$ & 0.85 & 3689 & -5036 & 0.11 & $<0.001$ \\
\hline & $\mathrm{Ca}$ & 0.93 & 3725 & -391 & 0.07 & $<0.001$ \\
\hline & $\mathrm{Mg}$ & 0.45 & 1049 & -4484 & 2.24 & $<0.001$ \\
\hline & $\mathrm{Fe}$ & 0.94 & 719 & -1073 & 0.01 & $<0.001$ \\
\hline & $\mathrm{Cu}$ & 0.91 & 192 & -417 & 0.01 & $<0.001$ \\
\hline & $\mathrm{Zn}$ & 0.52 & 76 & -153 & 0.01 & $<0.001$ \\
\hline \multirow{7}{*}{$\begin{array}{l}\text { ICP Vs } 20-30 \% \\
\text { moisture range }\end{array}$} & $P$ & 0.59 & 2340 & -876 & 0.34 & $<0.001$ \\
\hline & K & 0.80 & 4317 & -3227 & 0.14 & $<0.001$ \\
\hline & $\mathrm{Ca}$ & 0.92 & 4002 & 183 & 8.42 & $<0.001$ \\
\hline & $\mathrm{Mg}$ & 0.20 & 1273 & 2111 & 0.87 & $<0.001$ \\
\hline & $\mathrm{Fe}$ & 0.94 & 687 & -935 & 0.02 & $<0.001$ \\
\hline & $\mathrm{Cu}$ & 0.91 & 197 & -575 & 0.01 & $<0.001$ \\
\hline & $\mathrm{Zn}$ & 0.27 & 94 & -124 & 0.01 & $<0.001$ \\
\hline \multirow{7}{*}{$\begin{array}{l}\text { ICP Vs } 40-50 \% \\
\text { moisture range }\end{array}$} & $P$ & 0.80 & 1635 & -2957 & 0.48 & $<0.001$ \\
\hline & K & 0.83 & 3969 & -5037 & 0.18 & $<0.001$ \\
\hline & $\mathrm{Ca}$ & 0.94 & 3291 & 832 & 0.09 & $<0.001$ \\
\hline & $\mathrm{Mg}$ & 0.40 & 1101 & -3167 & 2.27 & $<0.001$ \\
\hline & $\mathrm{Fe}$ & 0.94 & 651 & -958 & 0.02 & $<0.001$ \\
\hline & $\mathrm{Cu}$ & 0.91 & 187 & -701 & 0.01 & $<0.001$ \\
\hline & $\mathrm{Zn}$ & 0.36 & 88 & -189 & 6.59 & $<0.001$ \\
\hline \multirow{7}{*}{$\begin{array}{l}\text { ICP Vs } 60-70 \% \\
\text { moisture range }\end{array}$} & $P$ & 0.53 & 2499 & -2567 & 0.55 & $<0.001$ \\
\hline & $\mathrm{K}$ & 0.70 & 5263 & 2117 & 0.14 & $<0.001$ \\
\hline & $\mathrm{Ca}$ & 0.83 & 5909 & 1736 & 0.11 & $<0.001$ \\
\hline & $\mathrm{Mg}$ & 0.30 & 1190 & 2945 & 2.23 & $<0.001$ \\
\hline & $\mathrm{Fe}$ & 0.89 & 924 & -927 & 0.02 & $<0.001$ \\
\hline & $\mathrm{Cu}$ & 0.91 & 184 & -955 & 0.02 & $<0.001$ \\
\hline & $\mathrm{Zn}$ & 0.41 & 84 & -282 & 0.01 & $<0.001$ \\
\hline
\end{tabular}


Table 2.10: Summary statistics for PXRF determined concentrations $(\mathrm{mg} / \mathrm{kg}$ ) of manure samples adjusted to four moisture ranges $(10-20 \%, 20-30 \%, 40-50 \%$, and $60-70 \%)(n=40)$.

\begin{tabular}{|c|c|c|c|c|c|c|}
\hline \multirow{2}{*}{$\begin{array}{l}\text { Moisture } \\
\text { range }\end{array}$} & \multirow{2}{*}{ Statistic } & \multicolumn{5}{|c|}{ PXRF determined concentrations (mg/kg) } \\
\hline & & $\mathrm{P}$ & K & $\mathrm{Ca}$ & $\mathrm{Mg}$ & $\mathrm{Fe}$ \\
\hline \multirow[t]{7}{*}{$10-20 \%$} & Mean & 5000 & 13000 & 19500 & 2900 & 1800 \\
\hline & Minimum & 2400 & 1600 & 5200 & 1000 & 100 \\
\hline & Maximum & 9200 & 22000 & 74800 & 12000 & 4900 \\
\hline & Standard Dev & 1900 & 4500 & 12800 & 2400 & 1300 \\
\hline & RSD & 37.32 & 34.31 & 65.80 & 80.71 & 70.58 \\
\hline & Skewness & 0.71 & -0.47 & 2.18 & 2.63 & 0.80 \\
\hline & Kurtosis & -0.39 & 0.29 & 7.85 & 7.48 & 0.05 \\
\hline \multirow[t]{7}{*}{$20-30 \%$} & Mean & 4100 & 10200 & 17300 & 2800 & 1700 \\
\hline & Minimum & 2200 & 800 & 5300 & 900 & 100 \\
\hline & Maximum & 8300 & 19600 & 56500 & 12000 & 4600 \\
\hline & Standard Dev & 1500 & 4400 & 10300 & 2200 & 1200 \\
\hline & RSD & 35.70 & 42.76 & 59.79 & 80.18 & 68.67 \\
\hline & Skewness & 0.97 & -0.02 & 1.73 & 2.74 & 0.64 \\
\hline & Kurtosis & 0.56 & -0.22 & 4.37 & 8.11 & -0.20 \\
\hline \multirow[t]{7}{*}{$40-50 \%$} & Mean & 3700 & 7200 & 15200 & 2200 & 1500 \\
\hline & Minimum & 2100 & 0 & 5400 & 1100 & 200 \\
\hline & Maximum & 6900 & 12400 & 51800 & 8700 & 4300 \\
\hline & Standard Dev & 1300 & 3300 & 8700 & 1400 & 1000 \\
\hline & RSD & 35.04 & 45.11 & 57.62 & 62.27 & 67.49 \\
\hline & Skewness & 1.00 & -0.29 & 2.23 & 3.52 & 0.98 \\
\hline & Kurtosis & 0.15 & -0.71 & 7.42 & 14.42 & 0.80 \\
\hline \multirow[t]{7}{*}{$60-70 \%$} & Mean & 3000 & 5900 & 11900 & 1900 & 1200 \\
\hline & Minimum & 1400 & -800 & 4500 & 1100 & 200 \\
\hline & Maximum & 6900 & 15500 & 36500 & 8400 & 4100 \\
\hline & Standard Dev & 1000 & 3700 & 6600 & 1100 & 800 \\
\hline & RSD & 34.01 & 63.88 & 55.49 & 55.79 & 70.54 \\
\hline & Skewness & 1.68 & 0.38 & 2.41 & 5.72 & 1.50 \\
\hline & Kurtosis & 4.73 & -0.18 & 7.24 & 34.86 & 3.09 \\
\hline
\end{tabular}


Table 2.11: Repeated measures ANOVA results for the effect of moisture on elemental concentration $(\mathrm{mg} / \mathrm{kg})$ measured by PXRF $(\mathrm{n}=40)$.

\begin{tabular}{ccccc}
\hline Element & Effect & $\begin{array}{c}\text { Degrees of } \\
\text { freedom (df) }\end{array}$ & F value & p-value \\
\hline $\mathrm{P}$ & Moisture & 4 & 59.71 & $<0.001$ \\
$\mathrm{~K}$ & Moisture & 4 & 61.18 & $<0.001$ \\
$\mathrm{Ca}$ & Moisture & 4 & 10.80 & $<0.001$ \\
$\mathrm{Fe}$ & Moisture & 4 & 31.26 & $<0.001$ \\
\hline
\end{tabular}

Table 2.12: Welch two-sample t-test results for the effect of moisture on elemental concentration $(\mathrm{mg} / \mathrm{kg}$ ) measured by PXRF $(\mathrm{n}=40)$.

\begin{tabular}{|c|c|c|c|c|}
\hline \multirow{2}{*}{ Element } & \multirow{2}{*}{$\begin{array}{l}\text { PXRF measured } \\
\text { concentration }\end{array}$} & \multicolumn{3}{|c|}{ Two sample t-test } \\
\hline & & t value & $\mathrm{df}$ & $p$-value \\
\hline \multirow[t]{4}{*}{$P$} & $<10 \%$ and $10-20 \%$ & 1.44 & 78 & 0.15 \\
\hline & $10-20 \%$ and $20-30 \%$ & 2.35 & 78 & 0.022 \\
\hline & $20-30 \%$ and $40-50 \%$ & 1.36 & 78 & 0.18 \\
\hline & $40-50 \%$ and $60-70 \%$ & 2.79 & 78 & 0.006 \\
\hline \multirow[t]{4}{*}{ K } & $<10 \%$ and $10-20 \%$ & 1.43 & 78 & 0.156 \\
\hline & $10-20 \%$ and $20-30 \%$ & 2.84 & 78 & 0.005 \\
\hline & $20-30 \%$ and $40-50 \%$ & 3.46 & 78 & $<0.001$ \\
\hline & $40-50 \%$ and $60-70 \%$ & 1.72 & 78 & 0.08 \\
\hline \multirow[t]{4}{*}{$\mathrm{Ca}$} & $<10 \%$ and $10-20 \%$ & 0.49 & 78 & 0.62 \\
\hline & $10-20 \%$ and $20-30 \%$ & 0.82 & 78 & 0.41 \\
\hline & $20-30 \%$ and $40-50 \%$ & 0.99 & 78 & 0.32 \\
\hline & $40-50 \%$ and $60-70 \%$ & 0.99 & 78 & 0.32 \\
\hline \multirow[t]{4}{*}{$\mathrm{Fe}$} & $<10 \%$ and $10-20 \%$ & 0.37 & 78 & 0.71 \\
\hline & $10-20 \%$ and $20-30 \%$ & 0.19 & 78 & 0.85 \\
\hline & $20-30 \%$ and $40-50 \%$ & 0.98 & 78 & 0.32 \\
\hline & $40-50 \%$ and $60-70 \%$ & 1.61 & 78 & 0.11 \\
\hline
\end{tabular}


Table 2.13: Regression between PXRF concentration of manure samples adjusted to four moisture ranges and ICP determined concentrations $(\mathrm{mg} / \mathrm{kg})$.

\begin{tabular}{ccccccc}
\hline Experiment & Element & $\mathrm{r}^{2}$ & $\mathrm{RMSE}$ & Intercept & Slope & p-value \\
\hline ICP Vs 10-20\% & $\mathrm{P}$ & 0.49 & 2607 & 48 & 1.36 & $<0.001$ \\
moisture & $\mathrm{K}$ & 0.78 & 4459 & -4385 & 1.89 & $<0.001$ \\
range & $\mathrm{Ca}$ & 0.90 & 4613 & 6263 & 1.05 & $<0.001$ \\
& $\mathrm{Mg}$ & 0.23 & 1246 & 4632 & 0.28 & 0.002 \\
& $\mathrm{Fe}$ & 0.85 & 1070 & 634 & 2.05 & $<0.001$ \\
ICP Vs 20-30\% & $\mathrm{P}$ & 0.42 & 2775 & 249 & 1.60 & $<0.001$ \\
moisture & $\mathrm{K}$ & 0.65 & 5693 & 2247 & 1.76 & $<0.001$ \\
range & $\mathrm{Ca}$ & 0.84 & 5754 & 4935 & 1.26 & $<0.001$ \\
& $\mathrm{Mg}$ & 0.08 & 1364 & 4978 & 0.18 & 0.082 \\
& $\mathrm{Fe}$ & 0.77 & 1356 & 728 & 2.05 & $<0.001$ \\
ICP Vs 40-50\% & $\mathrm{P}$ & 0.61 & 2285 & -1212 & 2.18 & $<0.001$ \\
moisture & $\mathrm{K}$ & 0.82 & 4044 & 1058 & 2.65 & $<0.001$ \\
range & $\mathrm{Ca}$ & 0.92 & 4062 & 3064 & 1.56 & $<0.001$ \\
& $\mathrm{Mg}$ & 0.08 & 1362 & 4826 & 0.29 & 0.076 \\
& $\mathrm{Fe}$ & 0.90 & 864 & 356 & 2.63 & $<0.001$ \\
range & $\mathrm{Ca}$ & 0.81 & 6194 & 3604 & 1.94 & $<0.001$ \\
& $\mathrm{Mg}$ & 0.10 & 1346 & 4662 & 0.41 & 0.078 \\
ICP Vs 60-70\% & $\mathrm{P}$ & 0.36 & 2924 & 462 & 2.15 & $<0.001$ \\
moisture & $\mathrm{K}$ & 0.71 & 5147 & 7613 & 2.15 & $<0.001$ \\
& $\mathrm{Fe}$ & 0.82 & 1212 & 719 & 3.07 & $<0.001$ \\
\hline & & & & & &
\end{tabular}


Figures
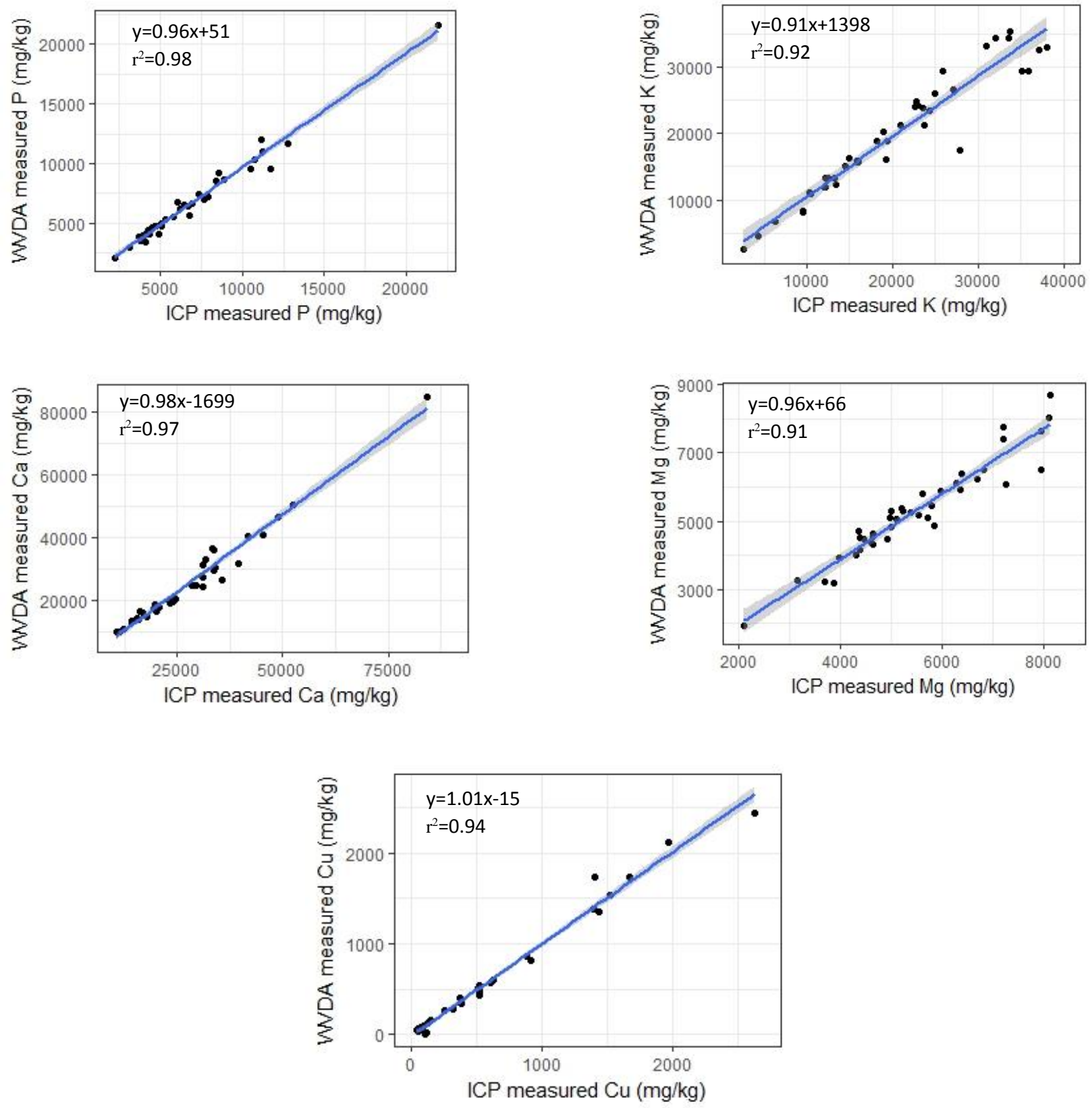

Fig 2.1: Regression plots between ICP and WVDA measured $\mathrm{P}, \mathrm{K}, \mathrm{Ca}, \mathrm{Mg}$, and $\mathrm{Cu}$ concentration. The shaded portion shows the standard error. 

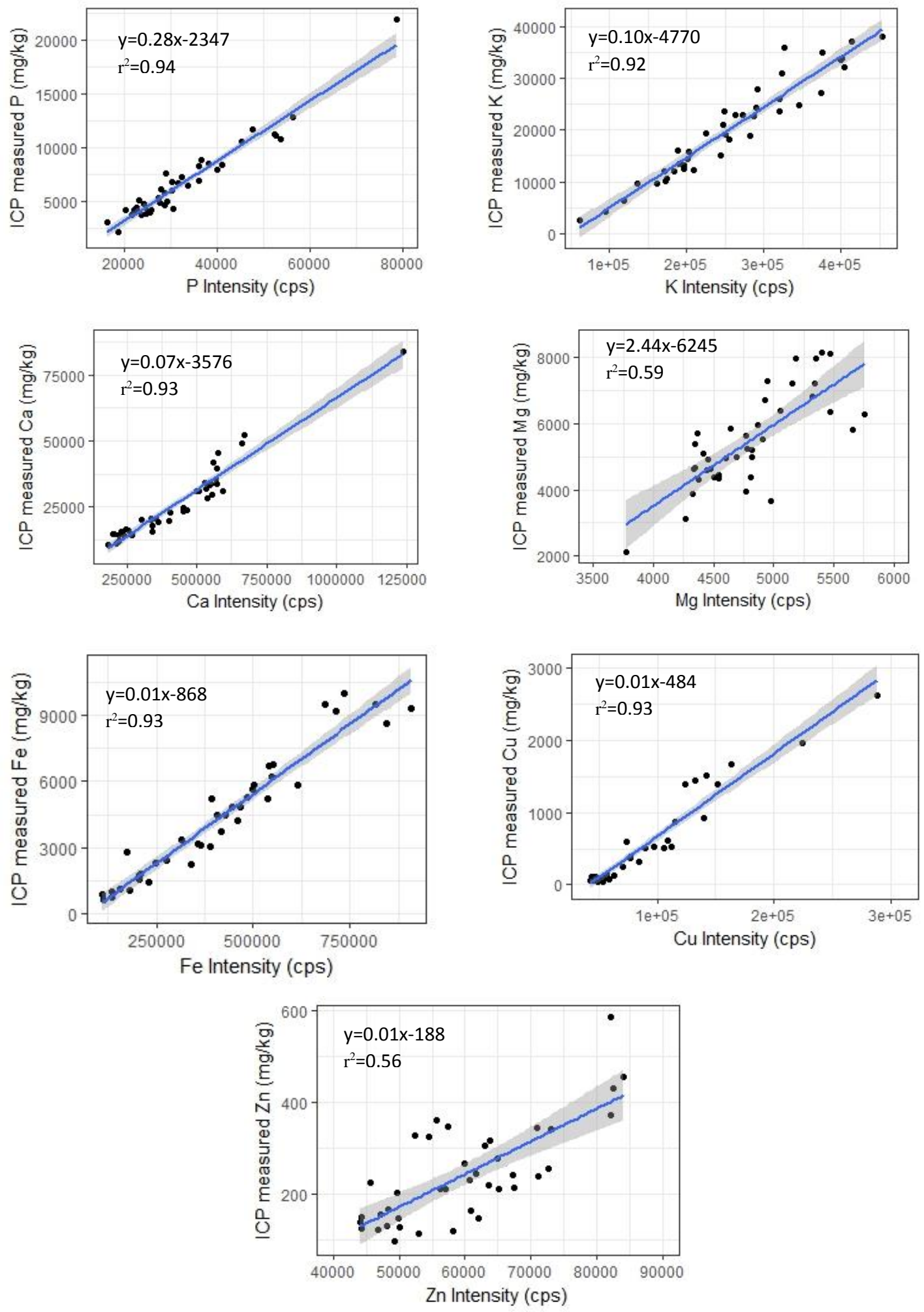

Fig 2.2: Regression plots between ICP measured concentration and PXRF intensities for $P, K$, $\mathrm{Ca}, \mathrm{Mg}, \mathrm{Fe}, \mathrm{Cu}$ and $\mathrm{Zn}$ in oven dried manure samples. The shaded portion shows the standard error. 

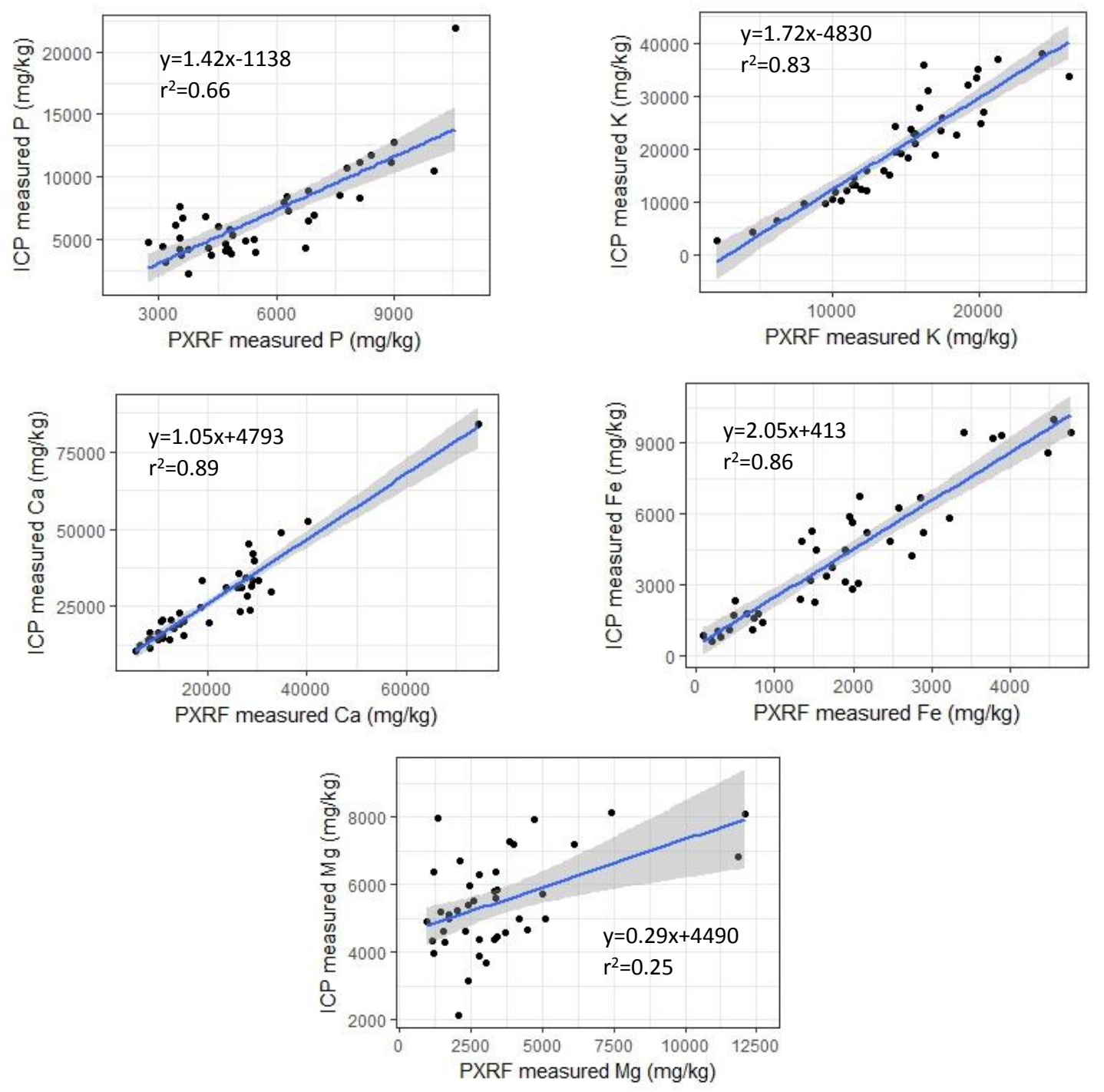

Fig 2.3: Regression plots between ICP and PXRF measured concentration for $\mathrm{P}, \mathrm{K}, \mathrm{Ca}, \mathrm{Mg}$ and Fe in oven dried manure samples. The shaded portion shows the standard error.
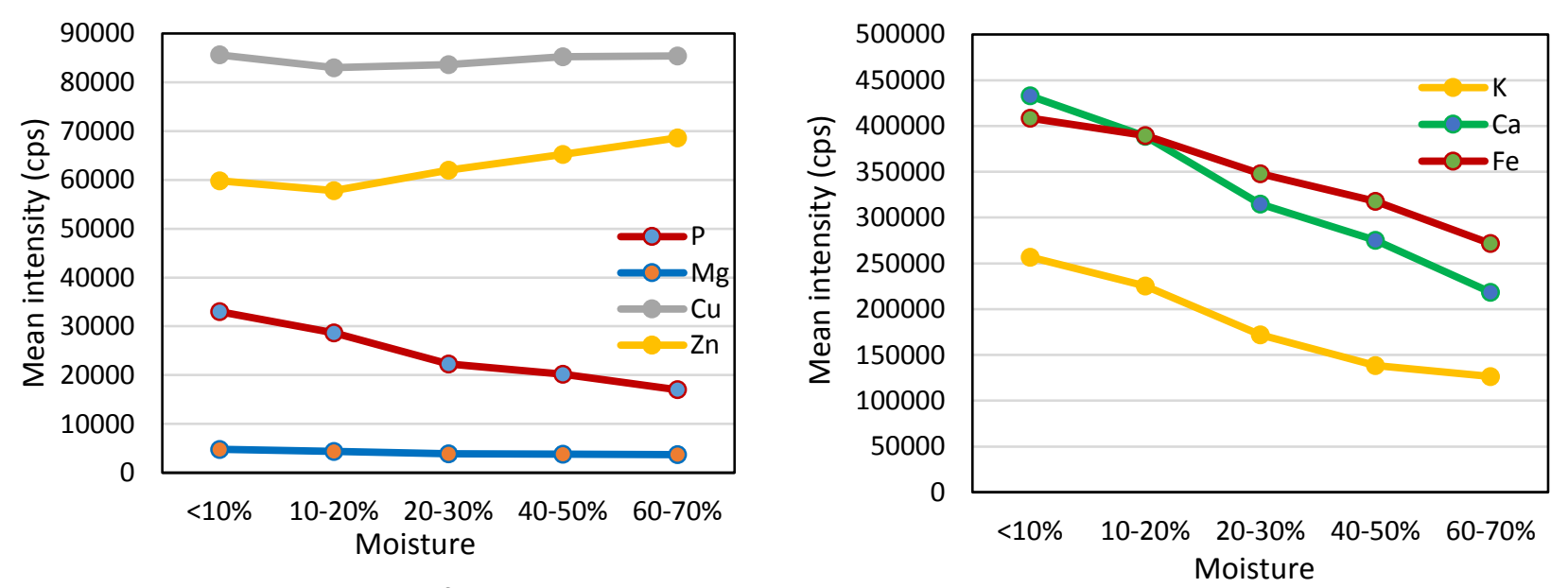

Fig 2.4: Mean comparison of $\mathrm{P}, \mathrm{K}, \mathrm{Ca}, \mathrm{Mg}, \mathrm{Fe}, \mathrm{Cu}$ and $\angle \mathrm{n}$ intensitıes measurea at tive moisture ranges 


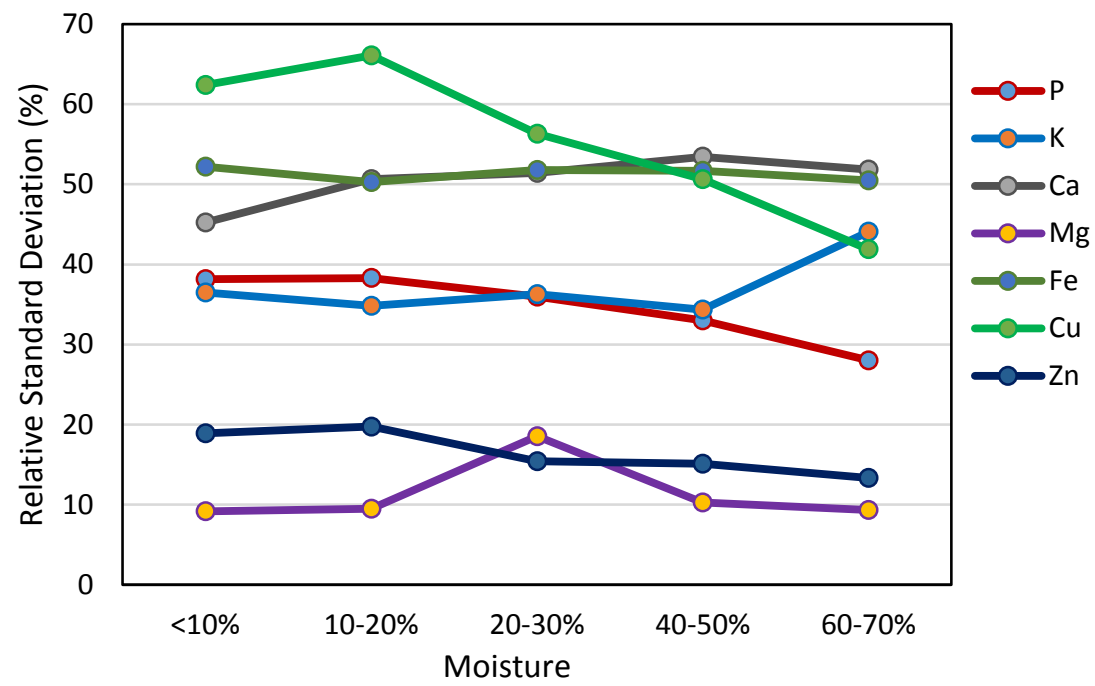

Fig 2.5: Relative Standard Deviation of PXRF intensities measured at five moisture ranges

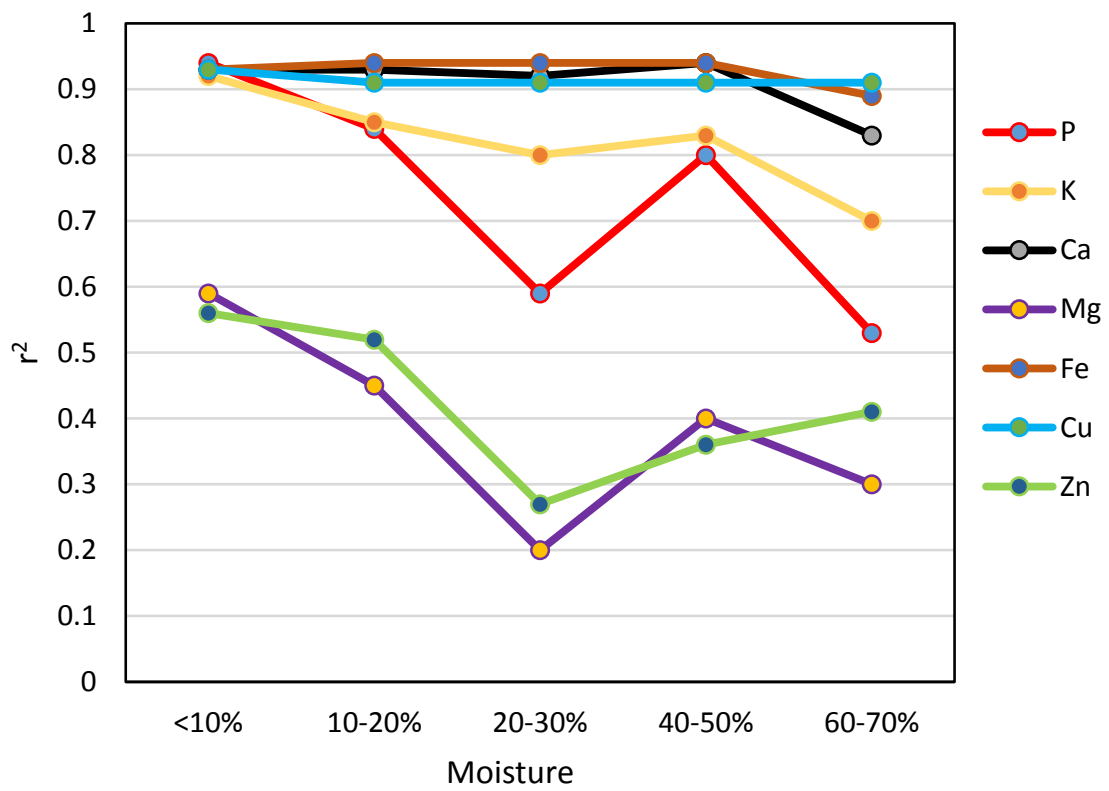

Fig 2.6: $r^{2}$ values (regression between ICP measured concentration PXRF intensities) produced over different 

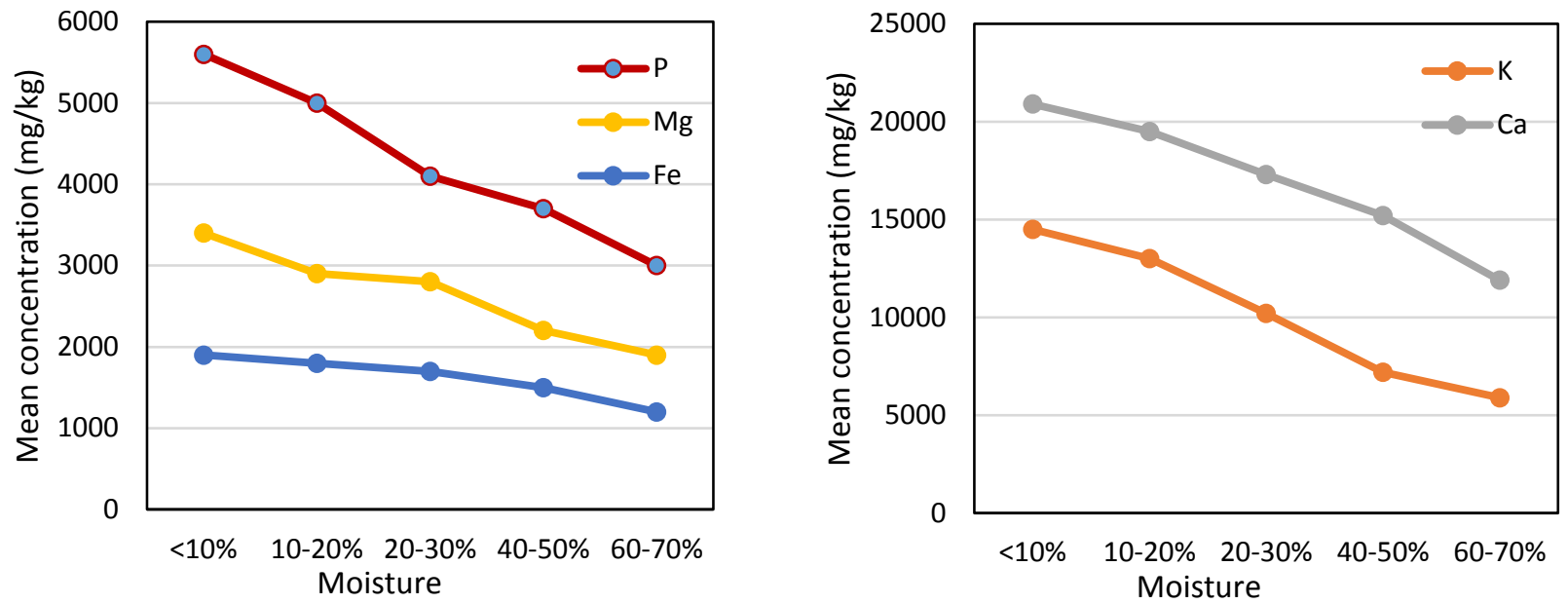

Fig 2.7: Mean comparison of $\mathrm{P}, \mathrm{K}, \mathrm{Ca}, \mathrm{Mg}$ and Fe concentrations measured at five moisture ranges

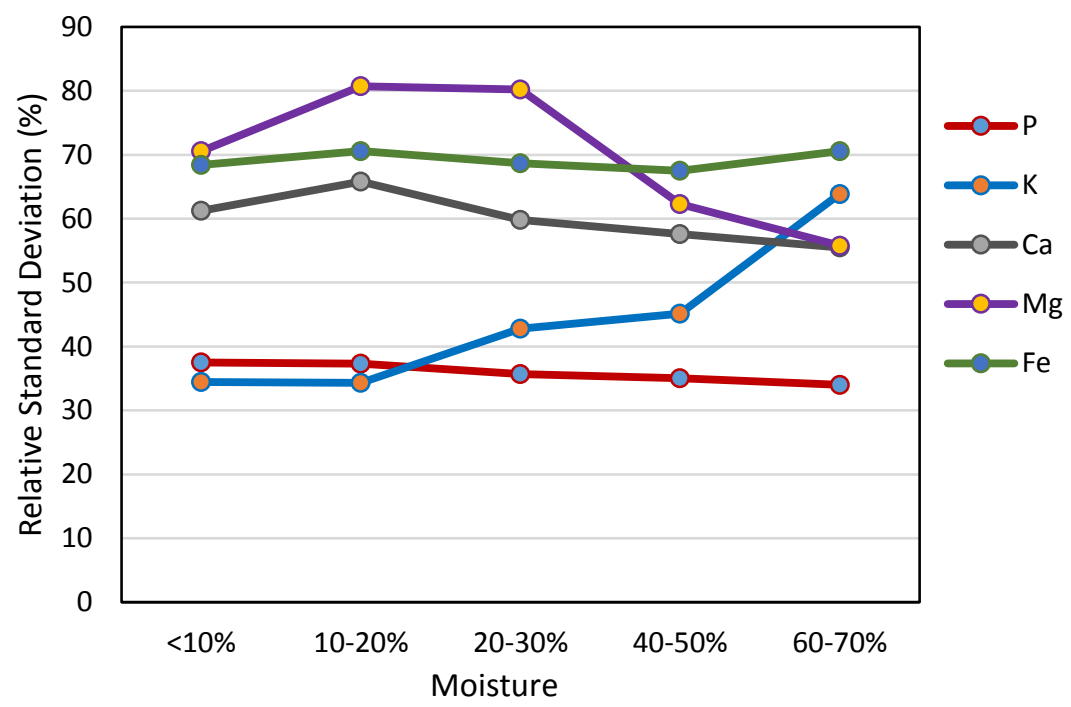

Fig 2.8: Relative Standard Deviation of PXRF concentration measured at five moisture ranges 


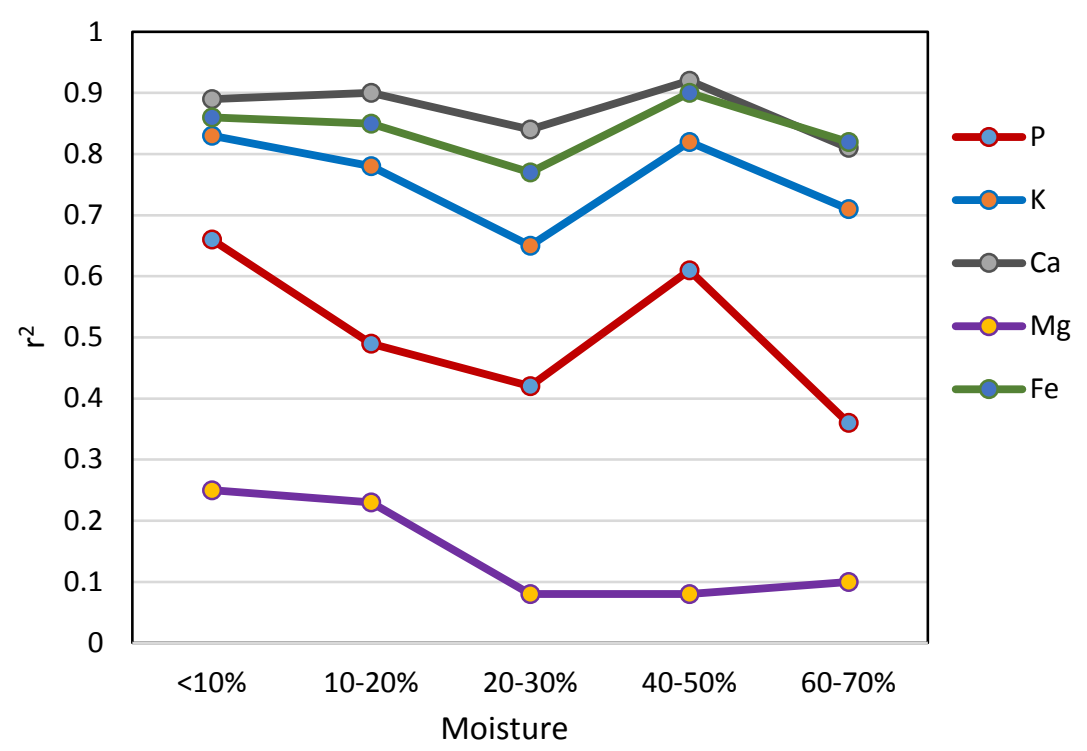

Fig 2.9: $r^{2}$ values (regression between ICP and PXRF measured concentration) produced over different moisture range

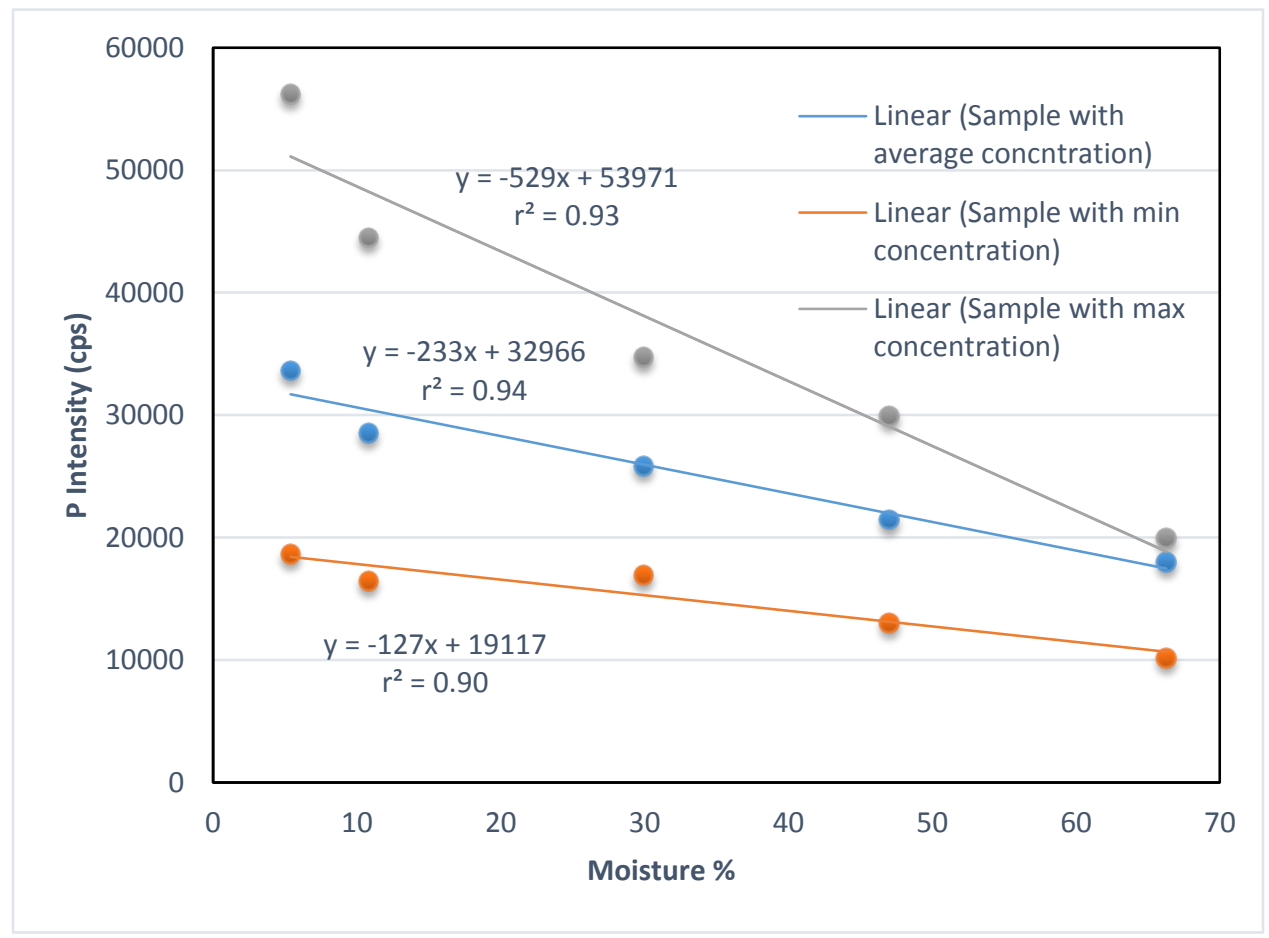

Fig 2.10: Regression between moisture content and $\mathrm{P}$ Intensity by sample for 3 samples varying in $\mathrm{P}$ concentration. 

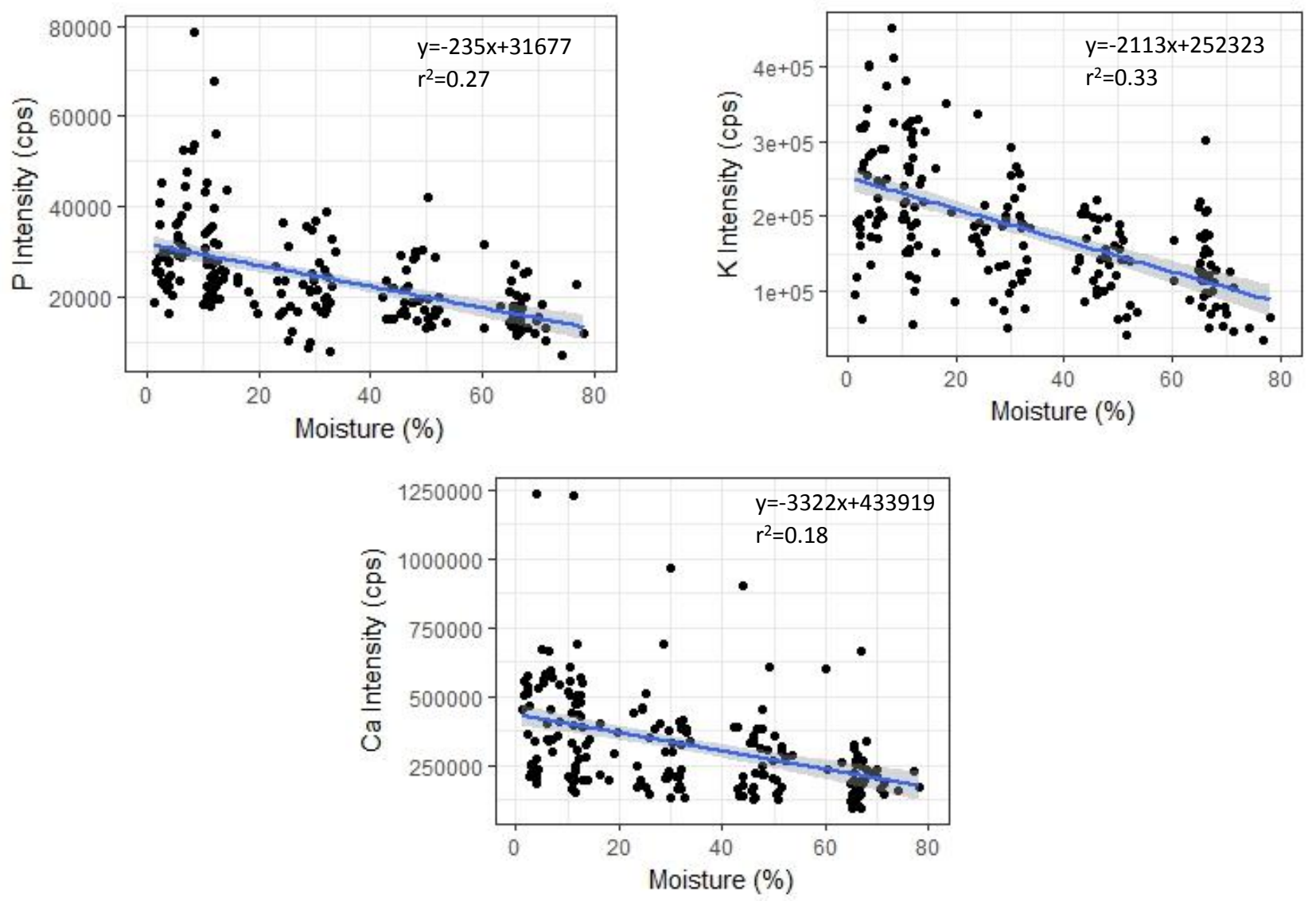

Fig 2.11: Regression between moisture content and $\mathrm{P}, \mathrm{K}$, and $\mathrm{Ca}$ Intensity. The shaded portion shows standard error. 


\section{Chapter 3: Particle Size Effect on Elemental Concentration Determination in Forage using Portable X-ray Fluorescence Spectroscopy}

\section{Introduction}

Forage is the major feed and source of minerals for ruminant farm animals. The performance and health of the animal are directly influenced by the mineral content of the forages (Minson, 1990; Van Soest, 1994). The deficiencies or excesses of specific mineral elements in forage decrease animal performance and economic return (Reid et al., 1970). The quantity of forage essential to each animal type is determined by the expected level of animal performance, quality of the forage, and its mineral content. Thus, knowing elemental composition ( $\mathrm{Mg}, \mathrm{Ca}, \mathrm{P}, \mathrm{K}, \mathrm{Fe}, \mathrm{Cu}$, and $\mathrm{Zn}$ ) in forage sources is crucial for farmers and/or nutritionists in formulating feeding plans for animals. In addition, large herds require enormous amounts of feed and forage for daily consumption indicating the need to know the nutritional status of the feed and forages frequently for appropriate feeding planning. Since the nutritional status of the forage changes over time, regular sampling and analysis are crucial for ration balancing. However, this increases the monetary burden to farmers (Berzaghi et al., 2005). However, getting mineral composition data is time-consuming and costly. Conventionally, minerals are quantified with expensive and time-consuming wet-chemical methods. This involves acid digestion of samples followed by spectroscopic techniques (Karla, 1998). Although they provide accurate quantification of minerals, they are not free from serious shortcomings. They require destructive sampling, are costly, time-consuming, and generate hazardous waste. X-ray fluorescence (XRF) could overcome many of these disadvantages of wet chemical analysis and allow quick determination of $P$ concentrations.

X-ray photons are emitted from an X-ray tube by the interaction of electrons with a metal anode. When the energy of the incident X-ray is greater than the binding energy of electrons in the shell, inner electrons are ejected leaving a vacant space. In order to fill this vacant space the electron from a higher shell moves to the inner shell emitting secondary X-ray radiation of energy/wavelength characteristic to each element. The emitted radiation is then detected. X-ray energy is inversely proportional to wavelength and is expressed as keV (kilo-electron volt) 
(Kalnicky and Singhvi, 2001). Portable XRF (PXRF) units are Energy Dispersive (ED) systems with low power X-ray tubes (10-40W) in comparison to benchtop units (50-300W). They are light and convenient to use either in benchtop or field-analysis modes.

When a sample is scanned, the resulting spectrum identifies the element (peak position or energy); area under the peak (intensity) is proportional to concentration (Willis and Duncan, 2008; Weindorf et. al., 2014). ). Although PXRF can measure most elements, air attenuation of low energy X-rays restricts the measurement of light elements in the periodic table, especially below silicon (Potts and West, 2008) except when equipped with a unique chamber capable of working under vacuum, or a helium atmosphere (Bueno Guerra et al., 2014; Brouwer, 2013). The critical penetration and escape depths are the depth of the sample beyond which almost all of emitted X-rays are absorbed, which is very low (in $\mu \mathrm{m}$ range) for light elements (Potts and West, 2008). PXRF may be qualitative, semi-quantitative, or quantitative as an analytical technique. The quantitative data are obtained by calibrating the XRF with reference wet chemical methods (Maarschalkerweerd and Husted, 2015) or standard addition methods (Reidinger et al., 2012).

Some portable units are comparable to benchtop XRF in elemental quantification and limits of detection (Bueno Guerra et al., 2014) but superior in terms of portability, cost-effectiveness, simplicity of operation, potential for in-situ measurement, and analysis of large samples (Bueno Guerra et al., 2014; AMC, 2008). In addition, it can be a superior alternative to wet chemistry in terms of cost- and time-effectiveness, and non-destructive analysis of samples (Reidinger et al., 2012).

The texture of sample surface is extremely important in XRF measurement. The surface of the sample should have mirror-finish, which can only be realized with fine powders and metals (Willis and Duncan, 2008). PXRF intensity increases with decrease in particle size of sample and is more sensitive for the light elements (Maruyama et al., 2008). Particle size effect is more pronounced in light elements than heavy elements because of lower penetration depth and measurement surface located on or in the proximity of the surface. In addition, there is shadowing effect if the sample is of heterogeneous particle size. Incoming X-rays will not irradiate all particles and thus no fluorescence will be received from shadowed particles (Yamada, 2014). The best approach to 
deal with a sample particle size is to grind to size less than the measurement depth of the elements to be determined (Willis and Duncan, 2008). However, grinding samples to fine power is not always beneficial; there is possibility of contamination by blades in grinding mill.

Raw peak count and spectral resolution increase with increasing scan time (McLaren et al., 2012, Kalnicky and Singhvi, 2001). Along with element of interest and sample matrix, detection limit depends on scan time. Scanning samples for longer time improves detection limit, however, the number of samples analyzed will be reduced (Kalnicky and Singhvi, 2001) and radiation damage is possible.

A few studies (Towett et al., 2016, Kalcsits ,2016, Bueno Guerra et al., 2014, McLaren et al., 2012, Reidinger et al., 2012, Paltridge et al. 2012a, and 2012b), have indicated the possible use of PXRF for the analysis of plant tissue. However, there is a lack of information for analysis of heterogeneous forage samples, including optimal sample preparation (particle size) and instrumental parameters (scan time).

We hypothesize that PXRF will be useful in the determination of forage elemental composition because our unit has vacuum capability, and PXRF has been used successfully to detect and quantify light elemental composition in a different plant, soil, geological and archeological samples.

The overall goal of this study was to evaluate the suitability of PXRF for P determination in forage samples. Because other elements are obtained simultaneously, results for $\mathrm{K}, \mathrm{Ca}, \mathrm{Mg}, \mathrm{Fe}, \mathrm{Cu}$, and $\mathrm{Zn}$ are also reported. To initiate this process we assumed that particle size of the sample would be the limiting factor for forage analyses. Thus, the specific objective was to quantify the effect of forage particle size and scan time on elemental concentrations.

\section{Material and Methods}

\section{Sample collection and preparation}

Hay samples $(n=42)$ were collected from hay bales of different West Virginia farms using a plunger corer in summer 2016. Samples were cored from hay bales representing legumes, grasslegume mixture, mixed grasses, first cut, and regrowth cut. 30 samples were subsampled in the 
field and sent to Cumberland Valley Analytical Services (CVAS), Waynesboro, PA for wet chemical analysis.

Collected samples were placed in paper bags and dried in an oven at $60^{\circ} \mathrm{C}$ for 72 hours. Milling of the dried samples was done in cyclone mill (FOSS Tecator 1093, FOSS North America, Eden Prairie, MN). The whole sample was allowed to pass through a $2 \mathrm{~mm}$ screen and then subsampled into three parts using the alternate scooping method. Two subsamples were re-ground separately and allowed to pass through the screens of $1 \mathrm{~mm}$ and $0.5 \mathrm{~mm}$ respectively. Thus, each hay samples had three subsamples with particles passing screens with $2 \mathrm{~mm}, 1 \mathrm{~mm}$ and $0.5 \mathrm{~mm}$ hole size.

In order to further investigate the effect of particle size of the sample, two particle sizes were selected. 1-2 $\mathrm{mm}$ (samples that pass through $2 \mathrm{~mm}$ sieve but retained on a $1 \mathrm{~mm}$ sieve) were obtained from existing $2 \mathrm{~mm}$ samples and 0.25 to $0.5 \mathrm{~mm}$ (samples that pass through $0.5 \mathrm{~mm}$ sieve but retained on a $0.25 \mathrm{~mm}$ sieve) were obtained from existing $0.5 \mathrm{~mm}$ samples.

\section{Wet Chemical Analysis}

Each hay sample were digested thrice in the microwave (MARS Xpress, CEM Inc., Matthews, NC) and the elemental concentration was determined using Inductively Coupled Plasma Optical Emission Spectrometry (ICP-OES) (Optima DV 2100, Perkin Elmer, Norwalk, CT). A Certified Reference Material (CRM), 1573a-tomato leaf, was digested with samples to check the accuracy of digestion. Exactly $10 \mathrm{~mL} 70 \%$ nitric acid was added to $0.5 \mathrm{~g}$ sample in digestion vessels and placed in a fume hood for 1 hour to eliminate gases produced. Then tubes were placed in a microwave, heat for 15 minutes at $200{ }^{\circ} \mathrm{C}$ followed by holding at $200{ }^{\circ} \mathrm{C}$ for 15 minutes and allowed to cool overnight. The digested liquid was transferred into test tubes, diluted and final volume was made $50 \mathrm{~mL}$ using volumetric flasks. The diluted liquid was filtered before analysis by ICP-OES. The WVU ICP-OES determined concentrations are abbreviated as ICP values.

\section{PXRF Scanning}

Samples were scanned using portable XRF (Tracer III-SD; Bruker Elemental, Kennewick, WA) in benchtop mode equipped with a rhodium tube from which X-rays are emitted, and a Peltiercooled, silicon PIN diode detector, with a voltage of $15 \mathrm{KeV}$ and anode current of $26 \mathrm{uA}$ without 
a filter. It was operated on PC trigger mode and vacuum ( $<10$ torrs) was used for all scans. Samples were placed in double open-ended sample cups (series: 1500, Chemplex Industries Inc., USA) over a thin X-ray film (4 um prolene). The cups containing ground samples were placed in the nose of the PXRF and covered with a X-ray shielding lid. All samples were scanned for 180s. Some forage samples $(n=29)$ were also scanned for the 60 s and 120 s for scan time analysis.

\section{Data Collection and Statistical Analysis}

Spectrum for each analysis was collected using S1PXRF software (Bruker Elemental, WA, USA). The intensity of $\mathrm{P}, \mathrm{K}, \mathrm{Ca}, \mathrm{Mg}, \mathrm{Fe}, \mathrm{Cu}$ and $\mathrm{Zn}$ in count per second (cps) and elemental concentration of $\mathrm{P}, \mathrm{K}, \mathrm{Ca}$ and $\mathrm{Mg}$ in weight percent were obtained from the same software. A standard-based calibration (obtained from personal communication with Dr. Lee Drake, Senior Application Scientist, Bruker AXS, Albuquerque, NM) for plant samples was used to get elemental concentration.

Data were organized in Microsoft Excel and analyzed by JMP (JMP ${ }^{\circledR}$, Version Pro 12.2, SAS Institute Inc., Cary, NC, Copyright (C2015), SAS (SAS ${ }^{\circledR}$, Version 9.4, SAS Institute Inc., Cary, NC, Copyright (C2002-2012), and R (R Foundation for Statistical Computing, Vienna, Austria). Regression analysis, matched paired t-tests, and repeated measures ANOVA followed by Tukey Kramer adjustment was used for data analysis. Scan time and particle size were considered as repeated. The intensity and elemental concentrations obtained from PXRF scanning were compared with the ICP-OES measured values to determine the effect of sample particle size and scan time on elemental quantification. Likewise, wet chemical analysis results from CVAS and WVU lab were also compared. Significance criterion (alpha) for all tests was 0.05.

\section{Result and Discussion}

\section{Wet chemical elemental concentrations}

The average relative standard deviation (RSD) for three sets of digestion, RSD for SRM digestion and difference between standard value and ICP determined value of CRM have been presented in Table 3.1. The RSD below 10\% is acceptable for plant elemental analysis (Bueno Guerra et al., 2014). 


\section{Sample description}

Forage samples had variable RSD for different element ranging from $19 \%$ for $\mathrm{Mg}$ to $64 \%$ for $\mathrm{Zn}$. All the elements under consideration were in RSD of nearly 19\% to 32\% except Zn (Table 3.2). Moreover, 30 subsets of the sample analyzed by CVAS had RSD ranging from $17 \%$ for $\mathrm{K}$ to $45 \%$ for Fe (Table: 3.3).

\section{Comparability between ICP-OES and CVAS concentration}

The comparability evaluation between ICP-OES and CVAS determined elemental concentration was done by using linear regression analysis (Fig 3.1). Regression models were significant for $P$, $\mathrm{K}, \mathrm{Ca}$, and $\mathrm{Mg}$ with $\mathrm{r}^{2}$ values of $0.88,0.85,0.74$, and 0.81 respectively. The slopes of the regression lines were between 0.66 and 0.75 . The models for $\mathrm{Fe}, \mathrm{Cu}$, and $\mathrm{Zn}$ were not significant.

\section{PXRF analysis of forage samples PXRF intensity}

The summary statistics PXRF intensities for three particle sizes of the sample scanned at 180 seconds is presented in Table 3.4. The intensities had RSD ranging from $2.29 \%$ for $\mathrm{Cu}(1 \mathrm{~mm}$ samples) to $35.45 \%$ for Fe (1 $\mathrm{mm}$ samples). RSD was comparable for each particle size of the samples. RSD of the PXRF intensities were lower than the RSD of the elemental concentration (reference standard) determined using ICP. Symmetry in the distribution of dataset was evaluated using the measure of skewness. All of the datasets were right skewed except $\mathrm{Cu}$ measured with $0.5 \mathrm{~mm}$ samples. The $\mathrm{P}, \mathrm{Mg}$, and Cu were symmetrical (skewness between -0.5 to 0.5 ) while the $\mathrm{K}, \mathrm{Ca}, \mathrm{Mg}$ and $\mathrm{Zn}$ were moderate to highly right-skewed (skewness greater than $0.5)$.

Regression models between PXRF counts and ICP determined concentration were significant for $\mathrm{P}, \mathrm{K}, \mathrm{Ca}, \mathrm{Fe}$ and $\mathrm{Zn}$ while not significant for $\mathrm{Cu}$ in the samples of all particle sizes (Fig 3.2). Mg was not significant for $0.5 \mathrm{~mm}$ sample while significant for $1 \mathrm{~mm}$ and $2 \mathrm{~mm}$ samples. P, K, Ca and Fe had $R^{2}$ values ranging from 0.7 to 0.93 while 0.23 to 0.47 for $Z n$. The particle size of the sample did not produce a significant impact on the strength of relationship for all elements (Fig 3.2). 


\section{PXRF determined concentrations}

The elemental concentrations had RSD ranging from 10.53\% for $\mathrm{Mg}$ ( $2 \mathrm{~mm}$ samples) to $84.21 \%$ for Fe. RSD was comparable for each particle size of the samples (Table 3.5). All of the datasets were moderate to highly right-skewed.

Furthermore, these datasets were checked for normal distribution using Shapiro-Wilk W (goodness-of-fit) test. All elements had lack of normality of distribution, which was then corrected by the Ln-transformation. Then the data were analyzed using Proc Mixed of SAS as repeated measures ANOVA, followed by multiple comparisons on Least Square (LS) means with Tukey-Kramer adjustment for multiple comparisons.

Repeated measures ANOVA results demonstrate that there is an evidence of significant relationship and particle size of the sample affects $P$ concentration $(F=4.22,2 \mathrm{df}, p=0.018)$. The LS means were significant $(P<0.001)$ at each particle size of the samples. Differences in the least square means were significant $(p=0.018)$ only for the particle size of $2 \mathrm{~mm}$ and $1 \mathrm{~mm}$ samples.

However, the similar analysis with $\mathrm{K}(\mathrm{F}=2.33,2 \mathrm{df}, \mathrm{p}=0.114)$ and $\mathrm{Ca}(\mathrm{F}=2.47,2 \mathrm{df}, \mathrm{p}=0.091)$ demonstrate that there is no evidence of the relationship and particle size of the samples were not significant. Differences in LS mean were not significant to any pair of particle sizes.

Likewise, there is an evidence of significant relationship and the particle size of the sample affects Mg concentration $(F=10.75,2 d f, P<0.001)$. The least square means were significant $(P<0.001)$. Differences in the least square means were also significant for $1 \mathrm{~mm}$ and $2 \mathrm{~mm}$ samples $(P<0.001)$ and $0.5 \mathrm{~mm}$ and $2 \mathrm{~mm}$ samples $(P<0.001)$.

Regression models between PXRF determined and ICP determined concentration were significant for $\mathrm{P}, \mathrm{K}, \mathrm{Ca}$ and Fe while not significant for $\mathrm{Mg}$ in the samples of all particle sizes (Fig 3.3). The particle size of the sample did not produce a significant impact on the strength of relationship for all elements. The strength of the relationship was lower for the PXRF determined concentration in comparison to the intensities indicating the need for some revision in the calibration. 
The concentration of $\mathrm{P}, \mathrm{K}, \mathrm{Ca}$, and Fe can reliably be measured in dry and ground forage samples with PXRF. Some elements indicated a significant effect of particle while others not. Since, the particle size of the sample was determined by passing the sample through the screen ( $2 \mathrm{~mm}$, $1 \mathrm{~mm}$, and $0.5 \mathrm{~mm}$ ), each sample was a mixture of the particles below the determined size. The elements under consideration had very low penetration depth, generally determined at the surface. The smaller particles settle at the bottom of the sample cups during measurement. This might be the cause of getting similar results from the samples of all particle sizes.

\section{PXRF analysis of new particle sizes}

In order to further, investigate the effect of particle size of the sample, two particle size of the samples were selected from the existing samples. 1-2 mm (samples that pass through $2 \mathrm{~mm}$ sieve but retained on a $1 \mathrm{~mm}$ sieve) were obtained from existing $2 \mathrm{~mm}$ samples and 0.25-0.5 $\mathrm{mm}$ (samples that pass through $0.5 \mathrm{~mm}$ sieve but retained on a $0.25 \mathrm{~mm}$ sieve) were obtained from existing $0.5 \mathrm{~mm}$ samples.

\section{PXRF Counts: New particle size}

The summary statistics PXRF intensities for two new particle sizes of the sample scanned at 180 seconds are presented in Table 3.6. The intensities of 0.25-0.5 mm samples had RSD ranging from $3.97 \%$ for $\mathrm{Cu}$ to $25.69 \%$ for $\mathrm{Ca}$ and intensities of $1-2 \mathrm{~mm}$ samples had RSD ranging from $7.83 \%$ for Cu to 29.60 for Ca. RSD was approximately $4 \%$ higher in larger particle size of the samples than the smaller one except for Fe (approximately 4\% lower). All of the datasets had a different degree of right skewness. The right skewness of the dataset increased with the particle size except for the $\mathrm{Zn}$. The differences in the intensity between two particle sizes of the samples for each element were significant (Matched Paired t-test). There is decreasing trend in the photon counts with an increase in particle size of the samples.

Regression models between PXRF counts and ICP determined concentration were significant for $\mathrm{P}, \mathrm{K}, \mathrm{Ca}$ and Fe while not significant for $\mathrm{Mg}$ in the samples of all particle sizes. (Fig 3.4) The strength of relationship decreased with increase in the particle size of the sample. 


\section{PXRF measured concentration: New particle size}

The summary statistics of PXRF determined concentration of $\mathrm{P}, \mathrm{K}, \mathrm{Ca}$, and $\mathrm{Mg}$ has been presented in Table 3.11. The elemental concentrations had RSD ranging from $11.54 \%$ for $\mathrm{Mg}$ to $27.27 \%$ for P. RSD was comparable for both particle size of the samples. All of the datasets were moderate to highly right-skewed.

The matched paired t-test result is presented in table 3.8. Forage samples with larger particle size had a greater bias (mean difference) with ICP determined concentration except for Ca. The bias was not significant for the P measured by PXRF in $0.25-0.5 \mathrm{~mm}$ samples. Likewise, in PXRF analysis particle size of the sample produced a significant bias for all analyzed elements.

Moreover, regression models between PXRF and ICP measured concentration were significant for $\mathrm{P}, \mathrm{K}$ and $\mathrm{Ca}(\mathrm{P}<0.001)$ while not significant for $\mathrm{Mg}$ in the samples of both particle sizes (Fig 3.5). The strength of relationship decreased with increase in the particle size of the sample. Likewise, the $r^{2}$ values were lower in comparison to the regression between PXRF intensity and ICP measured concentration, adding insights for the need of the calibration equation revision.

\section{Effect of scan time}

Doubly repeated measures ANOVA followed by Tukey-Kramer adjustment was used to analyze the effect of particle size, scan time and their interaction in PXRF measured concentration of P, $\mathrm{K}$ and $\mathrm{Ca}$. The particle size of the sample was significant while scan time and interaction between scan time and particle size of the sample was not significant (Table 3.9).

The regression analysis between ICP determined concentration and PXRF determined concentration/intensity at different scan time produced similar $r^{2}$ (data not shown) values further confirming the nominal effect of the scan time on elemental quantification.

Elemental concentration ( $\mathrm{P}, \mathrm{K}, \mathrm{Ca}, \mathrm{Fe}$ ) in dry and ground forage samples can reliably be measured by PXRF. The particle size of the sample significantly affects the result; however, compromising some accuracy PXRF can be reliably used to measure P concentrations. Scanning time was not significant indicating the potentiality of getting a result even faster, however, longer scanning time increases detection limit. Reduced strength of the relationship with PXRF concentration indicates the need for calibration update. 
$\mathrm{Mg}, \mathrm{Cu}$ and $\mathrm{Zn}$ were significantly different from the ICP values. The weak relationship of $\mathrm{Mg}$ might be due to the absorption of the characteristic $X$-ray before reaching the detector. However, in case of $\mathrm{Cu}$ and $\mathrm{Zn}$ presence of very low concentration affected the result. The weaker strength in case of $\mathrm{Cu}$ and $\mathrm{Zn}$ might be due to the use of same factory setting used for other light elements.

\section{Conclusion}

Since the PXRF results were in close agreement with ICP and CVAS results, it can be used as a prominent technique in elemental $(\mathrm{P}, \mathrm{K}, \mathrm{Ca}$, and $\mathrm{Fe}$ ) concentration determination in forage samples. It removes several disadvantages of traditional wet chemical analysis techniques. The result can be obtained quickly at a reduced cost. The scan time did not affect the result indicating the potentiality of getting a result even faster. The particle size of the sample affects the result, however, compromising some accuracy, it can be used for larger particle size of the samples. This method could be helpful in preparing feeding plans for animal farms and even promote hay marketing based on the mineral composition. To obtain better result drying and grinding of the sample is recommended, which would still be cheaper and quicker than wet chemical analysis. Additional work is recommended to extend this to in-field analysis. 


\section{Literature Cited}

Analytical Methods Committee (AMC), Royal Society of Chemistry. 2008. Evaluation of analytical instrumentation. Part xxiii. Instrumentation for portable x-ray fluorescence spectrometry. Accred. Qual. Assur. 13:453-464

Berzaghi, P., L. Serva, M. Piombino, M. Mirisola, and F. Benozzo. 2005. Prediction performances of portable near infrared instruments for at farm forage analysis. Ital. J. Anim. Sci. 4(SUPPL. 3): 145-147.

Brouwer, P. 2013. Theory of XRF. PANanalytial B.V., Almelo, The Netherlands.

Bueno Guerra, M.B., E. de Almeida, G.G.A. Carvalho, P.F. Souza, L.C. Nunes, D.S. Júnior, and F.J. Krug. 2014. Comparison of analytical performance of benchtop and handheld energy dispersive X-ray fluorescence systems for the direct analysis of plant materials. J. Anal. At. Spectrom. 29(9): 1667.

Kalcsits, L.A. 2016. Non-destructive measurement of calcium and potassium in apple and pear using handheld X-ray fluorescence. Front. Plant Sci. 7:442.

Kalnicky, D.J., and R. Singhvi. 2001. Field portable XRF analysis of environmental samples. J. Hazard. Mater. 83(1-2): 93-122.

Karla, Y. P. 1998. Handbook of reference methods for plant analysis. CRC Press Taylor \& Francis Group.

Maarschalkerweerd, M., and S. Husted. 2015. Recent developments in fast spectroscopy for plant mineral analysis. Front. Plant Sci. 6(March): 1-14.

Maruyama, Y., K. Ogawa, T. Okada, and M. Kato. 2008. Laboratory experiments of particle size effect in X-ray fluorescence and implications to remote $X$-ray spectrometry of lunar regolith surface. Earth Planets Sp. 60: 293-297.

McLaren, T.I., C.N. Guppy, and M.K. Tighe. 2012. A rapid and nondestructive plant nutrient analysis using portable X-ray fluorescence. Soil Sci. Soc. Am. J. 76(4): 1446-1453.

Minson, D.J. 1990. Forage in ruminant nutrition. Academic Press, San Diego, USA.

Paltridge, N.G., L.J. Palmer, P.J. Milham, G.E. Guild, and J.C.R. Stangoulis. 2012a. Energydispersive $X$-ray fluorescence analysis of zinc and iron concentration in rice and pearl millet grain. Plant Soil 361(1-2): 251-260.

Paltridge, N.G., P.J. Milham, J.I. Ortiz-Monasterio, G. Velu, Z. Yasmin, L.J. Palmer, G.E. Guild, and J.C.R. Stangoulis. 2012b. Energy-dispersive X-ray fluorescence spectrometry as a tool for zinc, iron and selenium analysis in whole grain wheat. Plant Soil 361(1-2): 261-269.

Potts, P. J., and M. West. 2008. Portable X-ray fluorescence spectrometry: capabilities for in situ analysis. The Royal Society of Chemistry, UK. 
Reid, R. L., A. J. Post, and G. A. Jung. 1970. Mineral composition of forages. West Virginia University, Agricultural Experiment Station, Morgantown. Bulletin 589T.

Reidinger, S., M.H. Ramsey, and S.E. Hartley. 2012. Rapid and accurate analyses of silicon and phosphorus in plants using a portable X-ray fluorescence spectrometer. New Phytol. 195(3): 699-706.

Towett, E.K., K.D. Shepherd, and B. L. Drake. 2016. Plant elemental composition and portable Xray fluorescence ( $p X R F$ ) spectroscopy: Quantification under different analytical parameters. X-Ray Spectrom. 45(2): 117-124.

Van Soest, P. J. 1994. Nutritional ecology of the ruminant. 2nd ed. Comstock Publishing Associates, Ithaca, NY.

Weindorf, D.C., N. Bakr, and Y. Zhu. 2014. Advances in portable X-ray fluorescence (PXRF) for environmental, pedological, and agronomic applications. Adv. Agron. 128:1-45.

Willis, J. P., and A. R. Duncan. 2008. Understanding XRF spectrometry, Vol I. PANanalytial B.V., Almelo, The Netherlands.

Yamada, Y. 2014. Sample preparation for X-ray fluorescence analysis I . Outline of sample preparation. Rigaku J. 30(1): 26-29. 
Tables

Table 3.1: Average Relative Standard Deviation (RSD) for 3 replications of forage sample digestion and RSD for SRM digested with forage samples ( $n=42)$.

\begin{tabular}{lccc}
\hline Elements & $\begin{array}{c}\text { Average RSD for } \\
\text { forage samples (\%) }\end{array}$ & $\begin{array}{c}\text { RSD for } \\
\text { SRM (\%) }\end{array}$ & $\begin{array}{c}\text { Difference between standard and } \\
\text { ICP concentration for SRM (\%) }\end{array}$ \\
\hline $\mathrm{P}$ & 6.3 & 5.53 & 4.09 \\
$\mathrm{~K}$ & 7.19 & 3.93 & 4.80 \\
$\mathrm{Ca}$ & 4.24 & 4.25 & 2.42 \\
$\mathrm{Mg}$ & 5.82 & 5.10 & 14.13 \\
$\mathrm{Fe}$ & 10.01 & 8.25 & 13.64 \\
$\mathrm{Cu}$ & 12 & 23.21 & 42.34 \\
$\mathrm{Zn}$ & 20.75 & 14.82 & 97.89 \\
\hline
\end{tabular}

Table 3.2: Summary Statistics for ICP determined elemental concentrations $(\mathrm{mg} / \mathrm{kg})$ forage samples $(n=42)$.

\begin{tabular}{lccccccc}
\hline \multirow{2}{*}{ Statistic } & \multicolumn{7}{c}{ Elemental Concentration $(\mathrm{mg} / \mathrm{kg})$} \\
& $\mathrm{P}$ & $\mathrm{K}$ & $\mathrm{Ca}$ & $\mathrm{Mg}$ & $\mathrm{Fe}$ & $\mathrm{Cu}$ & $\mathrm{Zn}$ \\
\hline Mean & 2100 & 17100 & 4700 & 1800 & 200 & 11 & 41 \\
Minimum & 1000 & 11500 & 2700 & 1100 & 44 & 7 & 23 \\
Maximum & 3500 & 27400 & 9000 & 2600 & 448 & 17 & 200 \\
Standard Dev & 600 & 4000 & 1500 & 350 & 105 & 3 & 26 \\
RSD (\%) & 28.57 & 23.39 & 31.91 & 19.44 & 52.50 & 27.27 & 63.41 \\
Skewness & 0.40 & 1.13 & 1.46 & 0.42 & 0.75 & 0.37 & 5.65 \\
Kurtosis & -0.29 & 0.33 & 1.42 & -0.70 & -0.51 & -0.81 & 29.07 \\
\hline
\end{tabular}

Table 3.3: Summary Statistics for CVAS determined elemental concentrations $(\mathrm{mg} / \mathrm{kg})$ in 30 subsets of forage samples.

\begin{tabular}{lccccccc}
\hline \multirow{2}{*}{ Statistic } & \multicolumn{7}{c}{ Elemental Concentration $(\mathrm{mg} / \mathrm{kg})$} \\
& $\mathrm{P}$ & $\mathrm{K}$ & $\mathrm{Ca}$ & $\mathrm{Mg}$ & $\mathrm{Fe}$ & $\mathrm{Cu}$ & $\mathrm{Zn}$ \\
\hline Mean & 2500 & 22900 & 4900 & 2000 & 500 & 7 & 22 \\
Minimum & 1600 & 16300 & 3200 & 1500 & 80 & 5 & 16 \\
Maximum & 3900 & 33600 & 7400 & 3000 & 6100 & 12 & 30 \\
Standard Dev & 600 & 3900 & 1000 & 350 & 225 & 2 & 4 \\
RSD (\%) & 24 & 17 & 20.41 & 17.50 & 45 & 28.57 & 18.18 \\
Skewness & 0.36 & 1.12 & 0.58 & 0.28 & 1.85 & 1.10 & 0.65 \\
Kurtosis & -0.79 & 0.73 & -0.19 & -0.08 & 1.82 & 0.15 & -0.93 \\
\hline
\end{tabular}


Table 3.4: Summary statistics for PXRF intensities (cps) for 3 different particle size forage samples $(n=42)$.

\begin{tabular}{clccccccc}
\hline \multirow{2}{*}{ Method } & Statistic & \multicolumn{7}{c}{ PXRF intensities (cps) } \\
& & $\mathrm{P}$ & $\mathrm{K}$ & $\mathrm{Ca}$ & $\mathrm{Mg}$ & $\mathrm{Fe}$ & $\mathrm{Cu}$ & $\mathrm{Zn}$ \\
\hline PXRF & Mean & 15700 & 284900 & 146800 & 3600 & 98800 & 55200 & 55500 \\
$(0.5$ & Minimum & 10300 & 188700 & 100500 & 3300 & 63600 & 50200 & 49900 \\
$\mathrm{~mm})$ & Maximum & 21900 & 399300 & 294700 & 4000 & 205300 & 58800 & 67100 \\
& SD & 2900 & 54200 & 41900 & 200 & 31500 & 1800 & 2600 \\
& RSD (\%) & 18.47 & 19.02 & 28.54 & 5.56 & 31.88 & 3.26 & 4.68 \\
& Skewness & 0.34 & 0.56 & 1.86 & 0.30 & 1.38 & -0.25 & 1.99 \\
& Kurtosis & -0.62 & -0.46 & 2.71 & -0.90 & 1.61 & 0.23 & 6.73 \\
& & & & & & & & \\
PXRF & Mean & 15300 & 276800 & 141800 & 3600 & 99300 & 54600 & 55000 \\
& Minimum & 10400 & 188500 & 95100 & 3300 & 61700 & 50800 & 50200 \\
& Maximum & 21600 & 402200 & 290700 & 3900 & 210900 & 58600 & 60600 \\
& SD & 2700 & 53800 & 39100 & 200 & 35200 & 1600 & 2000 \\
& RSD (\%) & 17.65 & 19.44 & 27.57 & 5.56 & 35.45 & 2.93 & 3.64 \\
& Skewness & 0.34 & 0.73 & 1.89 & 0.38 & 1.45 & 0.45 & 0.74 \\
& Kurtosis & -0.61 & -0.41 & 3.55 & -0.82 & 1.58 & 0.63 & 0.85 \\
& & & & & & & & \\
PXRF & Mean & 15400 & 271700 & 149000 & 3500 & 96500 & 52100 & 52400 \\
(2 mm) & Minimum & 10300 & 181500 & 100100 & 3200 & 58700 & 47200 & 47100 \\
& Maximum & 22000 & 383800 & 302200 & 3900 & 211100 & 57200 & 59100 \\
& SD & 2800 & 52400 & 42400 & 200 & 33300 & 1900 & 2300 \\
& RSD (\%) & 18.18 & 19.29 & 28.46 & 5.71 & 34.51 & 3.65 & 4.39 \\
& Skewness & 0.32 & 0.56 & 1.75 & 0.25 & 1.42 & 0.18 & 0.75 \\
& Kurtosis & -0.44 & -0.53 & 2.60 & -0.65 & 1.88 & 0.19 & 0.94 \\
\hline
\end{tabular}


Table 3.5: Summary statistics for PXRF determined concentrations $(\mathrm{mg} / \mathrm{kg})$ for 3 different particle size forage samples $(n=42)$.

\begin{tabular}{|c|c|c|c|c|c|c|}
\hline \multirow{2}{*}{ Method } & \multirow{2}{*}{ Statistic } & \multicolumn{5}{|c|}{ PXRF determined elemental concentration $(\mathrm{mg} / \mathrm{kg}$ ) } \\
\hline & & $\mathrm{P}$ & $\mathrm{K}$ & $\mathrm{Ca}$ & $\mathrm{Mg}$ & $\mathrm{Fe}$ \\
\hline \multirow{7}{*}{$\begin{array}{c}\text { PXRF (0.5 } \\
\mathrm{mm})\end{array}$} & Mean & 2500 & 16300 & 6100 & 2000 & 180 \\
\hline & Minimum & 1700 & 11200 & 2800 & 1700 & 0.2 \\
\hline & Maximum & 4300 & 25700 & 15600 & 2700 & 620 \\
\hline & Standard Dev & 600 & 3300 & 2400 & 300 & 150 \\
\hline & RSD & 24.00 & 20.25 & 39.34 & 15.00 & 83.33 \\
\hline & Skewness & 1.31 & 1.03 & 1.76 & 1.01 & 1.01 \\
\hline & Kurtosis & 0.63 & 0.73 & 3.93 & -0.36 & 0.45 \\
\hline \multirow{7}{*}{$\begin{array}{c}\text { PXRF } \\
(1 \mathrm{~mm})\end{array}$} & Mean & 2400 & 16100 & 6000 & 2000 & 190 \\
\hline & Minimum & 1700 & 11300 & 2500 & 1600 & 1 \\
\hline & Maximum & 4300 & 26100 & 15600 & 2800 & 530 \\
\hline & Standard Dev & 600 & 3400 & 2300 & 300 & 160 \\
\hline & RSD & 25.00 & 21.12 & 38.33 & 15.00 & 84.21 \\
\hline & Skewness & 1.35 & 1.13 & 1.87 & 0.98 & 0.66 \\
\hline & Kurtosis & 0.73 & 0.87 & 4.86 & 0.18 & -0.81 \\
\hline \multirow{7}{*}{$\begin{array}{c}\text { PXRF } \\
(2 \mathrm{~mm})\end{array}$} & Mean & 2500 & 16000 & 6300 & 1900 & 190 \\
\hline & Minimum & 1700 & 10700 & 3000 & 1600 & 1 \\
\hline & Maximum & 4500 & 25200 & 10500 & 2400 & 670 \\
\hline & Standard Dev & 600 & 3400 & 1900 & 200 & 160 \\
\hline & RSD & 24.00 & 21.25 & 30.16 & 10.53 & 84.21 \\
\hline & Skewness & 1.43 & 1.02 & 0.66 & 0.97 & 1.10 \\
\hline & Kurtosis & 1.05 & 0.69 & -0.22 & 0.03 & 0.78 \\
\hline
\end{tabular}


Table 3.6: Summary statistics for PXRF intensities (cps) for 2 different particle size (new particle size) forage samples $(n=42)$.

\begin{tabular}{clccccccc}
\hline & & \multicolumn{7}{c}{ PXRF intensities (cps) } \\
Method & Statistic & $\mathrm{P}$ & $\mathrm{K}$ & $\mathrm{Ca}$ & $\mathrm{Mg}$ & $\mathrm{Fe}$ & $\mathrm{Cu}$ & $\mathrm{Zn}$ \\
\hline PXRF & Mean & 13400 & 264200 & 130800 & 3300 & 77100 & 52900 & 53400 \\
$(0.25-0.5$ & Minimum & 8900 & 178200 & 87400 & 2900 & 54900 & 48800 & 48600 \\
$\mathrm{~mm})$ & Maximum & 19100 & 393500 & 226700 & 3700 & 111400 & 57800 & 67700 \\
& SD & 2400 & 51700 & 33600 & 200 & 16800 & 2100 & 3200 \\
& RSD & 17.91 & 19.57 & 25.69 & 6.06 & 21.79 & 3.97 & 5.99 \\
& Skewness & 0.59 & 0.81 & 1.36 & 0.33 & 0.43 & 0.40 & 2.20 \\
& Kurtosis & 0.17 & 0.14 & 1.47 & 0.07 & -1.03 & 0.03 & 8.57 \\
& & & & & & & & \\
PXRF (1-2 & Mean & 10800 & 208800 & 86500 & 2900 & 58000 & 43400 & 42200 \\
& Minimum & 7000 & 135800 & 56200 & 2600 & 43900 & 37300 & 36100 \\
& Maximum & 16700 & 345600 & 185300 & 3300 & 95000 & 51000 & 50400 \\
& SD & 2200 & 44800 & 25600 & 200 & 9600 & 3400 & 3700 \\
& RSD & 20.37 & 21.46 & 29.60 & 6.90 & 16.55 & 7.83 & 8.77 \\
& Skewness & 0.95 & 1.07 & 2.03 & 0.64 & 1.33 & 0.41 & 0.48 \\
& Kurtosis & 1.21 & 1.35 & 5.11 & -0.13 & 3.75 & -0.28 & -0.29 \\
\hline
\end{tabular}

Table 3.7: Summary statistics for PXRF determined concentrations ( $\mathrm{mg} / \mathrm{kg}$ ) for two new particle size of forage samples $(n=42)$.

\begin{tabular}{llcccc}
\hline & & \multicolumn{4}{c}{ PXRF determined elemental concentration $(\mathrm{mg} / \mathrm{kg})$} \\
\hline Method & Statistic & $\mathrm{P}$ & $\mathrm{K}$ & $\mathrm{Ca}$ & $\mathrm{Mg}$ \\
\hline \multirow{3}{*}{ PXRF (0.25-0.5 mm) } & & & & \\
& Mean & 2200 & 15800 & 5800 & 2500 \\
& Minimum & 1500 & 10800 & 2600 & 2200 \\
& Maximum & 3800 & 25900 & 12700 & 3300 \\
& Standard Dev & 600 & 3400 & 2000 & 300 \\
& RSD & 27.27 & 21.52 & 34.48 & 12.00 \\
& Skewness & 1.39 & 1.17 & 1.23 & 1.18 \\
& Kurtosis & 1.36 & 1.54 & 2.45 & 0.68 \\
& & & & & \\
& Mean & 1900 & 13100 & 4300 & 2600 \\
& Minimum & 1200 & 8200 & 2300 & 2000 \\
& Maximum & 3500 & 24100 & 10700 & 3300 \\
& Standard Dev & 500 & 3100 & 1400 & 300 \\
& RSD & 26.32 & 23.66 & 32.56 & 11.54 \\
& Skewness & 1.73 & 1.51 & 2.24 & 0.66 \\
& Kurtosis & 2.76 & 3.49 & 9.18 & -0.32 \\
\hline
\end{tabular}


Table 3.8: Matched paired t-test between ICP and PXRF measured concentration $(\mathrm{mg} / \mathrm{kg})$ for for 2-particle size (new particle size) of forage samples $(n=42)$.

\begin{tabular}{ccccc}
\hline Experiment & Element & $\begin{array}{c}\text { Bias } \\
(\mathrm{mg} / \mathrm{kg})\end{array}$ & t-ratio & P value \\
\hline \multirow{3}{*}{ ICP vs PXRF 0.25- } & $\mathrm{P}$ & 52 & 0.97 & 0.334 \\
0.5 mm & $\mathrm{Ca}$ & -1044 & 6.91 & $<0.001$ \\
& $\mathrm{Mg}$ & -750 & 10.48 & $<0.001$ \\
& $\mathrm{P}$ & 275 & -5.08 & $<0.001$ \\
& $\mathrm{~K}$ & 4049 & -13.34 & $<0.001$ \\
ICP vs PXRF 1-2 & $\mathrm{Ca}$ & 452 & -2.67 & 0.01 \\
$\mathrm{~mm}$ & $\mathrm{Mg}$ & -829 & 10.56 & $<0.001$ \\
& & & & \\
& $\mathrm{P}$ & 327 & -9.41 & $<0.001$ \\
PXRF 0.25-0.5 mm & $\mathrm{K}$ & 2640 & -13.94 & $<0.001$ \\
vs PXRF 1-2 mm & $\mathrm{Ca}$ & 1497 & -9.41 & $<0.001$ \\
& $\mathrm{Mg}$ & 79 & 3.16 & 0.003 \\
\hline
\end{tabular}

Table 3.9: Repeated measures ANOVA results for the effect of scan time and particle size on PXRF measured elemental concentration $(n=29)$.

\begin{tabular}{clccc}
\hline Element & \multicolumn{1}{c}{ Effect } & $\begin{array}{c}\text { Degree of } \\
\text { freedom (df) }\end{array}$ & F value & p-value \\
\cline { 2 - 4 } & Particle size & 1 & 5.09 & 0.0373 \\
& Time & 2 & 0.02 & 0.9804 \\
& Particle size*Time & 2 & 0.31 & 0.7368 \\
K & Particle size & 1 & 6.75 & 0.0185 \\
& Time & 2 & 0.92 & 0.4059 \\
& Particle size*Time & 2 & 0.3 & 0.7403 \\
& & & & \\
Ca $\quad$ Particle size & 1 & 3.78 & 0.0101 \\
& Time & 2 & 3.12 & 0.0502 \\
& Particle size*Time & 2 & 4.86 & 0.0694 \\
\hline
\end{tabular}


Figures
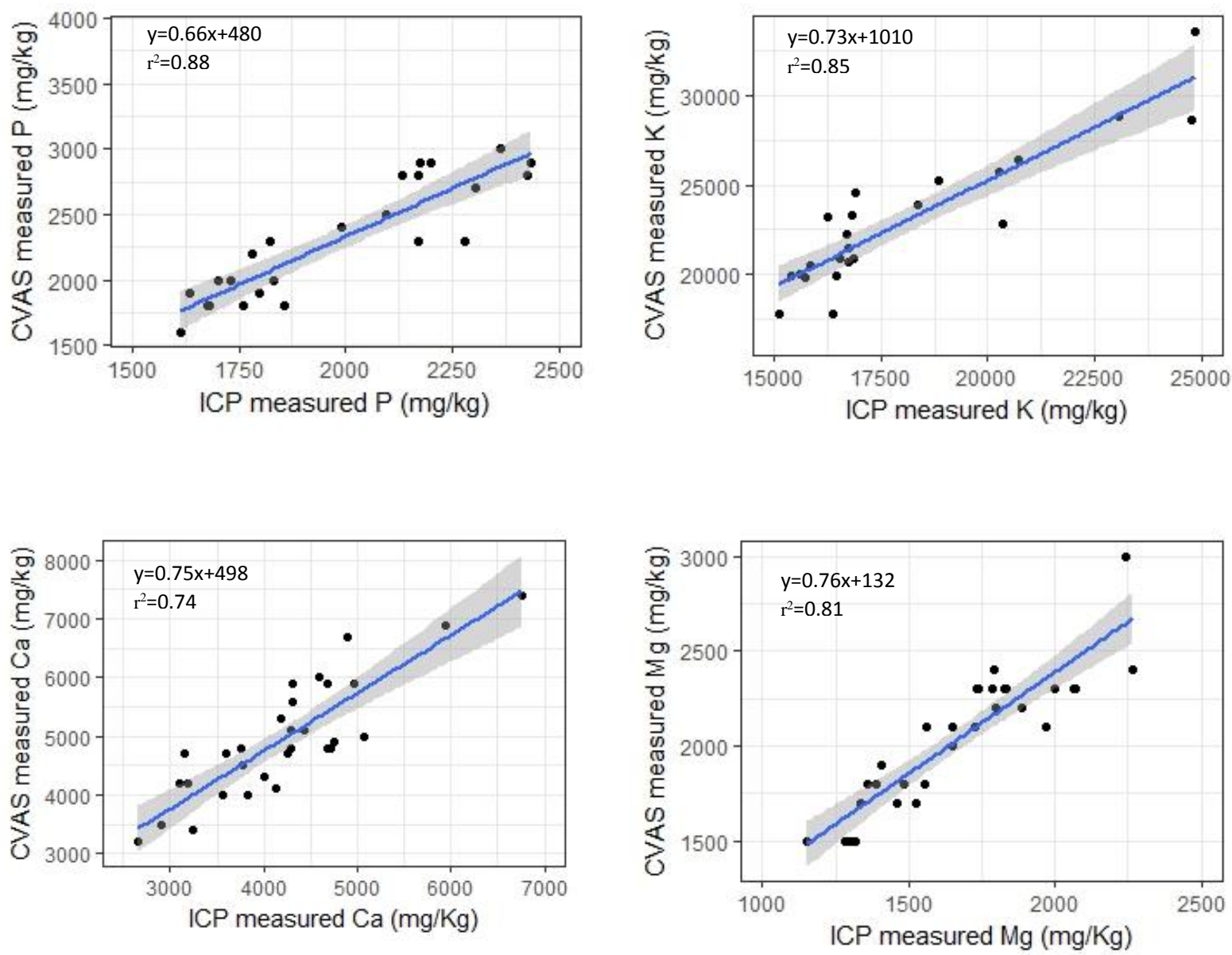

Fig 3.1: Regression plots between ICP and CVAS measured $\mathrm{P}, \mathrm{K}, \mathrm{Ca}$ and $\mathrm{Mg}$. The shaded region shows standard error. 
$0.5 \mathrm{~mm}$ forage samples
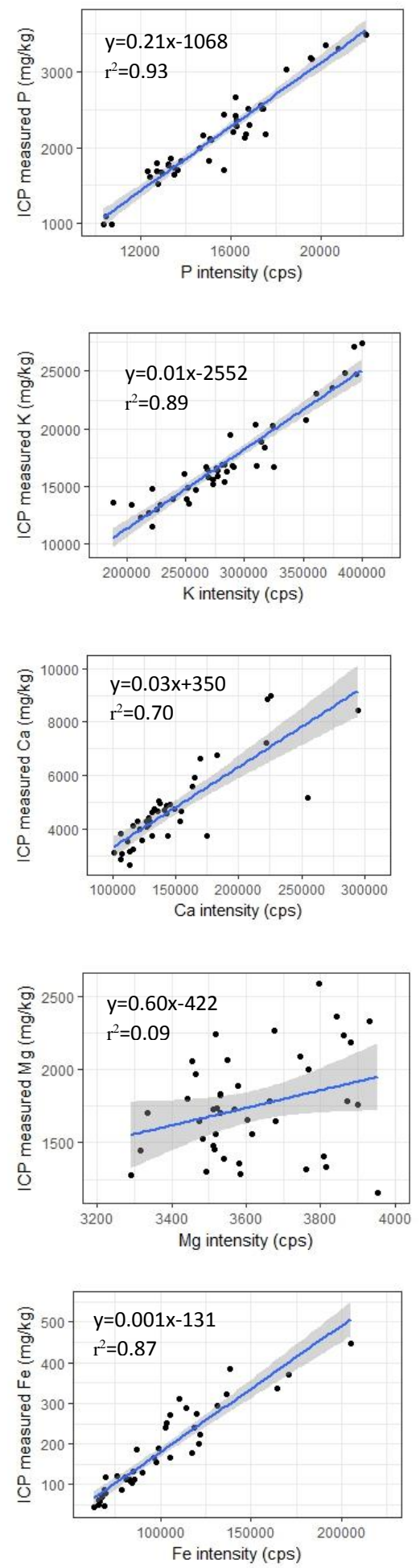

$1 \mathrm{~mm}$ forage samples
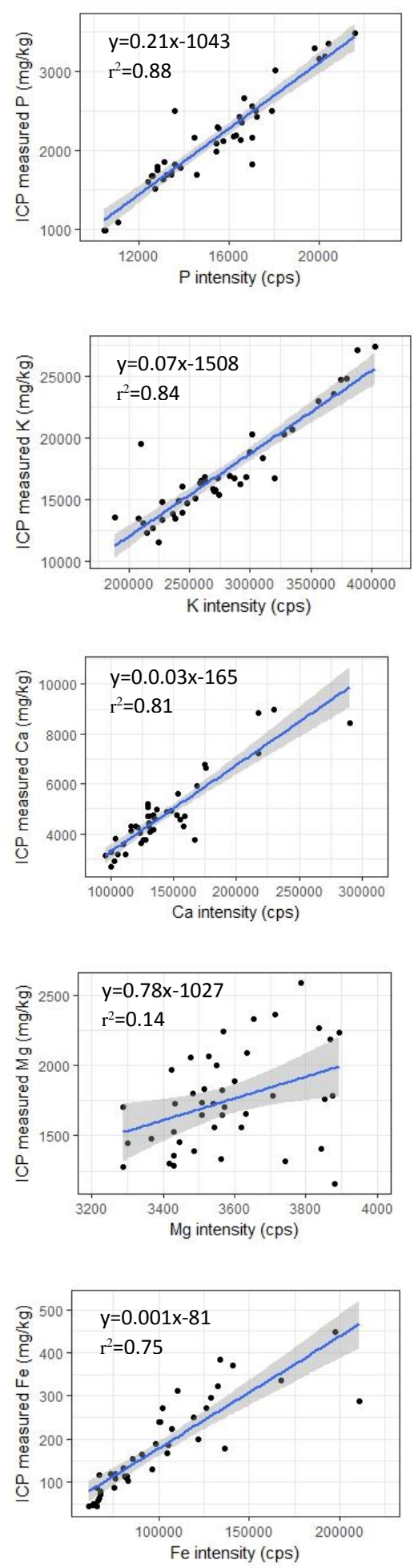

$2 \mathrm{~mm}$ forage samples
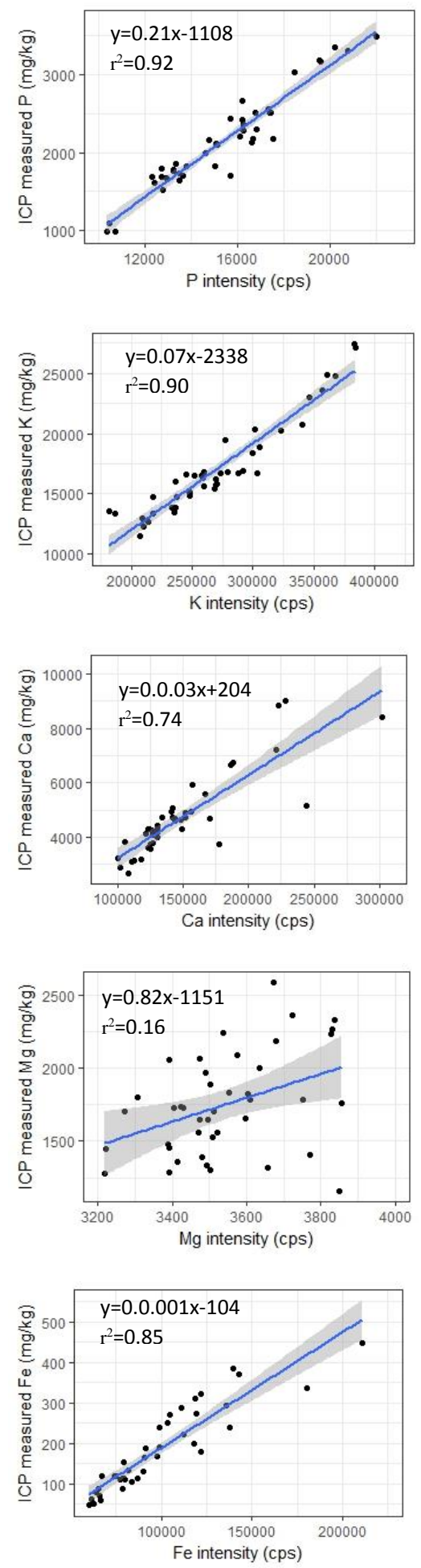

Fig 3.2: Regression plots between ICP measured concentration and PXRF intensity for $P, K, C a$, $\mathrm{Mg}$, and Fe. The shaded portion shows the standard error. 
$0.5 \mathrm{~mm}$ forage samples
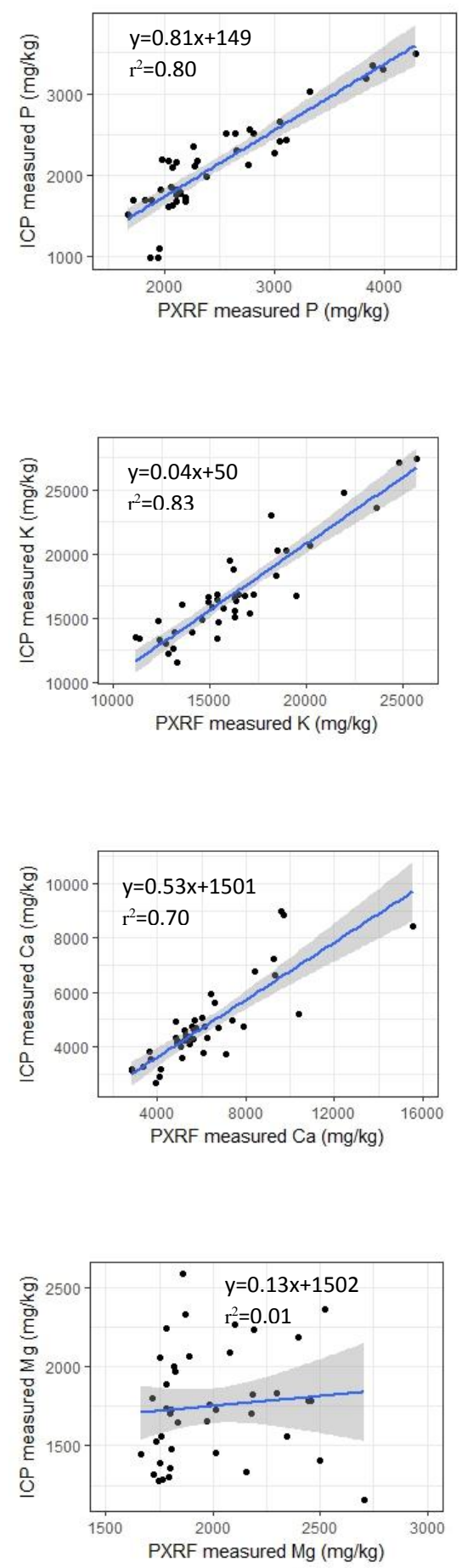

$1 \mathrm{~mm}$ forage samples
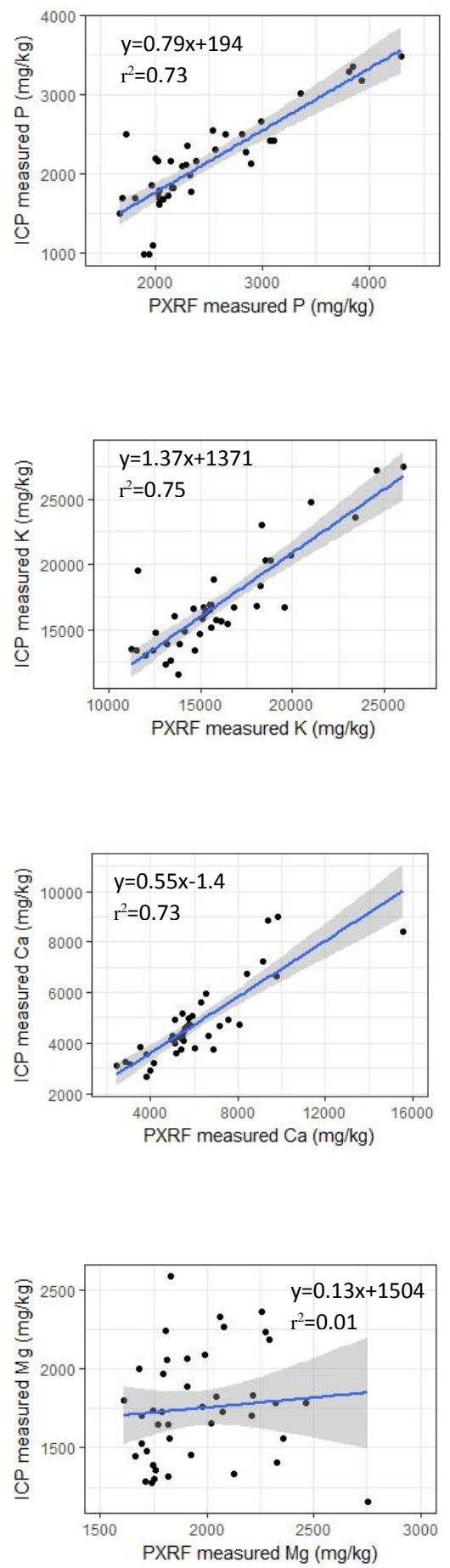

$2 \mathrm{~mm}$ forage samples
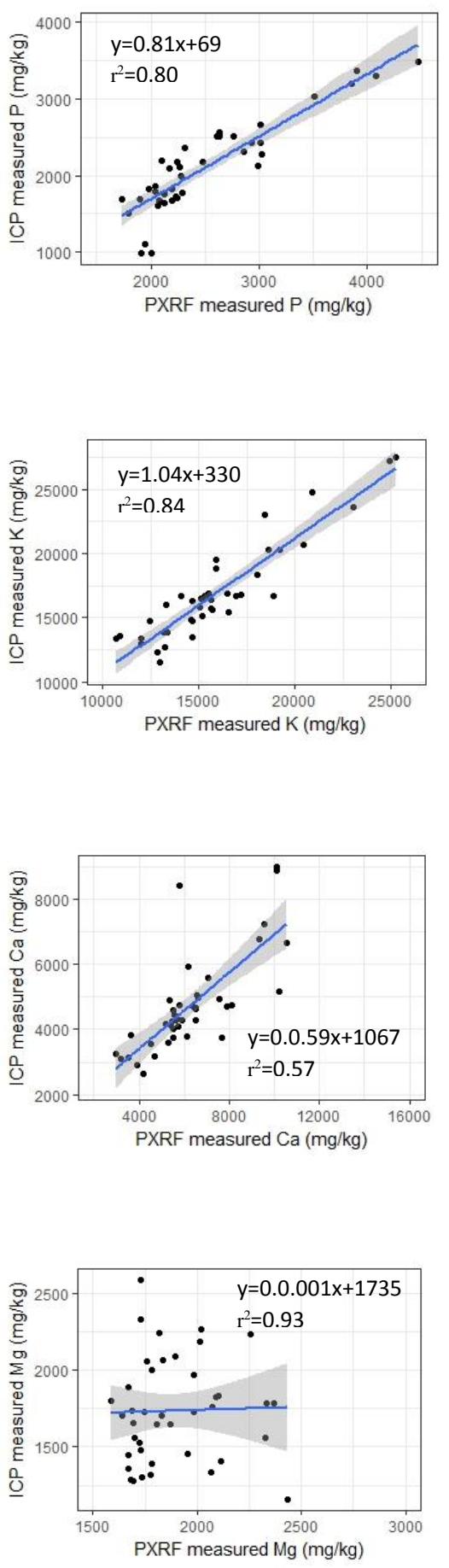

Fig 3.3: Regression plots between ICP measured concentration and PXRF measured concentration for $\mathrm{P}, \mathrm{K}, \mathrm{Ca}$ and $\mathrm{Mg}$. The shaded portion shows the standard error. 


\subsection{5-0.5 mm particle size}
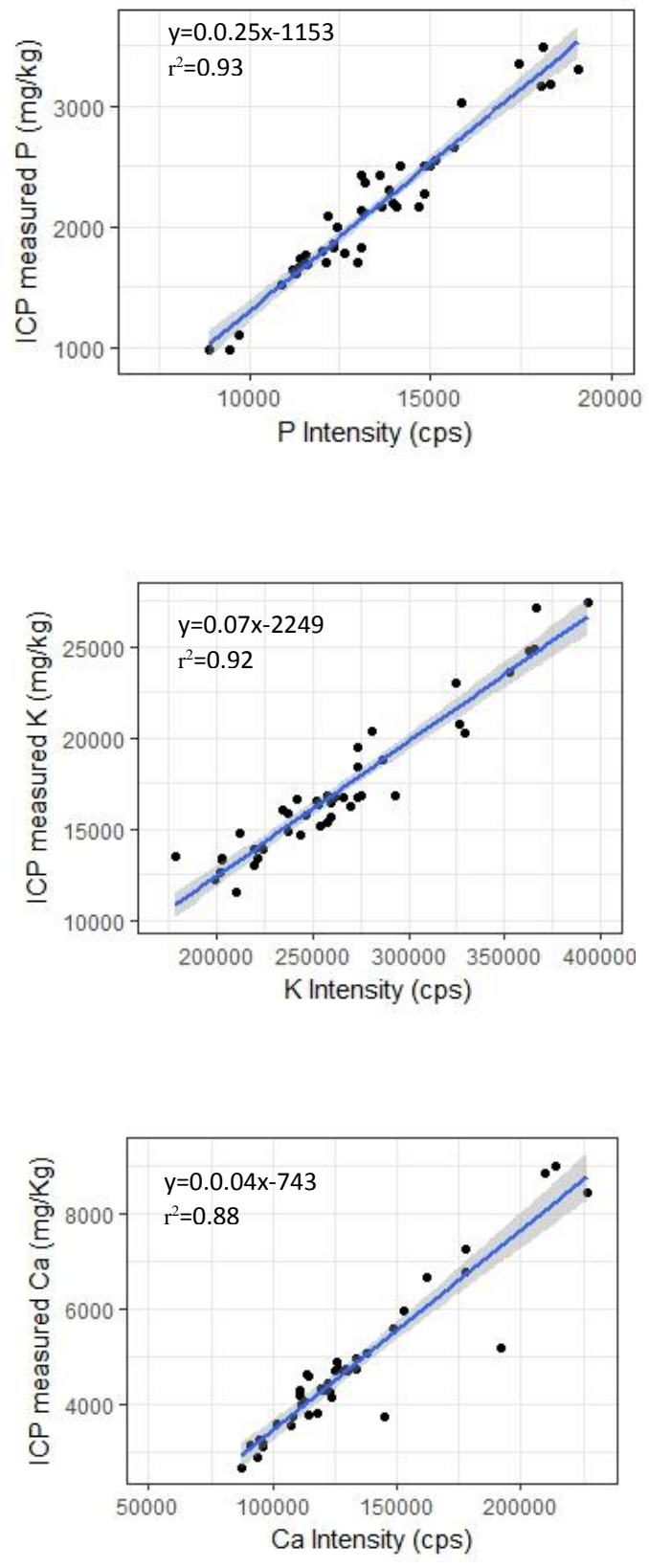

1-2 $\mathrm{mm}$ particle size
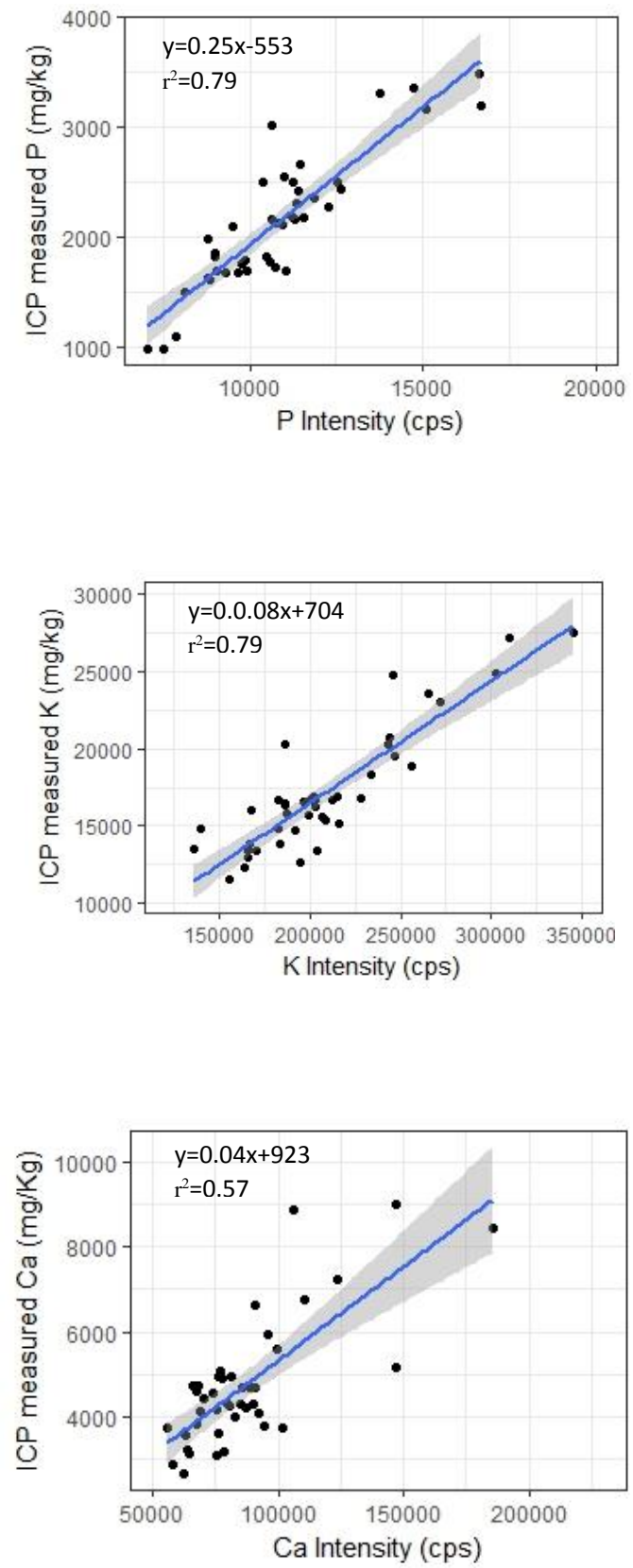

Fig 3.4 (a): Regression plots between ICP measured concentration and PXRF intensity for P, K, and $\mathrm{Ca}$ for two new particle size of forage samples. The shaded portion shows the standard error. 


\subsection{5-0.5 mm particle size}
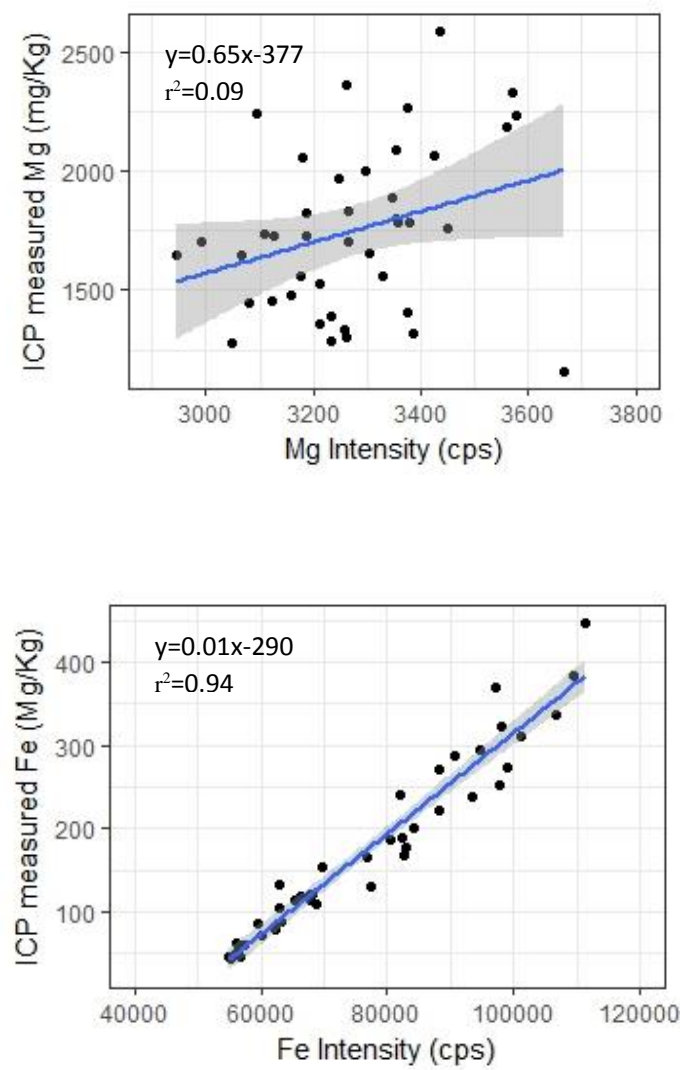

1-2 $\mathrm{mm}$ particle size
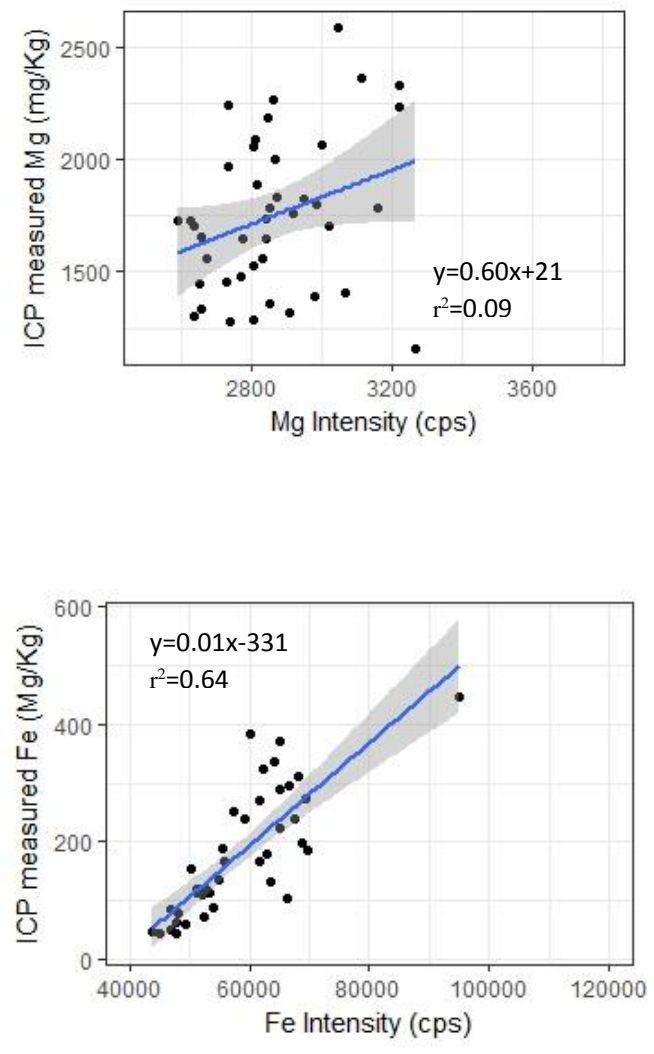

Fig 3.4 (b): Regression plots between ICP measured concentration and PXRF intensity for Mg, Fe and $\mathrm{Zn}$ for two new particle size of forage samples. The shaded portion shows the standard error. 
0.25-0.5 $\mathrm{mm}$ particle size
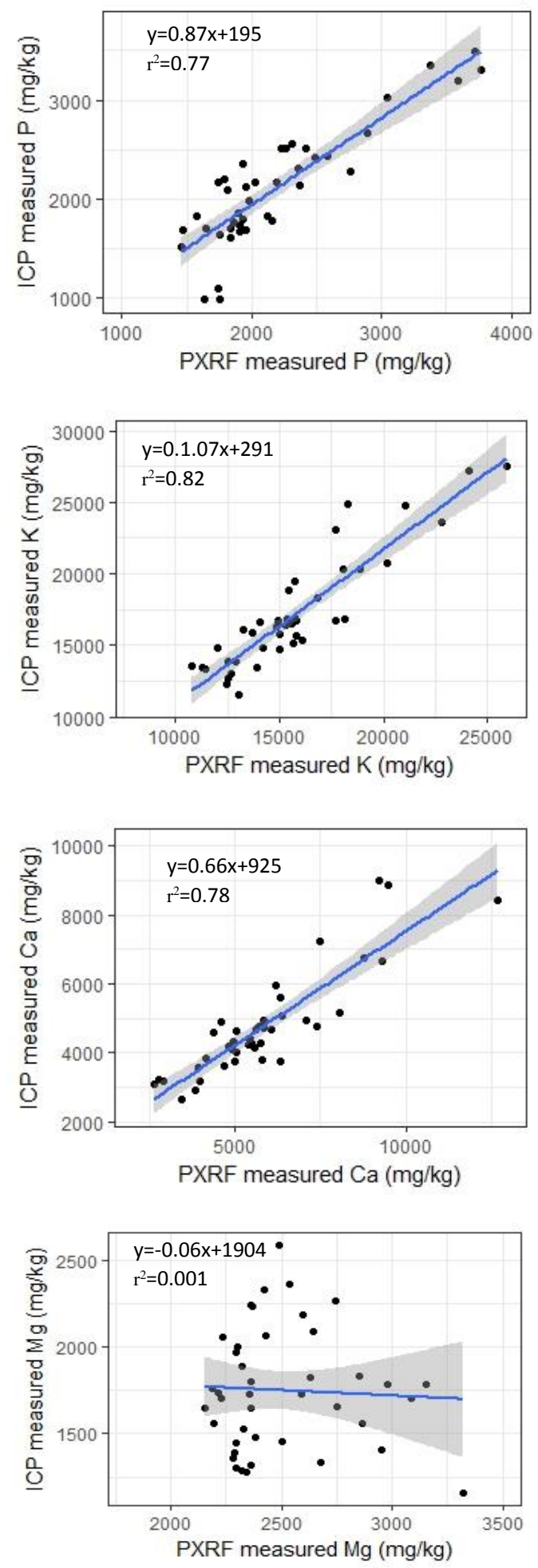

1-2 $\mathrm{mm}$ particle size
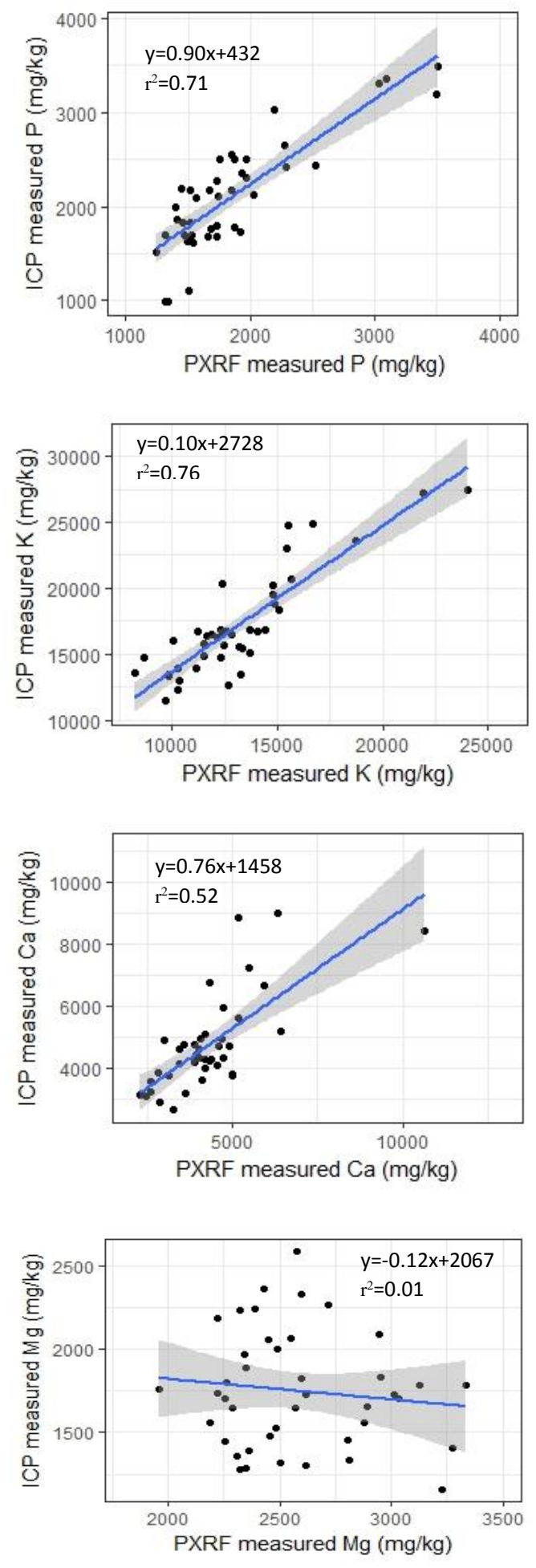

Fig 3.5: Regression plots between ICP and PXRF measured $\mathrm{P}, \mathrm{K}, \mathrm{Ca}, \mathrm{Mg}$ and $\mathrm{Fe}$ concentrations. The shaded region shows confidence interval. 


\section{Chapter 4: Conclusion}

A phosphorus mass balance across animal-based farms could be part of the solution to water quality problems. Comprehensive Nutrient Management Planning (CNMP) does this. The major basis of the CNMP is the $\mathrm{P}$ data from soil and manure. Any cost-effective and rapid $\mathrm{P}$ measurement technique would expedite CNMP planning process at a reduced cost. Accurate data on manure can be obtained using PXRF. The units are equipped with low power X-ray tubes, light and convenient to use either in benchtop or field-analysis modes. They are comparable to wet chemical methods in terms of elemental concentration determination but superior in terms of portability, cost-effectiveness, the simplicity of operation, the potential for in-situ measurement, and analysis of large samples. Moreover, the presence of vacuum facility further improves the measurement of light elements.

Moisture significantly affected the elemental determination in manure samples. The effect is more pronounced in elements like $\mathrm{P}, \mathrm{K}, \mathrm{Mg}$ and less pronounced for $\mathrm{Ca}, \mathrm{Fe}, \mathrm{Cu}$, and $\mathrm{Zn}$. This is because the light elements have lower energy levels. However, elemental concentration in manure samples can be measured, without losing accuracy, up to $20 \%$ moisture. Beyond this moisture correction is advisable especially for elements like P and K. Drying and grinding of the manure samples improved results, however, losing some accuracy PXRF can even be used in wet and unground samples.

Forage is the major feed and source of minerals for animals. The performance and health of the animal are directly influenced by the mineral content of the forages. Thus, mineral composition date in forage is the most important part of the animal feeding plan. The mineral composition data can be quickly obtained with PXRF at a reduced cost. The scan time did not affect the result indicating the potentiality of getting a result even faster. The particle size of the sample affects the result, however, compromising some accuracy, it can be used for larger particle size of the samples. To obtain better result drying and grounding of the sample is recommended, which would still be cheaper and quicker than wet chemical analysis. 
This simplification of mineral determination techniques can contribute to better whole-farm $\mathrm{P}$ management and CNMP development. This will reduce the costs of forage and manure mineral analysis. Knowing forage mineral composition will ultimately increases the efficiency of animal feeding. In addition, this tool will be helpful in price determination of dried hay bales in forage markets. Likewise, the manure composition data at low cost will help farmers plan manure applications to their fields in ways to obtain maximum use efficiency and minimize runoff to water bodies, thus reducing environmental hazards. Nevertheless, this will be a great tool for researchers working in animal feeding management, manure management, and forage breeding activities. This work demonstrated that with the right sample preparation PXRF can obtain results comparable to digestion and ICP. Further study is warranted to extend this analysis to in-the-field measurements. 
Appendix:

Appendix 1: Regression between ICP and WVDA determined elemental concentrations $(\mathrm{mg} / \mathrm{kg})$ in manure samples $(\mathrm{n}=40)$.

\begin{tabular}{cccccc}
\hline Element & $\mathrm{r}^{2}$ & RMSE & Intercept & Slope & $\mathrm{p}$-value \\
\hline $\mathrm{P}$ & 0.98 & 528 & 50.76 & 0.96 & $<0.001$ \\
$\mathrm{~K}$ & 0.92 & 2570 & 1398 & 0.91 & $<0.001$ \\
$\mathrm{Ca}$ & 0.97 & 2481 & -1699 & 0.98 & $<0.001$ \\
$\mathrm{Mg}$ & 0.91 & 418 & 65.68 & 0.96 & $<0.001$ \\
$\mathrm{Cu}$ & 0.99 & 76 & -15.44 & 1.01 & $<0.001$ \\
\hline
\end{tabular}

Appendix 2: Regression between ICP determined concentration $(\mathrm{mg} / \mathrm{kg})$ and PXRF intensities (cps) for oven dried manure samples $(n=40)$.

\begin{tabular}{lccccc} 
Element & $\mathrm{r}^{2}$ & RMSE & Intercept & Slope & $\mathrm{p}$-value \\
\hline $\mathrm{P}$ & 0.94 & 916 & -2347 & 0.28 & $<0.001$ \\
$\mathrm{~K}$ & 0.92 & 2740 & -4770 & 0.10 & $<0.001$ \\
$\mathrm{Ca}$ & 0.93 & 3817 & -3576 & 0.07 & $<0.001$ \\
$\mathrm{Mg}$ & 0.59 & 909 & -6245 & 2.44 & $<0.001$ \\
$\mathrm{Fe}$ & 0.93 & 735 & -868 & 0.01 & $<0.001$ \\
$\mathrm{Cu}$ & 0.93 & 166 & -484 & 0.01 & $<0.001$ \\
$\mathrm{Zn}$ & 0.56 & 72 & -188 & 0.01 & $<0.001$ \\
\hline
\end{tabular}

Appendix 3: Regression between ICP and PXRF measured concentration $(\mathrm{mg} / \mathrm{kg})$ for oven dried manure samples $(n=40)$.

\begin{tabular}{lccccc}
\hline Element & $\mathrm{r}^{2}$ & RMSE & Intercept & Slope & $\mathrm{p}$-value \\
\hline $\mathrm{P}$ & 0.66 & 2117 & -1138 & 1.42 & $<0.001$ \\
$\mathrm{~K}$ & 0.83 & 3956 & -4830 & 1.72 & $<0.001$ \\
$\mathrm{Ca}$ & 0.89 & 4755 & 4793 & 1.05 & $<0.001$ \\
$\mathrm{Mg}$ & 0.25 & 1232 & 4490 & 0.29 & $<0.001$ \\
$\mathrm{Fe}$ & 0.86 & 1040 & 413 & 2.05 & $<0.001$ \\
\hline
\end{tabular}


Appendix 4: Regression between ICP and CVAS determined elemental concentrations $(\mathrm{mg} / \mathrm{kg})$ in forage samples $(\mathrm{n}=42)$.

\begin{tabular}{cccccc}
\hline Elements & $\mathrm{r}^{2}$ & RMSE & Intercept & Slope & P-value \\
\hline $\mathrm{P}$ & 0.88 & 142.30 & 479.85 & 0.66 & $<0.001$ \\
$\mathrm{~K}$ & 0.85 & 1225.00 & 1010.00 & 0.73 & $<0.001$ \\
$\mathrm{Ca}$ & 0.74 & 456.20 & 498.23 & 0.75 & $<0.001$ \\
$\mathrm{Mg}$ & 0.81 & 131.90 & 131.52 & 0.76 & $<0.001$ \\
$\mathrm{Fe}$ & 0.09 & 75.63 & 108.05 & 0.11 & 0.10 \\
$\mathrm{Cu}$ & 0.04 & 2.44 & 8.72 & 0.25 & 0.32 \\
$\mathrm{Zn}$ & 0.001 & 31.46 & 34.26 & 0.26 & 0.85 \\
\hline
\end{tabular}

Appendix 5: Regression between ICP-OES determined concentration $(\mathrm{mg} / \mathrm{kg})$ and PXRF intensities (cps) for 3 different particle size of forage samples $(n=42)$.

\begin{tabular}{ccccccc}
\hline Experiment & Element & $\mathrm{r}^{2}$ & RMSE & Intercept & Slope & P-value \\
\hline ICP-OES and PXRF & $\mathrm{P}$ & 0.93 & 168 & -1068 & 0.21 & $<0.001$ \\
intensities of 0.5 & $\mathrm{K}$ & 0.89 & 1319 & -2552 & 0.00 & $<0.001$ \\
mm forage & $\mathrm{Ca}$ & 0.70 & 829 & 350 & 0.03 & $<0.001$ \\
samples & $\mathrm{Mg}$ & 0.09 & 337 & -422 & 0.60 & 0.06 \\
& $\mathrm{Fe}$ & 0.87 & 38 & -131 & 0.00 & $<0.001$ \\
& $\mathrm{Cu}$ & 0.05 & 3 & 29 & 0.00 & 0.15 \\
& $\mathrm{Zn}$ & 0.47 & 19 & -338 & 0.01 & $<0.001$ \\
& & & & & & \\
ICP-OES and PXRF & $\mathrm{P}$ & 0.88 & 217 & -1043 & 0.21 & $<0.001$ \\
intensities of & $\mathrm{K}$ & 0.84 & 1622 & -1508 & 0.07 & $<0.001$ \\
1mm forage & $\mathrm{Ca}$ & 0.81 & 653 & -165 & 0.03 & $<0.001$ \\
samples & $\mathrm{Mg}$ & 0.14 & 327 & -1027 & 0.78 & 0.01 \\
& $\mathrm{Fe}$ & 0.75 & 53 & -81 & 0.00 & $<0.001$ \\
& $\mathrm{Cu}$ & 0.01 & 3 & 20 & 0.00 & 0.53 \\
& $\mathrm{Zn}$ & 0.25 & 23 & -319 & 0.01 & $<0.001$ \\
& & & & & & \\
ICP-OES and PXRF & $\mathrm{P}$ & 0.92 & 176 & -1108 & 0.21 & $<0.001$ \\
intensities of 2 & $\mathrm{K}$ & 0.90 & 1277 & -2338 & 0.07 & $<0.001$ \\
mm forage & $\mathrm{Ca}$ & 0.74 & 769 & 204 & 0.03 & $<0.001$ \\
samples & $\mathrm{Mg}$ & 0.16 & 325 & -1151 & 0.82 & 0.009 \\
& $\mathrm{Fe}$ & 0.85 & 42 & -104 & 0.00 & $<0.001$ \\
& $\mathrm{Cu}$ & 0.02 & 2.55 & 20 & 0.001 & 0.42 \\
& $\mathrm{Zn}$ & 0.23 & 23 & -244 & 0.01 & 0.009 \\
\hline
\end{tabular}


Appendix 6: Regression between ICP and PXRF concentration $(\mathrm{mg} / \mathrm{kg})$ for 3 different particle size of forage samples $(n=42)$.

\begin{tabular}{ccccccc}
\hline Experiment & Elements & $\mathrm{r}^{2}$ & RMSE & Intercept & Slope & P value \\
\hline ICP-OES and PXRF & $\mathrm{P}$ & 0.80 & 321 & 149 & 0.81 & $<0.001$ \\
concentrations of 0.5 & $\mathrm{K}$ & 0.83 & 1584 & 50 & 1.04 & $<0.001$ \\
mm forage samples & $\mathrm{Ca}$ & 0.70 & 836 & 1501 & 0.53 & $<0.001$ \\
& $\mathrm{Mg}$ & 0.01 & 352 & 1502 & 0.13 & 0.54 \\
& & & & & & \\
ICP-OES and PXRF & $\mathrm{P}$ & 0.73 & 308 & 194 & 0.79 & $<0.001$ \\
$\begin{array}{c}\text { concentrations of 1mm } \\
\text { forage samples }\end{array}$ & $\mathrm{K}$ & 0.75 & 1905 & 1371 & 1.37 & $<0.001$ \\
& $\mathrm{Ca}$ & 0.73 & 789 & 1.4 & 0.55 & $<0.001$ \\
& $\mathrm{Mg}$ & 0.01 & 352 & 1504 & 0.13 & 0.55 \\
ICP-OES and PXRF & $\mathrm{P}$ & 0.80 & 266 & 69 & 0.81 & $<0.001$ \\
concentrations of 2 & $\mathrm{K}$ & 0.84 & 1505 & 330 & 1.04 & $<0.001$ \\
mm forage samples & $\mathrm{Ca}$ & 0.57 & 997 & 1067 & 0.59 & $<0.001$ \\
& $\mathrm{Mg}$ & 0.08 & 400 & 1735 & 0.00 & 0.08 \\
\hline
\end{tabular}

Appendix 7: Regression between ICP determined concentration $(\mathrm{mg} / \mathrm{kg})$ and PXRF intensities (cps) for two new particle size of forage samples $(n=42)$.

\begin{tabular}{lcccccc}
\hline Experiment & Element & $\mathrm{r}^{2}$ & RMSE & Intercept & Slope & P value \\
\hline ICP Vs 0.25-0.5 mm & $\mathrm{P}$ & 0.93 & 163.70 & -1153.00 & 0.25 & $<0.001$ \\
& $\mathrm{~K}$ & 0.92 & 1159.00 & -2249.00 & 0.07 & $<0.001$ \\
& $\mathrm{Ca}$ & 0.88 & 519.60 & -743.00 & 0.04 & $<0.001$ \\
& $\mathrm{Mg}$ & 0.09 & 337.30 & -376.91 & 0.65 & 0.055 \\
& $\mathrm{Fe}$ & 0.94 & 26.75 & -290.40 & 0.01 & $<0.001$ \\
& $\mathrm{Cu}$ & 0.03 & 2.53 & -0.05 & 0.00 & 0.273 \\
& $\mathrm{Zn}$ & 0.58 & 17.22 & -289.80 & 0.01 & $<0.00$ \\
& & & & & \\
$\mathrm{ICP}$ Vs 1-2 mm & $\mathrm{P}$ & 0.79 & 281.00 & -552.88 & 0.25 & $<0.001$ \\
& $\mathrm{~K}$ & 0.79 & 1828.00 & 703.70 & 0.08 & $<0.001$ \\
& $\mathrm{Ca}$ & 0.57 & 994.10 & 923.40 & 0.04 & $<0.001$ \\
& $\mathrm{Mg}$ & 0.09 & 337.00 & 20.63 & 0.60 & $<0.001$ \\
& $\mathrm{Fe}$ & 0.64 & 63.70 & -330.60 & 0.01 & $<0.001$ \\
& $\mathrm{Cu}$ & 0.01 & 2.57 & 12.07 & 0.00 & 0.852 \\
& $\mathrm{Zn}$ & 0.01 & 26.50 & 19.91 & 0.00 & 0.642 \\
\hline
\end{tabular}


Appendix 8: Regression between ICP and PXRF concentration $(\mathrm{mg} / \mathrm{kg})$ for 2-particle size (new particle size) of forage samples ( $n=42)$.

\begin{tabular}{ccccccc}
\hline Method & Element & $\mathrm{r}^{2}$ & RMSE & Intercept & Slope & p-value \\
\hline PXRF & $\mathrm{P}$ & 0.77 & 289.00 & 195.18 & 0.87 & $<0.001$ \\
$(0.25-0.5$ & $\mathrm{K}$ & 0.82 & 1688.00 & 290.90 & 1.07 & $<0.001$ \\
$\mathrm{~mm})$ & $\mathrm{Ca}$ & 0.78 & 710.50 & 924.80 & 0.66 & $<0.001$ \\
& $\mathrm{Mg}$ & 0.001 & 353.00 & 1904.07 & -0.06 & 0.7497 \\
& & & & & & \\
PXRF (1-2 & $\mathrm{P}$ & 0.71 & 322.90 & 431.75 & 0.90 & $<0.001$ \\
$\mathrm{~mm})$ & $\mathrm{K}$ & 0.76 & 1965.00 & 2728.00 & 1.10 & $<0.001$ \\
& $\mathrm{Ca}$ & 0.52 & 1458.10 & 1458.10 & 0.76 & $<0.001$ \\
& $\mathrm{Mg}$ & 0.01 & 351.00 & 2068.61 & -0.12 & 0.4607 \\
\hline
\end{tabular}


Appendix 9: WVDA, ICP, and PXRF measured P concentration $(\mathrm{mg} / \mathrm{kg})$ and PXRF intensity of $P$ (cps) in manure samples at different moisture level.

\begin{tabular}{|c|c|c|c|c|c|c|c|c|c|c|c|c|}
\hline S.No & $\begin{array}{c}\text { P conc } \\
M \\
\text { WVDA }\end{array}$ & $\begin{array}{c}P \\
\text { conc } \\
\text { M ICP }\end{array}$ & $\begin{array}{c}P \\
\text { conc } \\
M \\
<10\end{array}$ & $\begin{array}{c}P \\
\text { conc } \\
M 10- \\
20\end{array}$ & $\begin{array}{c}P \\
\text { conc } \\
\text { M 20- } \\
30\end{array}$ & $\begin{array}{c}\mathrm{P} \\
\text { conc } \\
\mathrm{M} 40- \\
50\end{array}$ & $\begin{array}{c}\mathrm{P} \\
\text { conc } \\
\mathrm{M} 60- \\
70\end{array}$ & $\begin{array}{l}P \text { Int } \\
M \\
<10\end{array}$ & $\begin{array}{c}\text { P Int } \\
\text { M 10- } \\
20\end{array}$ & $\begin{array}{c}\mathrm{P} \text { Int } \\
\mathrm{M} 20- \\
30\end{array}$ & $\begin{array}{c}P \text { Int } \\
\text { M 40- } \\
50\end{array}$ & $\begin{array}{c}P \text { Int } \\
M 60- \\
70\end{array}$ \\
\hline 1 & 9592 & 11711 & 8422 & 7655 & 6273 & 5455 & 4475 & 47662 & 43248 & 36371 & 30090 & 25492 \\
\hline 2 & 8712 & 8866 & 6806 & 5792 & 4820 & 4352 & 3351 & 36579 & 28392 & 24525 & 22417 & 18125 \\
\hline 3 & 6556 & 6477 & 6820 & 5890 & 5023 & 4269 & 3431 & 33645 & 28558 & 25866 & 21464 & 18036 \\
\hline 4 & 9240 & 8576 & 7601 & 7067 & 5984 & 5490 & 3098 & 38039 & 34048 & 31132 & 28493 & 17558 \\
\hline 5 & 3872 & 3738 & 4328 & 4686 & 3103 & 2115 & 2120 & 23671 & 23488 & 17876 & 7009 & 11992 \\
\hline 6 & 7436 & 7322 & 6317 & 6062 & 5312 & 4605 & 2140 & 32318 & 30700 & 27011 & 23685 & 13014 \\
\hline 7 & 8536 & 8364 & 8135 & 8250 & 8250 & 6938 & 6896 & 35939 & 35844 & 35844 & 30514 & 31728 \\
\hline 8 & 12012 & 11156 & 8941 & 9212 & 5413 & 4947 & 4205 & 52706 & 56136 & 33031 & 29368 & 25210 \\
\hline 9 & 3560 & 3764 & 3575 & 3080 & 2641 & 2617 & 2074 & 21653 & 18248 & 15796 & 14837 & 12355 \\
\hline 10 & 6160 & 6178 & 3408 & 2792 & 2588 & 2529 & 1886 & 27919 & 20791 & 17864 & 16698 & 13521 \\
\hline 11 & 5368 & 5352 & 4892 & 4049 & 33 & 2937 & 2593 & 27451 & 24361 & 21039 & 17043 & 15524 \\
\hline 12 & 4180 & 4265 & 3521 & 2805 & 2153 & 2497 & 3097 & 22027 & 19407 & 7941 & 15273 & 16608 \\
\hline 13 & 6952 & 7635 & 3544 & 3262 & 2296 & 2764 & 1387 & 29008 & 23065 & 10515 & 17077 & 11502 \\
\hline 14 & 4796 & 4787 & 2723 & 2446 & 2499 & 2214 & 2629 & 24259 & 21042 & 20870 & 15211 & 20239 \\
\hline 15 & 4752 & 5113 & 3515 & 3577 & 3031 & 2685 & 1871 & 23242 & 22352 & 18115 & 15774 & 13536 \\
\hline 16 & 6732 & 6089 & 4527 & 4121 & & & 2955 & 30245 & & 23429 & & 15782 \\
\hline 17 & 4664 & 4478 & 3103 & 2522 & 2 & 247 & 2265 & 22738 & 19968 & 17145 & 16305 & 575 \\
\hline 18 & 4400 & 4273 & 4259 & 3586 & 2970 & 2752 & 2254 & 22499 & 18646 & 16826 & 15291 & 12959 \\
\hline 19 & 5632 & 6813 & 4175 & 3450 & 3063 & 2452 & 2596 & 30200 & 23237 & 19609 & 15265 & 13453 \\
\hline 20 & 2957 & 3137 & 3182 & 3816 & 3367 & 2951 & 2447 & 16334 & 18596 & 16712 & 15302 & 14255 \\
\hline 21 & 4162 & 4204 & 3760 & 3364 & 2995 & 2488 & 2800 & 20366 & 18022 & 16216 & 13770 & 14796 \\
\hline 22 & 4972 & 5055 & 5432 & 5348 & 4422 & 3786 & 2570 & 29152 & 28152 & 23806 & 20146 & 14706 \\
\hline 23 & 4708 & 4657 & 4702 & 3838 & 2733 & 2829 & 2135 & 28729 & 26099 & 10147 & 17082 & 13361 \\
\hline 24 & 3969 & 3905 & 4831 & 4140 & 3455 & 3230 & 2529 & 24745 & 21657 & 18574 & 17251 & 13214 \\
\hline 25 & 6380 & 6693 & 3618 & 2839 & 2752 & 2736 & 2659 & 31617 & 23839 & 20192 & 18818 & 16305 \\
\hline 26 & 4132 & 4320 & 6756 & 6352 & 4892 & 4416 & 3298 & 30466 & 28524 & 23516 & 21884 & 17641 \\
\hline 27 & 4013 & 3985 & 5445 & 4915 & 3767 & 3112 & 2539 & 25649 & 22593 & 18853 & 16039 & 13581 \\
\hline 28 & 4057 & 1903 & 5221 & 4613 & & & 32 & 27582 & 24321 & 12518 & 58 & 17948 \\
\hline 29 & 3428 & 4140 & 4713 & 3884 & 2991 & 2667 & 2134 & 25050 & 19698 & 8965 & 14286 & 12062 \\
\hline 30 & 4202 & 4260 & 4787 & 5819 & 4193 & 3549 & 2706 & 25790 & 31488 & 22622 & 18740 & 16014 \\
\hline 31 & 9504 & 10529 & 10014 & 8959 & 7566 & 6092 & 4601 & 45373 & 39746 & 34901 & 28753 & 22731 \\
\hline 32 & 8536 & 8399 & 6262 & 4734 & 3924 & 3679 & 3592 & 41058 & 32214 & 25045 & 21931 & 19702 \\
\hline 33 & 6644 & 6972 & 6954 & 5250 & 3991 & 3141 & 2657 & 36093 & 27143 & 21527 & 17288 & 15657 \\
\hline 34 & 2064 & 2246 & 3734 & 3315 & 3362 & 2465 & 1798 & 18640 & 16472 & 16936 & 13043 & 10190 \\
\hline 35 & 5500 & 5766 & 4808 & 4908 & 4157 & 3751 & 2536 & 28791 & 27170 & 22223 & 18988 & 14927 \\
\hline 36 & 7172 & 7931 & 6207 & 4185 & 3721 & 3551 & 3180 & 39948 & 25044 & 21481 & 19621 & 18288 \\
\hline 37 & 10956 & 11218 & 8123 & 7126 & 4987 & 4886 & 3663 & 52509 & 45419 & 27480 & 26045 & 21353 \\
\hline 38 & 10296 & 10750 & 7811 & 6361 & 5621 & 5030 & 4063 & 53661 & 43703 & 37014 & 28666 & 23640 \\
\hline 39 & 21560 & 21921 & 10557 & 8436 & 6323 & 6849 & 4423 & 78724 & 67751 & 38782 & 42148 & 27385 \\
\hline 40 & 11660 & 12800 & 9015 & 6735 & 5811 & 5426 & 3550 & 44501 & 34768 & 29953 & 19944 & 19944 \\
\hline
\end{tabular}


Appendix 10: WVDA, ICP, and PXRF measured $K$ concentration $(\mathrm{mg} / \mathrm{kg})$ and PXRF intensity of $K$ (cps) in manure samples at different moisture level.

\begin{tabular}{|c|c|c|c|c|c|c|c|c|c|c|c|c|}
\hline S.No & $\begin{array}{c}\mathrm{K} \text { conc } \\
\mathrm{M} \\
\text { WVDA }\end{array}$ & $\begin{array}{c}\mathrm{K} \\
\text { conc } \\
\mathrm{M} \text { ICP }\end{array}$ & $\begin{array}{c}\mathrm{K} \\
\text { conc } \\
\mathrm{M} \\
<10\end{array}$ & $\begin{array}{c}\mathrm{K} \text { conc } \\
\mathrm{M} 10- \\
20\end{array}$ & $\begin{array}{c}K \text { conc } \\
\text { M 20- } \\
30\end{array}$ & $\begin{array}{c}\mathrm{K} \\
\text { conc } \\
\mathrm{M} 40- \\
50\end{array}$ & $\begin{array}{c}\text { K conc } \\
\text { M } 60- \\
70\end{array}$ & $\begin{array}{c}\mathrm{K} \operatorname{Int} \mathrm{M} \\
<10\end{array}$ & $\begin{array}{c}K \operatorname{Int} M \\
10-20\end{array}$ & $\begin{array}{c}K \operatorname{Int~M} \\
20-30\end{array}$ & $\begin{array}{c}K \operatorname{Int~M} \\
40-50\end{array}$ & $\begin{array}{c}K \operatorname{Int} M \\
60-70\end{array}$ \\
\hline 1 & 16019 & 9189 & 14633 & 14219 & 10446 & 7032 & 5942 & 50024 & 241034 & 192119 & 143466 & 128342 \\
\hline 2 & 21331 & 3659 & 15387 & 12783 & 524 & 7870 & 5962 & 248616 & 195504 & 161104 & 142451 & 120796 \\
\hline 3 & 11869 & 1958 & 10204 & 9287 & 5130 & 4629 & 4013 & 171445 & 155767 & 123236 & 102055 & 97735 \\
\hline 4 & 331 & 20952 & 15671 & 14209 & 10286 & 7886 & 59 & 246860 & 217442 & 178935 & 149771 & 125817 \\
\hline 5 & & 12177 & 12297 & 96 & & 2931 & 24 & 208867 & 161503 & 88610 & 50366 & 65691 \\
\hline 6 & 18841 & 9424 & 14293 & 130 & 45 & 7721 & 005 & 224523 & 204349 & 169931 & 140805 & 114893 \\
\hline 7 & 15687 & 988 & 12351 & 123 & 9 & 1118 & 195 & 307 & 070 & 070 & 62204 & 167299 \\
\hline 8 & 106 & 478 & 11389 & $12 C$ & 64 & 5340 & 72 & 44 & 1776 & 418 & 72 & 99494 \\
\hline 9 & 18758 & 3209 & 15151 & 122 & 43 & 6980 & 332 & 828 & 105 & 977 & 35187 & 121025 \\
\hline 10 & 34279 & 542 & 19888 & 18120 & 14496 & 12365 & 8660 & 400016 & 328632 & 254230 & 21198 & 175853 \\
\hline 11 & 20169 & 3863 & 16997 & 1589 & 10288 & 7025 & 719 & 281484 & 266246 & 193747 & 142136 & 150785 \\
\hline 12 & & & 20180 & & & 10114 & 119 & & & & & \\
\hline 13 & & 9 & 1656 & & & 10847 & & 38 & & 20 & 47 & 375 \\
\hline 14 & 3 & 053 & 19302 & 172 & 4 & 10974 & 1 & 31 & 32 & 69 & 15 & 69 \\
\hline 15 & 24153 & 936 & 15583 & 13526 & 2 & 8004 & 442 & 30 & 65 & 25 & 45 & 82 \\
\hline 16 & 24900 & 834 & 15600 & 135 & 37 & 7573 & 6393 & 357 & 20930 & 5985 & 23847 & 068 \\
\hline 17 & 29465 & 9920 & 17494 & 172 & 55 & 10805 & 890 & 19915 & 320943 & 38771 & 98794 & 169758 \\
\hline 18 & 35275 & 33776 & 26185 & & & 12421 & & & & & & \\
\hline 19 & & & 19976 & & & 12264 & & & & & 17 & \\
\hline 20 & & & 13485 & & & 8 & & & & & & \\
\hline 21 & 2 & 665 & 18470 & & 9 & 967 & 9 & 286386 & 994 & 59 & 16 & 556 \\
\hline 22 & 13363 & 445 & 11940 & 117 & & 656 & 3 & 197050 & 92743 & 03 & 27846 & 22 \\
\hline 23 & 16351 & 14994 & 13839 & 1362 & 889 & 5736 & 4221 & 243591 & 243490 & 34747 & 120067 & 104818 \\
\hline 24 & 11122 & 10251 & 10550 & 93 & 590 & 4235 & 2669 & 173420 & 152098 & 13350 & 96118 & 79389 \\
\hline 25 & 23406 & 24358 & 14313 & 13223 & 0103 & 8563 & 5541 & 290466 & 250431 & 185271 & 156740 & 114405 \\
\hline 26 & & 64 & 971 & & 4 & 3266 & 15 & 35874 & 21212 & 631 & 85207 & 8733 \\
\hline 27 & & 63 & 6191 & & & 16 & & & & 05 & 24 & 776 \\
\hline 28 & & 13330 & 11550 & & & 48 & & & & & 106191 & 39 \\
\hline 29 & & & & & & 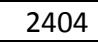 & & & 81 & & 44 & 373 \\
\hline 30 & 11869 & 12112 & 10923 & 112 & 6828 & 4549 & 2 & 183811 & 190820 & 132237 & 102194 & 7922 \\
\hline 31 & 2515 & 2687 & 2047 & 11 & 82 & 30 & -817 & 61610 & 56307 & 50553 & 41720 & 33169 \\
\hline 32 & 23738 & 23496 & 17374 & 16376 & 11675 & 9333 & 6410 & 319847 & 296569 & 211863 & 171532 & 135091 \\
\hline 33 & 10873 & 10510 & 9977 & 91 & 15 & 2944 & 1850 & 174772 & 151649 & 108203 & 80381 & 68721 \\
\hline 34 & 4507 & 4313 & 4467 & & 3707 & 1777 & 73 & 94278 & 84712 & 86744 & 63406 & 44825 \\
\hline 35 & 13280 & 13266 & 11331 & 1028 & & 517 & 3 & 196424 & 172056 & 125570 & 01093 & 8904 \\
\hline 36 & 26560 & 27082 & 20370 & & 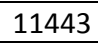 & 8492 & 132 & 374348 & 35 & 200152 & 5514 & 26592 \\
\hline 37 & & 666 & 24383 & & & 52 & & 453518 & 423 & 223866 & 5806 & 213967 \\
\hline 38 & & & 2 & & & 10678 & 11429 & 14052 & 14976 & 292877 & 97671 & 219008 \\
\hline 39 & & 346 & 16 & & 3 & 91 & 4 & 772 & 313809 & 210 & 77288 & 149614 \\
\hline 40 & 17430 & 9907 & 15906 & 14346 & 9603 & 7030 & 5009 & 291462 & 267954 & 184050 & 139612 & 112537 \\
\hline
\end{tabular}


Appendix 11: WVDA, ICP, and PXRF measured Ca concentration $(\mathrm{mg} / \mathrm{kg})$ and PXRF intensity of $\mathrm{Ca}$ (cps) in manure samples at different moisture level.

\begin{tabular}{|c|c|c|c|c|c|c|c|c|c|c|c|c|}
\hline S.No & $\begin{array}{c}\mathrm{Ca} \\
\text { conc } \\
\mathrm{M} \\
\text { WVDA }\end{array}$ & $\begin{array}{c}\text { Ca } \\
\text { conc } \\
\text { M ICP }\end{array}$ & $\begin{array}{c}\mathrm{Ca} \\
\text { conc } \\
\mathrm{M} \\
<10\end{array}$ & $\begin{array}{c}\mathrm{Ca} \\
\text { conc } \\
\text { M 10- } \\
20\end{array}$ & $\begin{array}{c}\mathrm{Ca} \\
\text { conc } \\
\mathrm{M} 20- \\
30\end{array}$ & $\begin{array}{c}\mathrm{Ca} \\
\text { conc } \\
\text { M 40- } \\
50\end{array}$ & $\begin{array}{c}\mathrm{Ca} \\
\text { conc } \\
\text { M 60- } \\
70\end{array}$ & $\begin{array}{l}a \operatorname{lnt} M \\
<10\end{array}$ & $\begin{array}{c}\text { Ca Int M } \\
10-20\end{array}$ & $\begin{array}{c}\text { Ca Int } \\
\text { M 20- } \\
30\end{array}$ & $\begin{array}{c}\text { Ca Int } \\
\text { M 40- } \\
50\end{array}$ & $\begin{array}{c}\text { Ca Int } \\
\text { M 60- } \\
70\end{array}$ \\
\hline 1 & 26700 & 35533 & 26246 & 25885 & 21196 & 19567 & 17726 & 566931 & 55 & 450496 & 383585 & 334620 \\
\hline 2 & 9900 & 45321 & 8387 & 27719 & 22656 & 21050 & 17827 & 577868 & 03312 & 13757 & 81357 & 23402 \\
\hline 3 & 8800 & 33604 & 0137 & 28193 & 2583 & 20810 & 16218 & 50101 & 98624 & 109953 & 59291 & 283279 \\
\hline 4 & 5400 & 48899 & 4717 & 33440 & 26805 & 24397 & 16911 & 62449 & 608140 & 11674 & 55720 & \\
\hline 5 & 9000 & 19861 & 20258 & 21706 & 14098 & 15886 & 10391 & 11 & & & & \\
\hline 6 & 600 & 9 & 9120 & 27506 & 23898 & 21233 & 11847 & & & & & \\
\hline 7 & 500 & 0 & 167 & 41859 & 41859 & 36929 & 35051 & & & & & \\
\hline 8 & 500 & 31140 & 7786 & 21001 & 17847 & 16322 & 13572 & & & & & \\
\hline 9 & 400 & 20251 & 15247 & 14257 & 12538 & 11883 & 9157 & & & & & \\
\hline 10 & 300 & 10514 & 433 & 5249 & 5315 & 5440 & 4480 & 34 & 152770 & & & \\
\hline 11 & 3500 & 14427 & 12367 & 10966 & 9311 & 8970 & 7505 & & & & & 1375 \\
\hline 12 & & & 8339 & 7239 & 9626 & 7126 & 815 & & & & & \\
\hline 13 & j & & 93 & 461 & 10143 & 116 & 32 & & & & & \\
\hline 14 & 200 & 121 & 6442 & 6264 & 3 & 6262 & 674 & 943 & & & & \\
\hline 15 & 500 & 14550 & 461 & 42 & 7191 & 6888 & 4724 & & & 65 & & \\
\hline 16 & 16700 & 16297 & 10215 & 8656 & 8045 & 7949 & 794 & 255306 & $\angle$ & 38 & 8 & 94 \\
\hline 17 & 600 & 14 & 090 & 6757 & 850 & 272 & 6794 & 70 & 23 & 491 & & 164 \\
\hline 18 & 100 & & 015 & 8424 & 7507 & 2 & 60 & & & & & \\
\hline 19 & & & 567 & 8956 & 9116 & 8252 & & & & & & \\
\hline 20 & & & 36 & 1847 & 77 & 514 & 841 & & & & & \\
\hline 21 & 500 & 71 & 966 & 10314 & 9099 & 36 & 788 & & & & & \\
\hline 22 & 100 & 33605 & 047 & 28337 & 24004 & 1290 & 13678 & & & 05 & & \\
\hline 23 & 14300 & 15737 & 15144 & 13265 & 15968 & 10546 & 8019 & 360 & 03 & 960 & 99 & 711 \\
\hline 24 & 000 & 31784 & 28731 & 25746 & 21074 & 19630 & 3222 & 1378 & 474809 & 464 & 73 & 2607 \\
\hline 25 & 17800 & 20611 & 10937 & 9832 & 9752 & 9910 & 9090 & 336267 & 277747 & 2618 & 11 & 041 \\
\hline 26 & 800 & & 74403 & 74789 & 56482 & 1753 & 6529 & 123 & 122 & 94 & & \\
\hline 27 & & & 08 & 31200 & 22792 & 10 & & & & & & \\
\hline 28 & 24400 & & 25968 & 215 & 31429 & 16826 & & & & & & \\
\hline 29 & & & 82 & 24413 & 9671 & 16999 & & & & & & \\
\hline 30 & 31800 & 39587 & 29501 & 28499 & 21379 & 18705 & 12440 & 80 & 565784 & 13 & 30800 & 500 \\
\hline 31 & 19700 & 23784 & 28595 & 27167 & 23361 & 18604 & 14564 & 125 & 430575 & 6928 & 96182 & 29401 \\
\hline 32 & 17400 & 19451 & 14283 & 11879 & 10185 & 10105 & 9832 & 364947 & 305789 & 0192 & 06493 & 181459 \\
\hline 33 & 25100 & 28466 & 27924 & 23791 & 18026 & 14988 & 13625 & 5586 & 441726 & 9572 & 63879 & 3240 \\
\hline 34 & 19300 & 23427 & 26584 & 22381 & 22638 & 16341 & 11399 & 452490 & 370163 & 380578 & 267020 & 182875 \\
\hline 35 & 27300 & 31144 & 23606 & 23633 & 20038 & 18311 & 11640 & & 469565 & 118 & 30 & 000 \\
\hline 36 & 15100 & 17728 & 13109 & 11967 & 10609 & 0400 & 01 & & & & & 277 \\
\hline 37 & 00 & & 16 & 94 & 10001 & 1274 & 379 & & & & & 184641 \\
\hline 38 & & & 14356 & 9 & 01 & 11883 & & & 94 & 120 & 44 & 190934 \\
\hline 39 & & & 881 & 16433 & 53 & 16 & 79 & & 45 & 374 & 00 & 251831 \\
\hline 40 & 20700 & 24580 & 3690 & 15733 & 15531 & 14447 & 10740 & 453347 & 392653 & 335523 & 279876 & 198951 \\
\hline
\end{tabular}


Appendix 12: WVDA, ICP, and PXRF measured $\mathrm{Mg}$ concentration $(\mathrm{mg} / \mathrm{kg})$ and PXRF intensity of $\mathrm{Mg}$ (cps) in manure samples at different moisture level.

\begin{tabular}{|c|c|c|c|c|c|c|c|c|c|c|c|c|}
\hline S.No & $\begin{array}{c}\text { Mg } \\
\text { conc } \\
M \\
\text { WVDA }\end{array}$ & $\begin{array}{c}\mathrm{Mg} \\
\text { conc } \\
\mathrm{M} \text { ICP }\end{array}$ & $\begin{array}{c}\mathrm{Mg} \\
\text { conc } \\
\mathrm{M}<10\end{array}$ & $\begin{array}{c}\mathrm{Mg} \\
\text { conc } \\
\mathrm{M} \mathrm{10-} \\
20\end{array}$ & $\begin{array}{c}\mathrm{Mg} \\
\text { conc } \\
\mathrm{M} 20- \\
30\end{array}$ & $\begin{array}{c}\mathrm{Mg} \\
\text { conc } \\
\mathrm{M} 40- \\
50\end{array}$ & $\begin{array}{c}\mathrm{Mg} \\
\text { conc } \\
\mathrm{M} 60- \\
70\end{array}$ & $\begin{array}{c}\mathrm{Mg} \\
\mathrm{Int} \\
\mathrm{M} \\
<10\end{array}$ & $\begin{array}{c}\mathrm{Mg} \\
\text { Int M } \\
10-20\end{array}$ & $\begin{array}{c}\mathrm{Mg} \\
\text { Int M } \\
20-30\end{array}$ & $\begin{array}{c}\mathrm{Mg} \\
\text { Int M } \\
40-50\end{array}$ & $\begin{array}{c}\mathrm{Mg} \\
\text { Int } \mathrm{M} \\
60-70\end{array}$ \\
\hline 1 & 6060 & 7264 & 3851 & 3305 & 2416 & 2410 & 1910 & 4944 & 4788 & 4486 & 4220 & 3939 \\
\hline 2 & 7640 & 7946 & 4747 & 4205 & 2560 & 2011 & 1525 & 5352 & 4718 & 4297 & 4050 & 3875 \\
\hline 3 & 4830 & 4998 & 5089 & 4225 & 2767 & 2041 & 1940 & 4692 & 4437 & 4241 & 3916 & 3778 \\
\hline 4 & 8700 & 8125 & 7444 & 7135 & 3703 & 3311 & 1648 & 5398 & 5099 & 4714 & 4461 & 3838 \\
\hline 5 & 3280 & 3140 & 2432 & 2638 & 1539 & 5567 & 1780 & 4268 & 4141 & 3794 & 2568 & 3241 \\
\hline 6 & 7400 & 7199 & 6111 & 4978 & 2898 & 2277 & 1457 & 5344 & 5019 & 4529 & 4236 & 3679 \\
\hline 7 & 8030 & 8093 & 12094 & 12018 & 12018 & 8694 & 8383 & 5468 & 5408 & 5408 & 4975 & 5174 \\
\hline 8 & 7760 & 7201 & 3991 & 3132 & 2049 & 1764 & 1871 & 5159 & 5019 & 4288 & 4010 & 3926 \\
\hline 9 & 4000 & 4299 & 1568 & 1258 & 1396 & 1357 & 1479 & 4373 & 4016 & 3797 & 3723 & 3505 \\
\hline 10 & 3930 & 3955 & 1186 & 1230 & 1084 & 1250 & 1551 & 4766 & 4127 & 3846 & 3765 & 3732 \\
\hline 11 & 5240 & 5374 & 2422 & 1582 & 1701 & 1751 & 1809 & 4343 & 4231 & 4244 & 3730 & 3600 \\
\hline 12 & 5040 & 5098 & 1733 & 1560 & 4147 & 1118 & 1805 & 4412 & 4352 & 2706 & 3774 & 3917 \\
\hline 13 & 6400 & 6370 & 1191 & 1279 & 2848 & 1374 & 2382 & 5052 & 4357 & 2939 & 3691 & 3625 \\
\hline 14 & 5280 & 5237 & 2010 & 2045 & 1953 & 1535 & 1596 & 4780 & 4412 & 4323 & 3809 & 4450 \\
\hline 15 & 4480 & 4911 & 984 & 1074 & 1184 & 1425 & 2104 & 4452 & 4089 & 3726 & 3394 & 3471 \\
\hline 16 & 5360 & 5191 & 1449 & 1213 & 1371 & 1296 & 1408 & 4819 & 4032 & 3783 & 3207 & 3347 \\
\hline 17 & 4720 & 4344 & 1175 & 1339 & 1329 & 1531 & 1524 & 4543 & 4259 & 4040 & 3929 & 3653 \\
\hline 18 & 5800 & 5614 & 3358 & 1982 & 1757 & 1549 & 1591 & 4766 & 4137 & 4075 & 3650 & 3645 \\
\hline 19 & 6490 & 7954 & 1349 & 1033 & 1418 & 1315 & 1359 & 5181 & 4307 & 4124 & 3533 & 3450 \\
\hline 20 & 4540 & 4627 & 1563 & 2244 & 1175 & 1448 & 1344 & 4339 & 4368 & 3944 & 3940 & 3629 \\
\hline 21 & 5100 & 4964 & 1730 & 1040 & 929 & 1231 & 1117 & 4602 & 4101 & 3845 & 3725 & 3734 \\
\hline 22 & 5280 & 4991 & 4179 & 3933 & 2801 & 2452 & 1851 & 4823 & 4713 & 4388 & 4087 & 3601 \\
\hline 23 & 4630 & 4626 & 2309 & 1740 & 4252 & 1831 & 1903 & 4472 & 4288 & 2765 & 3669 & 3568 \\
\hline 24 & 4530 & 4386 & 3350 & 2307 & 1915 & 2174 & 1732 & 4500 & 4203 & 3958 & 3941 & 3466 \\
\hline 25 & 6220 & 6687 & 2138 & 2209 & 2118 & 1999 & 1953 & 4930 & 4254 & 3898 & 3813 & 3559 \\
\hline 26 & 6510 & 6817 & 11876 & 10971 & 5656 & 4547 & 2425 & 5327 & 5197 & 4625 & 4476 & 3905 \\
\hline 27 & 4310 & 4647 & 4504 & 4106 & 2126 & 1979 & 1850 & 4342 & 4154 & 3857 & 3642 & 3445 \\
\hline 28 & 4860 & 5850 & 3438 & 2199 & 8392 & 1644 & 1618 & 4638 & 4123 & 3031 & 3806 & 3686 \\
\hline 29 & 3200 & 3864 & 2809 & 2080 & 8274 & 1527 & 1813 & 4329 & 3852 & 2783 & 3344 & 3348 \\
\hline 30 & 4490 & 4454 & 3437 & 2896 & 2171 & 1973 & 1873 & 4545 & 4551 & 4014 & 3688 & 3512 \\
\hline 31 & 5100 & 5701 & 5018 & 5155 & 3417 & 2606 & 2032 & 4361 & 4291 & 3999 & 3740 & 3491 \\
\hline 32 & 5870 & 5969 & 2459 & 1818 & 1949 & 1912 & 1877 & 4872 & 4341 & 3890 & 3624 & 3447 \\
\hline 33 & 4410 & 4583 & 3722 & 2237 & 1688 & 1902 & 1859 & 4442 & 3877 & 3580 & 3511 & 3363 \\
\hline 34 & 1950 & 2106 & 2086 & 1986 & 1879 & 1442 & 1536 & 3770 & 3689 & 3659 & 3373 & 3192 \\
\hline 35 & 4180 & 4373 & 2819 & 2766 & 2486 & 2344 & 1740 & 4812 & 4514 & 1012 & 3818 & 3464 \\
\hline 36 & 5160 & 5529 & 2625 & 1843 & 2011 & 2054 & 1970 & 4913 & 4045 & 3872 & 3664 & 3530 \\
\hline 37 & 5910 & 6356 & 3390 & 2451 & 1672 & 1841 & 1789 & 5471 & 4907 & 3685 & 3719 & 3734 \\
\hline 38 & 5450 & 5799 & 3312 & 2356 & 2136 & 2190 & 2170 & 5663 & 4992 & 4638 & 4096 & 4079 \\
\hline 39 & 6120 & 6282 & 2803 & 2120 & 1964 & 2203 & 1901 & 5758 & 5324 & 4109 & 4267 & 3943 \\
\hline 40 & 3220 & 3673 & 3018 & 1990 & 1950 & 2051 & 1929 & 4975 & 4578 & 4051 & 3735 & 3529 \\
\hline
\end{tabular}


Appendix 13: WVDA, ICP, and PXRF measured Fe concentration $(\mathrm{mg} / \mathrm{kg})$ and PXRF intensity of $\mathrm{Fe}$ (cps) in manure samples at different moisture level.

\begin{tabular}{|c|c|c|c|c|c|c|c|c|c|c|c|}
\hline S.No & $\begin{array}{c}\mathrm{Fe} \\
\text { conc } \\
\mathrm{M} \text { ICP }\end{array}$ & $\begin{array}{c}\mathrm{Fe} \\
\text { conc } \\
\mathrm{M}<10\end{array}$ & $\begin{array}{c}\mathrm{Fe} \\
\text { conc } \\
\mathrm{M} 10- \\
20\end{array}$ & $\begin{array}{c}\mathrm{Fe} \\
\text { conc } \\
\mathrm{M} 20- \\
30\end{array}$ & $\begin{array}{c}\mathrm{Fe} \\
\text { conc M } \\
40-50\end{array}$ & $\begin{array}{c}\mathrm{Fe} \\
\text { conc } \\
\mathrm{M} 60- \\
70\end{array}$ & $\begin{array}{l}\text { Fe Int } \\
M<10\end{array}$ & $\begin{array}{c}\text { Fe Int } \\
\text { M 10- } \\
20\end{array}$ & $\begin{array}{c}\text { Fe Int } \\
\text { M 20- } \\
30\end{array}$ & $\begin{array}{c}\text { Fe Int } \\
\text { M 40- } \\
50\end{array}$ & $\begin{array}{c}\text { Fe Int } \\
\text { M 60- } \\
70\end{array}$ \\
\hline 1 & 1575 & 729 & 716 & 608 & 594 & 570 & 204629 & 199720 & 182119 & 167548 & 158792 \\
\hline 2 & 9474 & 3409 & 3378 & 2877 & 2722 & 2246 & 684205 & 622250 & 550963 & 525653 & 454190 \\
\hline 3 & 3117 & 1895 & 1846 & 1496 & 1469 & 1125 & 363938 & 354745 & 312576 & 296401 & 247272 \\
\hline 4 & 6683 & 2863 & 2887 & 2286 & 2139 & 1584 & 540762 & 535010 & 466099 & 435253 & 340544 \\
\hline 5 & 2249 & 1502 & 1568 & 980 & 1308 & 620 & 340599 & 315907 & 242167 & 155525 & 166645 \\
\hline 6 & 9209 & 3782 & 3818 & 3384 & 3106 & 1877 & 712773 & 718220 & 639304 & 591786 & 436801 \\
\hline 7 & 10014 & 4545 & 4623 & 4623 & 4336 & 4062 & 736079 & 745370 & 745370 & 704970 & 693480 \\
\hline 8 & 1746 & 799 & 634 & 591 & 567 & 494 & 207327 & 207628 & 191022 & 178812 & 162760 \\
\hline 9 & 4471 & 1900 & 1826 & 1621 & 1567 & 1059 & 407057 & 404490 & 362386 & 331916 & 249993 \\
\hline 10 & 4834 & 1345 & 1323 & 1263 & 1353 & 996 & 443992 & 405255 & 355271 & 355034 & 289573 \\
\hline 11 & 2413 & 1334 & 1147 & 921 & 892 & 727 & 275830 & 289407 & 249781 & 22 & 197364 \\
\hline 12 & 3156 & 1455 & 1192 & 2229 & 1176 & 1379 & 357714 & 333506 & 273326 & 282494 & 296083 \\
\hline 13 & 5282 & 1477 & 1551 & 2512 & 1529 & 787 & 483243 & 441419 & 400197 & 369543 & 280207 \\
\hline 14 & 1719 & 469 & 473 & 488 & 539 & 567 & 207650 & 219622 & 216896 & 180938 & 219821 \\
\hline 15 & 5669 & 1981 & 1677 & 1740 & 1668 & 1016 & 497394 & 424488 & 407390 & 378730 & 296780 \\
\hline 16 & 5866 & 1953 & 1556 & 1456 & 1547 & 1433 & 500456 & & 368808 & & \\
\hline 17 & 4459 & 1531 & 1232 & 1287 & 1368 & 1233 & 429081 & 400728 & 364008 & 328 & 307076 \\
\hline 18 & 5853 & 3223 & 2628 & 2303 & 2134 & 1946 & 615148 & 508512 & 481040 & 436805 & 401263 \\
\hline 19 & 6738 & 2078 & 1662 & 1739 & 1555 & 1498 & 549465 & 452439 & 436972 & 375441 & 353004 \\
\hline 20 & 9466 & 4765 & 4890 & 4378 & 3874 & 2653 & 815766 & 841613 & 762583 & 700513 & 539896 \\
\hline 21 & 8616 & 4485 & 4136 & 3626 & 3214 & 3004 & 843992 & 787400 & 694184 & 618821 & 576157 \\
\hline 22 & 6238 & 2573 & 2597 & 2245 & 2082 & 1343 & 546190 & 524217 & 464204 & 422301 & 307562 \\
\hline 23 & 1423 & 847 & 684 & 1316 & & 438 & 228942 & 234364 & 185606 & 176996 & 147352 \\
\hline 24 & 5229 & 2894 & 2617 & 2227 & 2113 & 1409 & 538524 & 516644 & 451033 & 424109 & 314709 \\
\hline 25 & 2300 & 497 & 432 & 475 & 525 & 504 & 248748 & 218536 & 196220 & 191666 & 164339 \\
\hline 26 & 5203 & 2179 & 2206 & 1774 & 1698 & 1245 & 392206 & 393020 & 342139 & 337399 & 277424 \\
\hline 27 & 4208 & 2750 & 2691 & 2063 & 1763 & 1340 & 458786 & 461847 & 389384 & 343229 & 279499 \\
\hline 28 & 4834 & 2460 & 2041 & 3683 & & 1427 & 468194 & 417614 & & & \\
\hline 29 & 3707 & 1736 & 1796 & 2886 & & 1025 & 416295 & 353740 & 296836 & & 228091 \\
\hline 30 & 3337 & 1648 & 1578 & 1288 & 1170 & 713 & 316531 & 348662 & 286171 & 255034 & 191680 \\
\hline 31 & 2806 & 1985 & 1911 & 1672 & 1340 & 1045 & 175793 & 339444 & 312878 & 263639 & 222097 \\
\hline 32 & 1121 & 417 & 326 & 286 & 317 & 344 & 156215 & 157541 & 134716 & 128290 & 121735 \\
\hline 33 & 1070 & 720 & 599 & 481 & 41 & 368 & 182646 & 156623 & 138833 & 126126 & 117301 \\
\hline 34 & 3068 & 2057 & 1814 & 1894 & 1379 & 913 & & 343046 & 361701 & & \\
\hline 35 & 9315 & 3894 & 3884 & 3380 & 3070 & 2083 & 906601 & 793296 & 663310 & 568512 & 449098 \\
\hline 36 & 776 & 316 & 392 & 361 & 360 & 290 & 134135 & 135720 & 122053 & 115265 & 102751 \\
\hline 37 & 1800 & 651 & 631 & 411 & 561 & 482 & 208609 & 205943 & 136489 & 153533 & 148934 \\
\hline 38 & 1012 & 282 & 276 & 257 & 327 & 259 & 136897 & 139678 & 128556 & 119676 & 110849 \\
\hline 39 & 877 & 96 & 61 & 82 & 17 & 162 & 110710 & 114511 & 88804 & 102480 & 98766 \\
\hline 40 & 616 & 202 & 176 & 199 & 210 & 187 & 114772 & 116677 & 106066 & 97889 & 94335 \\
\hline
\end{tabular}


Appendix 14: WVDA and ICP measured Cu concentration $(\mathrm{mg} / \mathrm{kg})$ and PXRF intensity of $\mathrm{Cu}(\mathrm{cps})$ in manure samples at different moisture level.

\begin{tabular}{|c|c|c|c|c|c|c|c|}
\hline S.No & $\begin{array}{c}\text { Cu conc M } \\
\text { WVDA }\end{array}$ & $\begin{array}{c}\text { Cu conc } M \\
\text { ICP }\end{array}$ & $\begin{array}{c}\text { Cu Int M } \\
<10\end{array}$ & $\begin{array}{c}\text { Cu Int M 10- } \\
20\end{array}$ & $\begin{array}{c}\text { Cu Int M } \\
20-30\end{array}$ & $\begin{array}{c}\text { Cu Int M 40- } \\
50\end{array}$ & $\begin{array}{c}\text { Cu Int M } \\
60-70\end{array}$ \\
\hline 1 & 9 & 107 & 53744 & 53251 & 58947 & 63608 & 65158 \\
\hline 2 & 1350 & 1439 & 132730 & 117481 & 118756 & 118132 & 110464 \\
\hline 3 & 2440 & 2630 & 288056 & 283471 & 254000 & 241158 & 209562 \\
\hline 4 & 1740 & 1674 & 163137 & 147275 & 140209 & 136656 & 136994 \\
\hline 5 & 85 & 76 & 58548 & 55000 & 65155 & 64486 & 65286 \\
\hline 6 & 1530 & 1524 & 141672 & 135928 & 130638 & 126710 & 118259 \\
\hline 7 & 1380 & 1389 & 123556 & 127621 & 127621 & 121866 & 123310 \\
\hline 8 & 269 & 255 & 70598 & 66323 & 72776 & 74088 & 75988 \\
\hline 9 & 37 & 51 & 46828 & 48727 & 53073 & 56743 & 62082 \\
\hline 10 & 71 & 66 & 46337 & 42354 & 49460 & 53877 & 62029 \\
\hline 11 & 42 & 51 & 53016 & 50430 & 60090 & 63979 & 64969 \\
\hline 12 & 43 & 44 & 49633 & 47554 & 56164 & 60959 & 60873 \\
\hline 13 & 69 & 72 & 43489 & 42386 & 45406 & 49599 & 58060 \\
\hline 14 & 79 & 87 & 51130 & 53388 & 53964 & 61973 & 58021 \\
\hline 15 & 11 & 106 & 44315 & 39241 & 45447 & 51679 & 60633 \\
\hline 16 & 14 & 113 & 47053 & 39874 & 46307 & 45873 & 52684 \\
\hline 17 & 76 & 74 & 46204 & 43955 & 52787 & 56312 & 59883 \\
\hline 18 & 39 & 53 & 44197 & 38298 & 50178 & 53193 & 55783 \\
\hline 19 & 57 & 64 & 43269 & 38378 & 45860 & 45102 & 48972 \\
\hline 20 & 84 & 87 & 43431 & 43834 & 47529 & 50654 & 56472 \\
\hline 21 & 95 & 97 & 45450 & 43424 & 50751 & 54561 & 56211 \\
\hline 22 & 2110 & 1972 & 224137 & 224744 & 208172 & 199104 & 168375 \\
\hline 23 & 544 & 521 & 111842 & 106919 & 103074 & 103690 & 95663 \\
\hline 24 & 403 & 367 & 76713 & 71942 & 78416 & 79021 & 78462 \\
\hline 25 & 155 & 148 & 56791 & 51195 & 58955 & 63256 & 67934 \\
\hline 26 & 577 & 602 & 74239 & 72203 & 75556 & 75071 & 75718 \\
\hline 27 & 822 & 917 & 140169 & 134108 & 127898 & 123289 & 113323 \\
\hline 28 & 436 & 515 & 89434 & 85459 & 85273 & 88489 & 87705 \\
\hline 29 & 1730 & 1401 & 151301 & 204721 & 187903 & 177340 & 168097 \\
\hline 30 & 344 & 381 & 77406 & 78711 & 80161 & 79236 & 80379 \\
\hline 31 & 59 & 68 & 54413 & 54613 & 58708 & 62627 & 66382 \\
\hline 32 & 60 & 54 & 51984 & 50040 & 56144 & 61030 & 65350 \\
\hline 33 & 123 & 125 & 62954 & 56139 & 65549 & 69441 & 71488 \\
\hline 34 & 38 & 47 & 53371 & 56715 & 56645 & 62418 & 67391 \\
\hline 35 & 63 & 75 & 47789 & 47326 & 54214 & 54542 & 62221 \\
\hline 36 & 505 & 513 & 106165 & 95674 & 95059 & 95327 & 96711 \\
\hline 37 & 486 & 524 & 97654 & 88433 & 69891 & 80455 & 95451 \\
\hline 38 & 598 & 620 & 109336 & 100526 & 98366 & 98552 & 103562 \\
\hline 39 & 861 & 879 & 115533 & 103984 & 81987 & 105209 & 105228 \\
\hline 40 & 277 & 312 & 84779 & 76750 & 78524 & 77890 & 82943 \\
\hline
\end{tabular}


Appendix 15: ICP measured concentration $(\mathrm{mg} / \mathrm{kg})$ and PXRF intensity of $\mathrm{Zn}(\mathrm{cps})$ in manure samples at different moisture level.

\begin{tabular}{|c|c|c|c|c|c|c|}
\hline S.No & $\begin{array}{c}\text { Zn conc } M \\
I C P\end{array}$ & Zn Int $M<10$ & $\begin{array}{c}Z n \operatorname{Int} M 10- \\
20\end{array}$ & $\begin{array}{c}\text { Zn Int M 20- } \\
30\end{array}$ & $\begin{array}{c}\text { Zn Int M 40- } \\
50\end{array}$ & $\begin{array}{c}Z n \operatorname{Int} M 60 \\
70\end{array}$ \\
\hline 1 & 278 & 64970 & 63957 & 68638 & 72456 & 73419 \\
\hline 2 & 359 & 55734 & 50861 & 56793 & 58780 & 61320 \\
\hline 3 & 342 & 70966 & 69813 & 75425 & 75559 & 76395 \\
\hline 4 & 347 & 57354 & 56357 & 60146 & 62666 & 65556 \\
\hline 5 & 146 & 62014 & 59490 & 69258 & 67960 & 67665 \\
\hline 6 & 324 & 54450 & 53915 & 56530 & 59383 & 65255 \\
\hline 7 & 327 & 52412 & 53236 & 53236 & 53439 & 54656 \\
\hline 8 & 340 & 72984 & 69982 & 75680 & 77420 & 80088 \\
\hline 9 & 127 & 50070 & 52568 & 56322 & 60165 & 65169 \\
\hline 10 & 146 & 49795 & 46024 & 52337 & 56868 & 64797 \\
\hline 11 & 164 & 60815 & 57776 & 66964 & 70057 & 70805 \\
\hline 12 & 113 & 52903 & 50414 & 58401 & 62980 & 62717 \\
\hline 13 & 154 & 47214 & 45954 & 49012 & 52299 & 60863 \\
\hline 14 & 95 & 49258 & 51206 & 52170 & 61223 & 56547 \\
\hline 15 & 137 & 44198 & 39717 & 46597 & 52428 & 61386 \\
\hline 16 & 166 & 48303 & 41079 & 47909 & 46634 & 53812 \\
\hline 17 & 129 & 48111 & 45638 & 54615 & 57597 & 61449 \\
\hline 18 & 122 & 46903 & 39820 & 52339 & 54777 & 58819 \\
\hline 19 & 201 & 49700 & 43119 & 51238 & 48605 & 53192 \\
\hline 20 & 148 & 44251 & 44592 & 48679 & 51829 & 57886 \\
\hline 21 & 123 & 44266 & 42788 & 50215 & 54098 & 55637 \\
\hline 22 & 266 & 59820 & 59912 & 63915 & 65646 & 69948 \\
\hline 23 & 238 & 71153 & 69415 & 72972 & 77040 & 78027 \\
\hline 24 & 210 & 56311 & 55014 & 63181 & 65011 & 67719 \\
\hline 25 & 315 & 63715 & 58293 & 63919 & 68395 & 72721 \\
\hline 26 & 224 & 45597 & 45501 & 51482 & 52984 & 58074 \\
\hline 27 & 219 & 63555 & 62486 & 68657 & 69882 & 71966 \\
\hline 28 & 210 & 57079 & 58774 & 58828 & 66408 & 68409 \\
\hline 29 & 244 & 61555 & 58977 & 65458 & 69829 & 73539 \\
\hline 30 & 230 & 60599 & 62712 & 66880 & 68061 & 73485 \\
\hline 31 & 241 & 67231 & 67887 & 70678 & 71993 & 74963 \\
\hline 32 & 211 & 65172 & 61704 & 65627 & 69661 & 73664 \\
\hline 33 & 213 & 67494 & 60546 & 69394 & 73368 & 74952 \\
\hline 34 & 119 & 58168 & 60018 & 60597 & 66211 & 70589 \\
\hline 35 & 305 & 63025 & 61687 & 66918 & 66364 & 70601 \\
\hline 36 & 370 & 82011 & 78559 & 83881 & 85365 & 84256 \\
\hline 37 & 454 & 84028 & 77872 & 63561 & 74400 & 86496 \\
\hline 38 & 430 & 82428 & 80610 & 80654 & 81517 & 86143 \\
\hline 39 & 586 & 81972 & 79746 & 66622 & 84489 & 84337 \\
\hline 40 & 255 & 72622 & 73218 & 75050 & 74379 & 76372 \\
\hline
\end{tabular}


Appendix 16: CVAS, ICP and PXRF measured concentration $(\mathrm{mg} / \mathrm{kg})$ and PXRF intensity of $P$ (cps) in forage samples at two different particle size.

\begin{tabular}{|c|c|c|c|c|c|c|c|c|}
\hline S.No & $\begin{array}{l}\text { P conc } F \\
\text { CVAS }\end{array}$ & $\begin{array}{l}P \text { conc } F \\
\text { ICP }\end{array}$ & $\begin{array}{l}\text { P conc FNP } \\
<106 \mathrm{~mm}\end{array}$ & $\begin{array}{c}\text { P conc FNP } \\
0.25- \\
0.5 \mathrm{~mm}\end{array}$ & $\begin{array}{l}\text { P conc FNP } \\
1-2 \mathrm{~mm}\end{array}$ & $\begin{array}{l}\text { P Int FNP } \\
<106 \mathrm{~mm}\end{array}$ & $\begin{array}{c}\text { P Int FNP } \\
0.25- \\
0.5 \mathrm{~mm} \\
\end{array}$ & $\begin{array}{l}P \text { Int FNP } \\
1-2 \mathrm{~mm}\end{array}$ \\
\hline 1 & 2800 & 2425 & 3642 & 2494 & 2289 & 21635 & 13115 & 211936 \\
\hline 2 & 2800 & 2131 & 3560 & 2366 & 2024 & 20499 & 13088 & 208467 \\
\hline 3 & 2800 & 2169 & 2952 & 2021 & 1852 & 20586 & 14051 & 201958 \\
\hline 4 & 2200 & 1782 & 2833 & 2158 & 1870 & 17046 & 12635 & 227925 \\
\hline 5 & 2300 & 2168 & 2796 & 2198 & 1669 & 18997 & 14700 & 242854 \\
\hline 6 & 2700 & 2304 & 3333 & 2360 & 1962 & 20391 & 13871 & 244286 \\
\hline 7 & 1800 & 1682 & 2599 & 1955 & 1734 & 16325 & 11617 & 206628 \\
\hline 8 & 1900 & 1635 & 2504 & 1752 & 1490 & 16204 & 11167 & 200477 \\
\hline 9 & 3200 & 2510 & 3298 & 2259 & 1756 & 22840 & 15015 & 182146 \\
\hline 10 & 3900 & 3166 & 2931 & 2069 & 1964 & 22840 & 18051 & 302758 \\
\hline 11 & 2900 & 2173 & 2864 & 1738 & 1516 & 22094 & 13671 & 256105 \\
\hline 12 & 2300 & 1822 & 2657 & 1580 & 1460 & 20845 & 12331 & 202641 \\
\hline 13 & 2000 & 1701 & 2790 & 1834 & 1466 & 19893 & 12996 & 183452 \\
\hline 14 & 2500 & 2095 & 2562 & 1813 & 1564 & 18652 & 12153 & 187388 \\
\hline 15 & 2900 & 2508 & 3148 & 2412 & 1962 & 20453 & 14154 & 199028 \\
\hline 16 & 2900 & 2433 & 3407 & 2588 & 2519 & 19411 & 13584 & 204275 \\
\hline 17 & 3300 & 2659 & 3546 & 2895 & 2273 & 20806 & 15678 & 191363 \\
\hline 18 & 3000 & 2359 & 2781 & 1937 & 1935 & 20208 & 13192 & 165944 \\
\hline 19 & 2400 & 1989 & 2781 & 1974 & 1395 & 18819 & 12439 & 166238 \\
\hline 20 & 2000 & 1732 & 2560 & 1903 & 1921 & 16307 & 11379 & 233889 \\
\hline 21 & 2900 & 2199 & 2562 & 1794 & 1449 & 19426 & 13972 & 271868 \\
\hline 22 & 3400 & 3023 & 3967 & 3043 & 2191 & 21877 & 15876 & 185687 \\
\hline 23 & 2900 & 2556 & 3256 & 2311 & 1852 & 21673 & 15172 & 245968 \\
\hline 24 & 1600 & 1614 & 2495 & 1835 & 1541 & 15838 & 11282 & 186014 \\
\hline 25 & 1800 & 1759 & 2709 & 1860 & 1689 & 16774 & 11561 & 182637 \\
\hline 26 & 2300 & 2278 & 3918 & 2761 & 1727 & 21435 & 14830 & 216393 \\
\hline 27 & 1800 & 1675 & 2594 & 1905 & 1656 & 15831 & 11421 & 196378 \\
\hline 28 & 1800 & 1855 & 2448 & 1892 & 1416 & 16171 & 12311 & 165173 \\
\hline 29 & 1900 & 1799 & 2486 & 1931 & 1727 & 15888 & 12023 & 215313 \\
\hline 30 & 2000 & 1830 & 2596 & 2126 & 1512 & 16328 & 13078 & 186344 \\
\hline 31 & & 3302 & 4350 & 3774 & 3037 & 23356 & 19092 & 265067 \\
\hline 32 & & 3189 & 4392 & 3594 & 3492 & 23267 & 18353 & 345583 \\
\hline 33 & & 3353 & 4386 & 3383 & 3093 & 23420 & 17469 & 310497 \\
\hline 34 & & 3485 & 5074 & 3725 & 3506 & 26279 & 18106 & 194411 \\
\hline 35 & & 1700 & 2273 & 1650 & 1321 & 16614 & 12110 & 167543 \\
\hline 36 & & 1694 & 2381 & 1467 & 1531 & 17104 & 11577 & 170205 \\
\hline 37 & & 2507 & 3209 & 2223 & 1872 & 22065 & 14842 & 246486 \\
\hline 38 & & 2116 & 2742 & 1959 & 1746 & 18814 & 13129 & 202907 \\
\hline 39 & & 985 & 2387 & 1758 & 1313 & 13349 & 9422 & 135802 \\
\hline 40 & & 1512 & 2036 & 1453 & 1242 & 14682 & 10876 & 139153 \\
\hline 41 & & 1099 & 2280 & 1747 & 1511 & 12994 & 9689 & 155700 \\
\hline 42 & & 984 & 2246 & 1632 & 1345 & 12520 & 8866 & 164184 \\
\hline
\end{tabular}


Appendix 17: CVAS, ICP, and PXRF measured concentration $(\mathrm{mg} / \mathrm{kg})$ and PXRF intensity of $K$ (cps) in forage samples at two different particle size.

\begin{tabular}{|c|c|c|c|c|c|c|}
\hline S.No & $\begin{array}{c}\mathrm{K} \text { conc } \mathrm{F} \\
\text { CVAS }\end{array}$ & $\mathrm{K}$ conc $\mathrm{F} I \mathrm{CP}$ & $\begin{array}{c}\mathrm{K} \text { conc FNP } \\
0.25-0.5 \mathrm{~mm}\end{array}$ & $\begin{array}{c}\text { K conc FNP 1- } \\
2 \mathrm{~mm}\end{array}$ & $\begin{array}{c}\text { K Int FNP 0.25- } \\
0.5 \mathrm{~mm}\end{array}$ & $\begin{array}{l}\text { K Int FNP 1- } \\
2 \mathrm{~mm}\end{array}$ \\
\hline 1 & 21500 & 16723 & 17706 & 14018 & 273387 & 211936 \\
\hline 2 & 19900 & 15400 & 16112 & 13330 & 257162 & 208467 \\
\hline 3 & 24600 & 16897 & 15758 & 12317 & 275331 & 201958 \\
\hline 4 & 23300 & 16820 & 18125 & 14405 & 292989 & 227925 \\
\hline 5 & 25700 & 20283 & 18866 & 14772 & 329703 & 242854 \\
\hline 6 & 26400 & 20727 & 20157 & 15623 & 326494 & 244286 \\
\hline 7 & 20000 & 15623 & 15781 & 13156 & 259022 & 206628 \\
\hline 8 & 22200 & 16720 & 15834 & 12607 & 266398 & 200477 \\
\hline 9 & 20700 & 16730 & 14959 & 11242 & 261263 & 182146 \\
\hline 10 & 33600 & 24840 & 18260 & 16698 & 366089 & 302758 \\
\hline 11 & 25200 & 18850 & 15468 & 14867 & 286262 & 256105 \\
\hline 12 & 23200 & 16263 & 14839 & 12157 & 270022 & 202641 \\
\hline 13 & 17800 & 13880 & 12483 & 11143 & 223672 & 183452 \\
\hline 14 & 20500 & 15850 & 13702 & 11533 & 237474 & 187388 \\
\hline 15 & 19800 & 15733 & 15024 & 12431 & 246004 & 199028 \\
\hline 16 & 19600 & 13440 & 13910 & 13233 & 221635 & 204275 \\
\hline 17 & 21100 & 14707 & 14981 & 12327 & 243659 & 191363 \\
\hline 18 & 17600 & 13367 & 11453 & 9840 & 202151 & 165944 \\
\hline 19 & 18000 & 13897 & 12877 & 10271 & 219733 & 166238 \\
\hline 20 & 23900 & 18370 & 16795 & 15035 & 272946 & 233889 \\
\hline 21 & 28800 & 23050 & 17686 & 15410 & 324568 & 271868 \\
\hline 22 & 22800 & 20337 & 18085 & 12363 & 281140 & 185687 \\
\hline 23 & 28600 & 24777 & 21030 & 15513 & 363098 & 245968 \\
\hline 24 & 17800 & 16370 & 15268 & 11614 & 253141 & 186014 \\
\hline 25 & 18300 & 14853 & 14200 & 11533 & 236787 & 182637 \\
\hline 26 & 17800 & 15133 & 15674 & 13716 & 254183 & 216393 \\
\hline 27 & 20900 & 16553 & 15547 & 12837 & 251644 & 196378 \\
\hline 28 & 16300 & 13020 & 12694 & 10307 & 219291 & 165173 \\
\hline 29 & 20900 & 16860 & 15391 & 13716 & 257590 & 215313 \\
\hline 30 & 19900 & 16473 & 15484 & 11893 & 259674 & 186344 \\
\hline 31 & & 23577 & 22825 & 18689 & 352799 & 265067 \\
\hline 32 & & 27467 & 25938 & 24051 & 393486 & 345583 \\
\hline 33 & & 27173 & 24107 & 21961 & 366715 & 310497 \\
\hline 34 & & 12663 & 12529 & 12643 & 201605 & 194411 \\
\hline 35 & & 16058 & 13237 & 10060 & 233928 & 167543 \\
\hline 36 & & 13420 & 11261 & 9853 & 202338 & 170205 \\
\hline 37 & & 19490 & 15731 & 14784 & 273200 & 246486 \\
\hline 38 & & 16650 & 14061 & 12374 & 241552 & 202907 \\
\hline 39 & & 13540 & 10772 & 8219 & 178248 & 135802 \\
\hline 40 & & 14790 & 11992 & 8651 & 211552 & 139153 \\
\hline 41 & & 11540 & 13019 & 9684 & 209807 & 155700 \\
\hline 42 & & 12283 & 12414 & 10246 & 199282 & 164184 \\
\hline
\end{tabular}


Appendix 18: CVAS, ICP, and PXRF measured concentration $(\mathrm{mg} / \mathrm{kg})$ and PXRF intensity of $\mathrm{Ca}$ (cps) in forage samples at two different particle size.

\begin{tabular}{|c|c|c|c|c|c|c|}
\hline S.No & $\begin{array}{c}\text { Ca conc F } \\
\text { CVAS }\end{array}$ & Ca conc F ICP & $\begin{array}{l}\text { Ca conc FNP } \\
0.25-0.5 \mathrm{~mm}\end{array}$ & $\begin{array}{c}\text { Ca conc FNP 1- } \\
2 \mathrm{~mm}\end{array}$ & $\begin{array}{c}\text { Ca Int FNP 0.25- } \\
0.5 \mathrm{~mm}\end{array}$ & $\begin{array}{c}\text { Ca Int FNP 1- } \\
2 \mathrm{~mm}\end{array}$ \\
\hline 1 & 5600 & 4302 & 4960 & 4711 & 110870 & 90026 \\
\hline 2 & 5900 & 4687 & 6057 & 4564 & 129797 & 88931 \\
\hline 3 & 6900 & 5938 & 6182 & 4730 & 153130 & 96113 \\
\hline 4 & 5900 & 4315 & 4949 & 4016 & 119481 & 85156 \\
\hline 5 & 4000 & 3824 & 4136 & 2790 & 117682 & 67629 \\
\hline 6 & 4000 & 3559 & 3920 & 2573 & 107680 & 62949 \\
\hline 7 & 4100 & 4128 & 5560 & 3419 & 123636 & 69001 \\
\hline 8 & 3500 & 2905 & 3821 & 2846 & 93672 & 58009 \\
\hline 9 & 3200 & 2660 & 3439 & 3257 & 87405 & 62226 \\
\hline 10 & 4200 & 3107 & 2616 & 2444 & 95828 & 75733 \\
\hline 11 & 6700 & 4902 & 4600 & 2974 & 125599 & 77352 \\
\hline 12 & 6000 & 4588 & 4361 & 3432 & 114566 & 74203 \\
\hline 13 & 5900 & 4959 & 5819 & 4068 & 133791 & 81387 \\
\hline 14 & 5300 & 4181 & 4813 & 3888 & 110593 & 75221 \\
\hline 15 & 4300 & 4006 & 5030 & 4165 & 111956 & 82440 \\
\hline 16 & 4500 & 3776 & 5784 & 5007 & 114372 & 94306 \\
\hline 17 & 5100 & 4287 & 5753 & 4378 & 121740 & 80513 \\
\hline 18 & 4700 & 3601 & 4666 & 4079 & 101387 & 76169 \\
\hline 19 & 4800 & 3749 & 5005 & 3102 & 107995 & 56175 \\
\hline 20 & 4200 & 3189 & 3942 & 3589 & 95739 & 78585 \\
\hline 21 & 4700 & 3155 & 2885 & 2286 & 91319 & 64765 \\
\hline 22 & 5100 & 4430 & 5445 & 3925 & 122271 & 70285 \\
\hline 23 & 3400 & 3242 & 2749 & 2584 & 94300 & 63705 \\
\hline 24 & 4800 & 4685 & 5627 & 4601 & 125201 & 85420 \\
\hline 25 & 4800 & 4718 & 5817 & 4893 & 126354 & 91153 \\
\hline 26 & 7400 & 6760 & 8763 & 4307 & 178056 & 110835 \\
\hline 27 & 4800 & 4291 & 5454 & 4191 & 120290 & 80193 \\
\hline 28 & 5000 & 5065 & 6358 & 4187 & 137589 & 76905 \\
\hline 29 & 4700 & 4246 & 5407 & 4307 & 123329 & 87509 \\
\hline 30 & 4900 & 4745 & 5684 & 3568 & 129690 & 68134 \\
\hline 31 & & 8853 & 9484 & 5150 & 209629 & 106102 \\
\hline 32 & & 8997 & 9220 & 6318 & 214304 & 146706 \\
\hline 33 & & 7235 & 7478 & 5478 & 177670 & 123930 \\
\hline 34 & & 8431 & 12715 & 10655 & 226705 & 185321 \\
\hline 35 & & 5596 & 6319 & 5162 & 148697 & 99785 \\
\hline 36 & & 4082 & 4906 & 4546 & 112611 & 92434 \\
\hline 37 & & 5180 & 8070 & 6405 & 191957 & 146893 \\
\hline 38 & & 3745 & 6327 & 4964 & 145051 & 101847 \\
\hline 39 & & 6643 & 9328 & 5935 & 162068 & 91067 \\
\hline 40 & & 4627 & 5044 & 3993 & 114083 & 67412 \\
\hline 41 & & 4944 & 7072 & 4695 & 133598 & 76052 \\
\hline 42 & & 4753 & 7375 & 3890 & 133452 & 66265 \\
\hline
\end{tabular}


Appendix 19: CVAS, ICP, and PXRF measured concentration $(\mathrm{mg} / \mathrm{kg})$ and PXRF intensity of $\mathrm{Mg}$ (cps) in forage samples at two different particle size.

\begin{tabular}{|c|c|c|c|c|c|c|}
\hline S.No & $\begin{array}{l}\text { Mg conc } \mathrm{F} \\
\text { CVAS }\end{array}$ & $\begin{array}{l}\text { Mg conc F } \\
\text { ICP }\end{array}$ & $\begin{array}{c}\text { Mg conc } \\
\text { FNP } 0.25- \\
0.5 \mathrm{~mm}\end{array}$ & $\begin{array}{l}\text { Mg conc } \\
\text { FNP 1-2mm }\end{array}$ & $\begin{array}{c}\text { Mg Int FNP } \\
0.25- \\
0.5 \mathrm{~mm}\end{array}$ & $\begin{array}{l}\text { Mg Int FNP } \\
1-2 \mathrm{~mm}\end{array}$ \\
\hline 1 & 2100 & 1651 & 2151 & 2288 & 2945 & 2777 \\
\hline 2 & 3000 & 2244 & 2361 & 2392 & 3094 & 2732 \\
\hline 3 & 2400 & 2268 & 2744 & 2717 & 3374 & 2863 \\
\hline 4 & 2200 & 1800 & 2359 & 2258 & 3352 & 2988 \\
\hline 5 & 2300 & 2067 & 2432 & 2551 & 3423 & 3001 \\
\hline 6 & 2300 & 2000 & 2299 & 2489 & 3299 & 2868 \\
\hline 7 & 2300 & 2063 & 2234 & 2449 & 3179 & 2806 \\
\hline 8 & 2100 & 1727 & 2354 & 2620 & 3188 & 2624 \\
\hline 9 & 1700 & 1333 & 2679 & 2813 & 3259 & 2657 \\
\hline 10 & 1500 & 1154 & 3322 & 3225 & 3667 & 3270 \\
\hline 11 & 2300 & 1787 & 3156 & 3128 & 3377 & 3163 \\
\hline 12 & 2400 & 1789 & 2978 & 3336 & 3357 & 2854 \\
\hline 13 & 2300 & 1834 & 2850 & 2953 & 3265 & 2873 \\
\hline 14 & 2300 & 1826 & 2632 & 2594 & 3186 & 2948 \\
\hline 15 & 2000 & 1650 & 2364 & 2571 & 3067 & 2844 \\
\hline 16 & 2300 & 1741 & 2214 & 2221 & 3110 & 2842 \\
\hline 17 & 2100 & 1969 & 2294 & 2339 & 3249 & 2734 \\
\hline 18 & 2100 & 1563 & 2866 & 2879 & 3175 & 2832 \\
\hline 19 & 2300 & 1732 & 2590 & 3015 & 3125 & 2592 \\
\hline 20 & 1800 & 1390 & 2285 & 2361 & 3234 & 2979 \\
\hline 21 & 1900 & 1407 & 2950 & 3278 & 3377 & 3069 \\
\hline 22 & 1800 & 1557 & 2196 & 2190 & 3328 & 2675 \\
\hline 23 & 1500 & 1316 & 2362 & 2503 & 3385 & 2911 \\
\hline 24 & 1800 & 1483 & 2383 & 2458 & 3160 & 2768 \\
\hline 25 & 1700 & 1524 & 2325 & 2482 & 3212 & 2805 \\
\hline 26 & 2200 & 1888 & 2318 & 2345 & 3348 & 2815 \\
\hline 27 & 1800 & 1359 & 2281 & 2306 & 3212 & 2851 \\
\hline 28 & 1700 & 1458 & 2504 & 2808 & 3124 & 2731 \\
\hline 29 & 1500 & 1283 & 2319 & 2345 & 3232 & 2809 \\
\hline 30 & 1500 & 1302 & 2295 & 2619 & 3263 & 2636 \\
\hline 31 & & 2186 & 2597 & 2219 & 3561 & 2848 \\
\hline 32 & & 2233 & 2366 & 2320 & 3578 & 3221 \\
\hline 33 & & 1765 & 2184 & 1961 & 3451 & 2921 \\
\hline 34 & & 2364 & 2539 & 2432 & 3261 & 3112 \\
\hline 35 & & 2096 & 2644 & 2949 & 3355 & 2814 \\
\hline 36 & & 1703 & 3084 & 3030 & 3264 & 3024 \\
\hline 37 & & 2332 & 2420 & 2599 & 3572 & 3224 \\
\hline 38 & & 2594 & 2490 & 2574 & 3436 & 3046 \\
\hline 39 & & 1704 & 2225 & 2253 & 2992 & 2639 \\
\hline 40 & & 1656 & 2749 & 2894 & 3304 & 2658 \\
\hline 41 & & 1446 & 2296 & 2253 & 3079 & 2652 \\
\hline 42 & & 1275 & 2343 & 2319 & 3047 & 2740 \\
\hline
\end{tabular}


Appendix 20: CVAS and ICP measured concentration $(\mathrm{mg} / \mathrm{kg})$ and PXRF intensity of Fe (cps) in forage samples at two different particle size.

\begin{tabular}{|c|c|c|c|c|}
\hline S.No & Fe conc F CVAS & Fe conc F ICP & $\begin{array}{c}\text { Fe Int FNP 0.25- } \\
0.5 \mathrm{~mm}\end{array}$ & $\begin{array}{c}\text { Fe Int FNP 1- } \\
2 \mathrm{~mm}\end{array}$ \\
\hline 1 & 283 & 113 & 65320 & 51152 \\
\hline 2 & 576 & 104 & 63036 & 66171 \\
\hline 3 & 236 & 112 & 65819 & 53312 \\
\hline 4 & 217 & 186 & 80607 & 69811 \\
\hline 5 & 239 & 118 & 66204 & 51894 \\
\hline 6 & 149 & 86 & 59606 & 46895 \\
\hline 7 & 276 & 120 & 68028 & 52737 \\
\hline 8 & 6104 & 113 & 67860 & 52558 \\
\hline 9 & 102 & 51 & 56003 & 46780 \\
\hline 10 & 788 & 240 & 82095 & 67623 \\
\hline 11 & 240 & 59 & 57442 & 49411 \\
\hline 12 & 126 & 62 & 56026 & 47853 \\
\hline 13 & 165 & 87 & 63249 & 54049 \\
\hline 14 & 87 & 45 & 54911 & 47926 \\
\hline 15 & 90 & 71 & 60195 & 52515 \\
\hline 16 & 203 & 178 & 82919 & 62819 \\
\hline 17 & 100 & 79 & 62328 & 48003 \\
\hline 18 & 90 & 44 & 55189 & 45000 \\
\hline 19 & 79 & 46 & 56756 & 43884 \\
\hline 20 & 268 & 134 & 62852 & 54851 \\
\hline 21 & 875 & 114 & 65803 & 52212 \\
\hline 22 & 445 & 190 & 82411 & 55520 \\
\hline 23 & 908 & 154 & 69700 & 50332 \\
\hline 24 & 238 & 110 & 68635 & 52086 \\
\hline 25 & 254 & 323 & 97994 & 62237 \\
\hline 26 & 282 & 311 & 101008 & 68266 \\
\hline 27 & 188 & 166 & 76706 & 55725 \\
\hline 28 & 293 & 239 & 93453 & 59077 \\
\hline 29 & 318 & 223 & 88160 & 65121 \\
\hline 30 & 178 & 251 & 97606 & 57390 \\
\hline 31 & & 120 & 67981 & 51235 \\
\hline 32 & & 271 & 88333 & 61741 \\
\hline 33 & & 370 & 97038 & 65144 \\
\hline 34 & & 200 & 84193 & 68863 \\
\hline 35 & & 384 & 109316 & 60137 \\
\hline 36 & & 448 & 111440 & 94997 \\
\hline 37 & & 289 & 90499 & 65129 \\
\hline 38 & & 295 & 94567 & 66608 \\
\hline 39 & & 273 & 99100 & 69364 \\
\hline 40 & & 336 & 106777 & 64295 \\
\hline 41 & & 167 & 82599 & 61545 \\
\hline 42 & & 131 & 77365 & 63675 \\
\hline
\end{tabular}


Appendix 21: CVAS and ICP measured concentration $(\mathrm{mg} / \mathrm{kg})$ and PXRF intensity of $\mathrm{Cu}$ (cps) in forage samples at two different particle size.

\begin{tabular}{|c|c|c|c|c|}
\hline S.No & $\begin{array}{c}\text { Cu conc F CVAS } \\
(\mathrm{mg} / \mathrm{kg})\end{array}$ & $\begin{array}{c}\text { Cu conc F ICP } \\
(\mathrm{mg} / \mathrm{kg})\end{array}$ & $\begin{array}{c}\text { Cu Int FNP 0.25- } \\
0.5 \mathrm{~mm}\end{array}$ & $\begin{array}{c}\text { Cu Int FNP 1- } \\
2 \mathrm{~mm}\end{array}$ \\
\hline 1 & 7 & 8 & 51279 & 40117 \\
\hline 2 & 9 & 10 & 51527 & 40689 \\
\hline 3 & 9 & 10 & 51219 & 42817 \\
\hline 4 & 8 & 12 & 52075 & 47429 \\
\hline 5 & 6 & 11 & 52086 & 44598 \\
\hline 6 & 7 & 9 & 50713 & 39209 \\
\hline 7 & 7 & 9 & 52743 & 44221 \\
\hline 8 & 8 & 9 & 51995 & 41443 \\
\hline 9 & 6 & 9 & 51409 & 40842 \\
\hline 10 & 12 & 11 & 48755 & 40882 \\
\hline 11 & 10 & 9 & 49693 & 49081 \\
\hline 12 & 8 & 10 & 50530 & 39883 \\
\hline 13 & 7 & 11 & 51494 & 41205 \\
\hline 14 & 7 & 8 & 51302 & 45558 \\
\hline 15 & 5 & 9 & 53571 & 43581 \\
\hline 16 & 6 & 8 & 54052 & 46978 \\
\hline 17 & 6 & 9 & 54727 & 42807 \\
\hline 18 & 5 & 7 & 51546 & 40157 \\
\hline 19 & 6 & 7 & 52646 & 38447 \\
\hline 20 & 7 & 9 & 52539 & 44036 \\
\hline 21 & 8 & 11 & 50002 & 42187 \\
\hline 22 & 11 & 14 & 51173 & 39795 \\
\hline 23 & 11 & 13 & 49588 & 38017 \\
\hline 24 & 6 & 12 & 54293 & 43042 \\
\hline 25 & 6 & 13 & 54771 & 42966 \\
\hline 26 & 7 & 14 & 55372 & 45208 \\
\hline 27 & 6 & 11 & 52946 & 45145 \\
\hline 28 & 5 & 13 & 55425 & 45298 \\
\hline 29 & 7 & 17 & 54063 & 44918 \\
\hline 30 & 6 & 15 & 54551 & 42847 \\
\hline 31 & & 15 & 54018 & 42712 \\
\hline 32 & & 17 & 52672 & 42223 \\
\hline 33 & & 12 & 52020 & 41717 \\
\hline 34 & & 12 & 55500 & 46936 \\
\hline 35 & & 15 & 53016 & 38720 \\
\hline 36 & & 14 & 53490 & 46448 \\
\hline 37 & & 12 & 53029 & 46025 \\
\hline 38 & & 13 & 54134 & 44427 \\
\hline 39 & & 9 & 56674 & 50315 \\
\hline 40 & & 11 & 53471 & 37291 \\
\hline 41 & & 12 & 57833 & 50362 \\
\hline 42 & & 8 & 57689 & 50967 \\
\hline
\end{tabular}


Appendix 22: CVAS and ICP measured concentration $(\mathrm{mg} / \mathrm{kg}$ ) and PXRF intensity of $\mathrm{Zn}$ (cps) in forage samples at two different particle size.

\begin{tabular}{|c|c|c|c|c|}
\hline S.No & Zn conc F CVAS & Zn conc $\mathrm{F} I C P$ & $\begin{array}{c}\text { Zn Int FNP 0.25- } \\
0.5 \mathrm{~mm}\end{array}$ & $\begin{array}{c}\text { Zn Int FNP 1- } \\
2 \mathrm{~mm}\end{array}$ \\
\hline 1 & 19 & 27 & 50354 & 38418 \\
\hline 2 & 26 & 33 & 51178 & 38087 \\
\hline 3 & 23 & 34 & 51301 & 41737 \\
\hline 4 & 20 & 28 & 51542 & 45596 \\
\hline 5 & 18 & 31 & 52376 & 42878 \\
\hline 6 & 18 & 29 & 50734 & 36913 \\
\hline 7 & 17 & 25 & 53377 & 42561 \\
\hline 8 & 16 & 23 & 52616 & 39533 \\
\hline 9 & 21 & 29 & 51444 & 39195 \\
\hline 10 & 27 & 38 & 48640 & 39725 \\
\hline 11 & 24 & 28 & 49393 & 49585 \\
\hline 12 & 20 & 34 & 49675 & 38611 \\
\hline 13 & 20 & 40 & 51710 & 39907 \\
\hline 14 & 18 & 34 & 50990 & 44457 \\
\hline 15 & 17 & 35 & 53883 & 41866 \\
\hline 16 & 17 & 34 & 54034 & 45887 \\
\hline 17 & 20 & 201 & 67682 & 42877 \\
\hline 18 & 22 & 28 & 51662 & 38420 \\
\hline 19 & 16 & 27 & 52098 & 36818 \\
\hline 20 & 30 & 37 & 52685 & 42914 \\
\hline 21 & 28 & 42 & 49950 & 40597 \\
\hline 22 & 29 & 46 & 51531 & 38811 \\
\hline 23 & 29 & 44 & 49991 & 36148 \\
\hline 24 & 22 & 35 & 53854 & 42097 \\
\hline 25 & 19 & 38 & 54982 & 41628 \\
\hline 26 & 22 & 42 & 55682 & 43827 \\
\hline 27 & 22 & 39 & 52865 & 44234 \\
\hline 28 & 18 & 41 & 55477 & 43318 \\
\hline 29 & 27 & 35 & 53886 & 43406 \\
\hline 30 & 21 & 40 & 54736 & 41480 \\
\hline 31 & & 46 & 54651 & 41201 \\
\hline 32 & & 49 & 53230 & 41782 \\
\hline 33 & & 43 & 52011 & 41300 \\
\hline 34 & & 41 & 56372 & 47501 \\
\hline 35 & & 48 & 53585 & 37443 \\
\hline 36 & & 49 & 53783 & 45895 \\
\hline 37 & & 51 & 53901 & 45365 \\
\hline 38 & & 51 & 55297 & 43577 \\
\hline 39 & & 40 & 57504 & 49634 \\
\hline 40 & & 48 & 54848 & 36678 \\
\hline 41 & & 47 & 58073 & 49454 \\
\hline 42 & & 41 & 57868 & 50442 \\
\hline
\end{tabular}




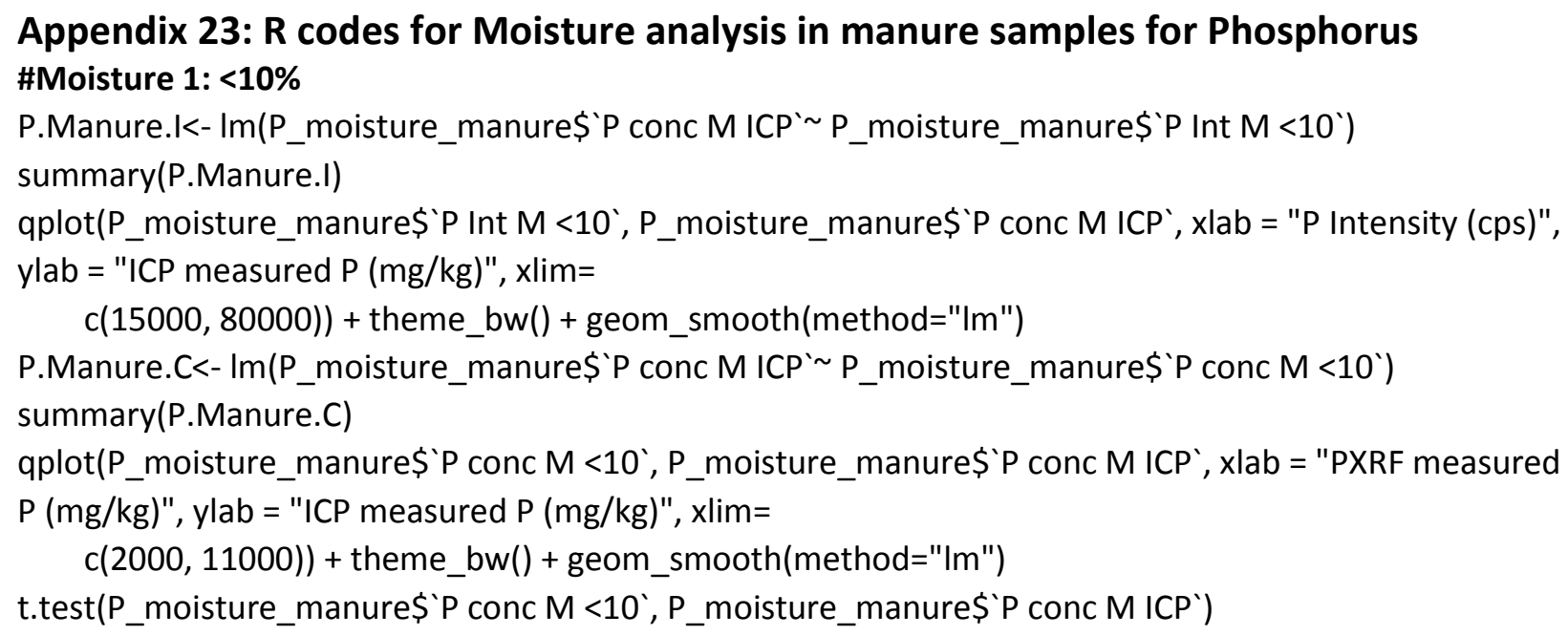

P.Manure.I2<- Im(P_moisture_manure\$ ’ conc M ICP` P_moisture_manure\$ ’ $\mathrm{P}$ Int M 10-20') summary(P.Manure.12)

qplot(P_moisture_manure\$ $P$ Int M 10-20`, P_moisture_manure\$ ${ }^{\prime}$ conc M ICP', xlab = "P Intensity (cps)", ylab = "ICP measured $P(\mathrm{mg} / \mathrm{kg}) "$ ", xlim=

$c(15000,70000))+$ theme_bw() + geom_smooth(method="Im")

P.Manure.C2<- Im(P_moisture_manure\$ ${ }^{\prime} P$ conc M ICP` P_moisture_manure\$`P conc M 10-20') summary(P.Manure.C2)

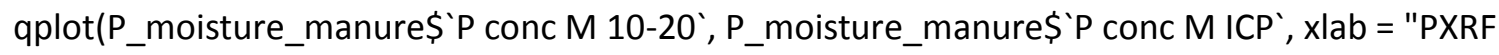
measured $P(\mathrm{mg} / \mathrm{kg})$ ", ylab = "ICP measured $P(\mathrm{mg} / \mathrm{kg})$ ", xlim=

$c(2000,10000))+$ theme_bw ()$+$ geom_smooth(method="Im")

t.test(P_moisture_manure\$ ${ }^{P}$ conc $M$ 10-20', P_moisture_manure\$ ${ }^{\prime} P$ conc M ICP')

\#Moisture: 3:20-30\%

P.Manure.13<- Im(P_moisture_manure\$`P conc M ICP` P_moisture_manure\$`P Int M 20-30`)

summary(P.Manure.13)

qplot(P_moisture_manure\$ $P$ Int M 20-30', P_moisture_manure\$ $P$ conc M ICP', xlab = "P Intensity

(cps)", ylab = "ICP measured $\mathrm{P}(\mathrm{mg} / \mathrm{kg}) "$, xlim=

$c(5000,40000))+$ theme_bw ()$+$ geom_smooth (method="Im")

P.Manure.C3<- Im(P_moisture_manure\$ 'P conc M ICP` P_moisture_manure\$ 'P conc M 20-30')

summary(P.Manure.C3)

qplot(P_moisture_manure\$ ${ }^{P}$ conc $M$ 20-30`, P_moisture_manure\$ ${ }^{P}$ conc $M$ ICP', xlab = "PXRF

measured $\mathrm{P}(\mathrm{mg} / \mathrm{kg})$ ", ylab = "ICP measured $\mathrm{P}(\mathrm{mg} / \mathrm{kg}) "$, xlim=

$c(2000,9000))+$ theme_bw ()$+$ geom_smooth(method="Im")

t.test(P_moisture_manure\$ ${ }^{\prime} P$ conc $M$ 20-30', P_moisture_manure\$ $P$ conc M ICP')

\section{\# Moisture 4: 40-50\%}

P.Manure.I4<- Im(P_moisture_manure\$ ${ }^{\prime}$ conc M ICP` P_moisture_manure\$ ${ }^{`}$ Int M 40-50`) summary(P.Manure.14) 
qplot(P_moisture_manure\$ $P$ Int M 40-50`, P_moisture_manure\$ $P^{\prime}$ conc M ICP', xlab = "P Intensity (cps)", ylab = "ICP measured $\mathrm{P}(\mathrm{mg} / \mathrm{kg}) "$, xlim=

$c(5000,45000))+$ theme_bw ()$+$ geom_smooth (method="Im")

P.Manure.C4<- Im(P_moisture_manure\$ 'P conc M ICP` P_moisture_manure\$ 'P conc M 40-50')

summary(P.Manure.C4)

qplot(P_moisture_manure\$ ${ }^{P}$ conc $M$ 40-50`, P_moisture_manure\$ $P$ conc $M I C P$ ', xlab = "PXRF

measured $\mathrm{P}(\mathrm{mg} / \mathrm{kg})$ ", ylab = "ICP measured $\mathrm{P}(\mathrm{mg} / \mathrm{kg}) ", \mathrm{xlim}=$

$c(2000,8000))+$ theme_bw() + geom_smooth(method="Im")

t.test(P_moisture_manure\$ ${ }^{P}$ conc $M$ 40-50', P_moisture_manure\$ ${ }^{\prime} P$ conc M ICP')

\section{\#Moisture 5: 60-70\%}

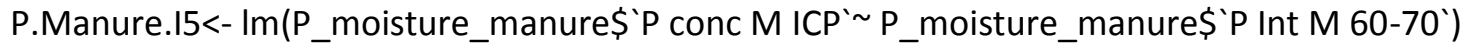

summary(P.Manure.15)

qplot(P_moisture_manure\$ 'P Int M 60-70', P_moisture_manure\$ $P$ conc M ICP', xlab = "P Intensity

(cps)", ylab = "ICP measured P (mg/kg)") + theme_bw() + geom_smooth(method="Im")

P.Manure.C5<- Im(P_moisture_manure\$`P conc M ICP` P_moisture_manure\$ ${ }^{\prime}$ conc M 60-70`)

summary(P.Manure.C5)

qplot(P_moisture_manure\$ 'P conc M 60-70', P_moisture_manure\$ ${ }^{\prime} P$ conc $M$ ICP', xlab = "PXRF

measured $P(\mathrm{mg} / \mathrm{kg})$ ", ylab = "ICP measured $P(\mathrm{mg} / \mathrm{kg}) ")$ + theme_bw ()$+$ geom_smooth (method="Im")

t.test(P_moisture_manure\$ $P$ conc M 60-70', P_moisture_manure\$ ${ }^{P}$ conc M ICP')

\section{\#\#t-test}

t.test(P_moisture_manure\$ $\mathrm{P}^{\mathrm{P}}$ conc $\mathrm{M}<10$ ', $\mathrm{P}$ _moisture_manure\$ $\mathrm{P}$ conc $\mathrm{M} 10-20$ ')

t.test(P_moisture_manure\$ ' $P$ conc $M$ 10-20', $P$ _moisture_manure\$ ' $P$ conc $M$ 20-30')

t.test(P_moisture_manure\$ $P$ conc $M$ 20-30', P_moisture_manure\$ $P^{\prime}$ conc $M$ 40-50')

t.test(P_moisture_manure\$ $P$ conc $M$ 40-50`, P_moisture_manure\$ $P$ conc $M$ 60-70')

\section{\#\# Regression between P and moisture percentage}

P.R.I<- Im(Moistue_Regression\$P Moistue_Regression\$Moisture)

summary(P.R.I)

qplot(Moistue_Regression\$Moisture, Moistue_Regression\$P, xlab = "Moisture (\%)", ylab = "P Intensity (cps)", $x \lim =$

$$
c(0,80))+ \text { theme_bw }()+\text { geom_smooth }(\text { method="Im") }
$$




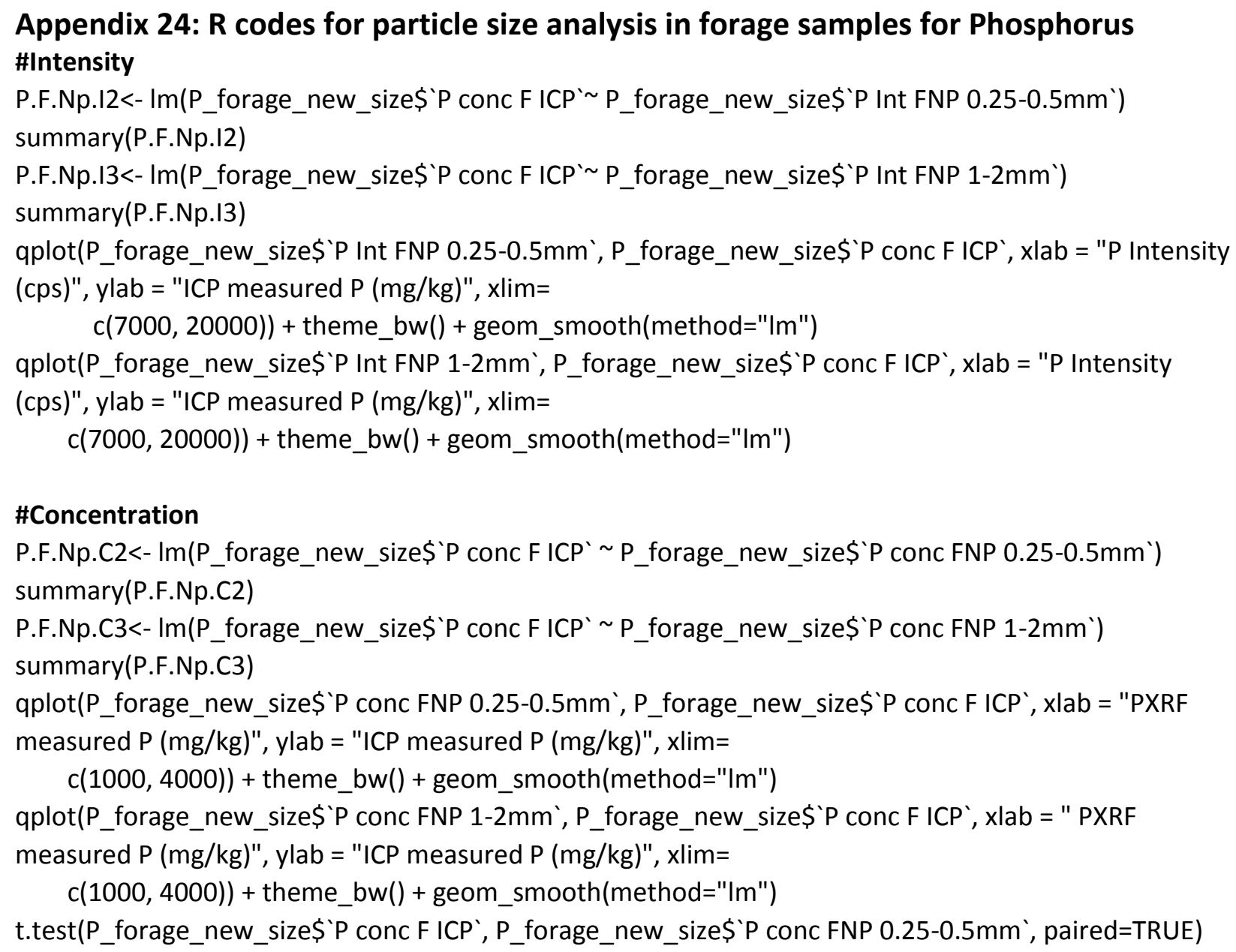

\section{\#Concentration}

P.F.Np.C2<- Im(P_forage_new_size\$ `P conc F ICP` P_forage_new_size\$ P conc FNP 0.25-0.5mm ) summary(P.F.Np.C2) 